\title{
Vascular Disorders of the Liver
}

\author{
Laurie D. DeLeve ${ }^{1}$, Dominique-Charles Valla ${ }^{2}$, Guadalupe Garcia-Tsao ${ }^{3}$ \\ ${ }^{1}$ Division of Gastrointestinal and Liver Diseases and the Research Center for Liver Diseases, \\ University of Southern California Keck School of Medicine, Los Angeles, CA \\ ${ }^{2}$ Service d'Hépatologie, Hôpital Beaujon, Université Denis-Diderot-Paris 7, and Institut National \\ de la Santé et de la Recherche Médicale U773, Clichy, France \\ ${ }^{3}$ Digestive Disease Section, Yale University School of Medicine and Veterans Administration- \\ Connecticut Healthcare System, New Haven, CT
}

\section{Abstract}

This guideline has been approved by the American Association for the Study of Liver Diseases (AASLD) and represents the position of the association.

\section{Preamble}

These recommendations provide a data-supported approach. They are based on the following: (1) formal review and analysis of the recently published world literature on the topic (Medline search); (2) American College of Physicians Manual for Assessing Health Practices and Designing Practice Guidelines ${ }^{1}$; (3) guideline policies, including the AASLD Policy on the Development and Use of Practice Guidelines and the American Gastroenterological Association Policy Statement on Guidelines ${ }^{2}$; and (4) the experience of the authors in the specified topic.

Intended for use by physicians, these recommendations suggest preferred approaches to the diagnostic, therapeutic, and preventive aspects of care. They are intended to be flexible, in contrast to standards of care, which are inflexible policies to be followed in every case. Specific recommendations are based on relevant published information. To more fully characterize the quality of evidence supporting recommendations, the Practice Guidelines Committee of the AASLD requires a Class (reflecting benefit versus risk) and Level (assessing strength or certainty) of Evidence to be assigned and reported with each recommendation (Table 1, adapted from the American College of Cardiology and the American Heart Association Practice Guidelines. ${ }^{3,4}$ )

Potential conflict of interest: Nothing to report.

All American Association for the Study Liver Diseases (AASLD) Practice Guidelines are updated annually. Ifyou are viewing a Practice Guideline that is more than 12 months old, please visit www.aasld.org for an update in the material. 


\section{Introduction}

The major vascular disorders of the liver are listed in Table 2. Most of the vascular disorders of the liver are rare, with the exception of portal vein thrombosis (PVT) in patients with cirrhosis, and therefore the best evidence about diagnosis and management has been acquired through prospective cohort studies rather than randomized clinical trials. Their importance lies in the very significant morbidity and mortality that can occur without timely diagnosis or disease-specific management or even with an inappropriate workup. The purpose of these guidelines is to provide clinicians with approaches to diagnose and manage the disorders for which there are sufficient data to make recommendations. Given the rarity of some of the vascular disorders, not all are suitable for practice guidelines, and these will not be discussed. These guidelines will review PVT, sinusoidal obstruction syndrome, BuddChiari syndrome (BCS), and congenital vascular malformations.

\section{Portal Vein Thrombosis}

Obstruction of the portal vein or its branches can be related to invasion or constriction by a malignant tumor, or to thrombosis. In developed countries, PVT might be more common than previously considered, as it was found at routine necropsy in about $1 \%$ of Swedish subjects in the 1970s. ${ }^{5}$ In developing countries, PVT has accounted for up to $30 \%$ and $75 \%$ of cases of portal hypertension in adults and children, respectively. ${ }^{6}$ From a clinical point of view, PVT consists of two different entities, acute PVT and chronic PVT, which represent successive stages of the same disease and share similar causes, but differ as to their management. ${ }^{7}$ Therefore, after considering their common causal factors, acute and chronic PVT will be discussed successively. Likewise, PVT occurring in children, in patients with cirrhosis, and in liver transplant recipients will be considered separately, because their features and management differ from those in other groups of patients.

\section{Causes of Portal Vein Thrombosis}

PVT is caused by a combination of local and general risk factors. A local risk factor can be identified in about $30 \%$ of patients, and a general risk factor in $70 \% .^{7-11}$

\section{Local Factors.}

A list of these local risk factors is provided in Table 3. Malignant tumors within the portal venous territory (in the absence of portal venous invasion or constriction), and cirrhosis are the leading local risk factors for PVT. ${ }^{5,9}$ In the rest of the patients, the most common local factor for PVT is inflammatory foci in the abdomen. ${ }^{7,12,13}$ A local factor for PVT is more frequently recognized at the acute stage of PVT than later on at the chronic stage. ${ }^{7}$

\section{General Factors.}

General risk factors are similar in nature and in prevalence in patients with acute PVT and chronic PVT. ${ }^{7}$ As shown in Table 4, an inherited or acquired prothrombotic condition has been found in many patients with PVT, whether a local risk factor had been identified. 8,9,11,14-19 Therefore, identification of a local risk factor does not exclude the possibility that a general risk factor is present. Malignancy is a well-established, although not fully 
understood, risk factor for deep vein thrombosis (DVT). ${ }^{20}$ This malignancy-associated prothrombotic state may play a role in PVT developing in patients with malignant abdominal tumors in the absence of compression or invasion. Likewise, systemic inflammatory response is a major general risk factor for thrombosis. ${ }^{21}$ In the context of acute PVT, however, it is difficult to determine whether inflammation is a cause or consequence of PVT.

In young adults without cancer or cirrhosis, PVT is frequently the presenting manifestation of a myeloproliferative disease. ${ }^{11,22}$ Overall, $30 \%-40 \%$ of patients with PVT are affected with chronic, Philadelphia-negative myeloproliferative diseases, usually polycythemia vera, essential thrombocythemia, or unclassified myeloproliferative diseases. However, due to portal hypertension and/or iron deficiency, the peripheral blood changes suggestive for a myeloproliferative disease are lacking in most affected patients. ${ }^{23}$ Furthermore, splenic enlargement is not specific for a diagnosis of myeloproliferative disease in a context of portal hypertension. Clusters of dystrophic megakaryocytes at bone marrow biopsy ${ }^{22}$ and endogenous erythroid colony formation in culture of bone marrow or circulating progenitors ${ }^{23}$ have been used in the past to make a diagnosis of occult or masked myeloproliferative disease. Recently, 1849G $\rightarrow 1849 \mathrm{~T}$ point mutation (V617F) of the tyrosine kinase Janus kinase 2 (JAK2) gene in myeloid cells has proved a highly specific and easily detectable marker for myeloproliferative disease. Among 388 patients with noncancerous, noncirrhotic PVT in four studies, this mutation was found in $21 \%-37 \%$ of patients with PVT. ${ }^{24-27}$ However, in 5\%-10\% of patients with PVT, this specific mutation was undetectable whereas bone marrow biopsy and assessment of endogenous erythroid colonies provided evidence for a myeloproliferative disease.

Identification of inherited deficiency of natural coagulation inhibitors can be difficult. ${ }^{9,11}$ In patients with acute PVT, the systemic inflammatory response may alter baseline levels of these inhibitors. In patients with chronic PVT, there can be a nonspecific decrease in the synthesis of coagulation factors and inhibitors even when liver dysfunction is not obvious. ${ }^{28}$

The concurrence of several prothrombotic disorders in a patient with PVT is more frequent than expected in the general population. ${ }^{9,11}$ Thus, the identification of a risk factor for thrombosis does not exclude other factors. The role of oral contraceptive use and pregnancy as causal factors for PVT is less clear than for thrombosis at other sites. ${ }^{9,11}$

In patients with cirrhosis, the risk of developing PVT has been related to the severity of liver disease, and to the presence of inherited prothrombotic disorders. ${ }^{29}$ In patients with impaired synthetic function and low plasma levels of natural coagulation inhibitors, there is currently no simple means for ascribing such low levels to a preexisting deficiency. In patients with cirrhosis and portal venous obstruction, invasion by hepatocellular carcinoma should be ruled out before making a diagnosis of bland thrombosis. ${ }^{30,31}$

Recommendations for investigating causes of PVT:

1. Check first for cirrhosis, cancer of the abdominal organs, and an inflammatory focus in the abdomen, based on initial computed tomography (CT) scan and 
sonography findings, followed by additional procedures, as appropriate (Class I, Level B).

2. Check for multiple, concurrent risk factors for thrombosis, in all patients without advanced cirrhosis or cancer, as indicated in Table 5 (Class I, Level B).

3. Do not rule out a diagnosis of myeloproliferative disease solely on the basis of normal or low peripheral blood cell counts (Class I, Level B).

4. When coagulation factor levels are decreased, consider low levels of protein C, protein S, or antithrombin as a possible consequence of liver dysfunction; consider inherited deficiency when screening of a first-degree relative is positive (Class I, Level C).

\section{Acute Portal Vein Thrombosis}

\section{Definition.}

Acute PVT is characterized by the sudden formation of a thrombus within the portal vein. The thrombus can involve a variable portion of the mesenteric veins and/or the splenic vein. Occlusion can be complete or it can be partial, leaving a peripheral circulating channel. Acute PVT has been rarely reported in children. Therefore, this section will focus on data collected in adults. PVT occurring in patients with cirrhosis will be discussed separately. Acute septic PVT is frequently referred to as acute pylephlebitis. This entity is characterized by the presence of infected thrombus/thrombi. ${ }^{32}$

\section{Clinical and Laboratory Features.}

Acute PVT usually presents with abdominal or lumbar pain of sudden onset or progressing over a few days. ${ }^{7,33,34}$ The abdomen might be moderately distended by ileus, but without any other features of intestinal obstruction. There is no guarding, except when an inflammatory focus is the cause for PVT or when PVT is complicated with intestinal infarction. The contrast between severity of pain and the absence of peritoneal signs has long been regarded as suggestive of mesenteric venous thrombosis in the differential diagnosis of peritonitis..$^{33,35}$

Partial thrombosis might be associated with fewer symptoms. Rapid and complete obstruction of the portal vein or mesenteric veins, without involvement of mesenteric venous arches, induces intestinal congestion, manifested by severe continuous colicky abdominal pain and occasionally nonbloody diarrhea. ${ }^{33}$

A marked systemic inflammatory response is common in patients with acute PVT in the absence of sepsis. Persistent, nonspiking fever and abdominal pain are usual. Plasma levels of acute phase reactants are frequently and sometimes markedly elevated. Liver function is preserved in patients with acute PVT, probably because increased hepatic arterial blood flow compensates for the decreased portal inflow; and because a collateral circulation develops rapidly from pre-existing veins in the porta hepatis. ${ }^{36}$ However, a transient, moderate increase in serum aminotransferases can be observed in some patients. 
Provided there is no extension of the thrombus to mesenteric venous arches, all manifestations of acute PVT are completely reversible, either by recanalization or by development of a cavernoma. ${ }^{7}$ When extensive thrombosis involves distal mesenteric veins, intestinal ischemia and eventually infarction can occur. The occurrence of infarction is probably related to complete obstruction of venous outflow (the mesenteric arches can no longer serve as collateral pathways), and to reflex arterial constriction and occlusion. ${ }^{33}$ Clinical features that suggest a patient has transmural intestinal ischemia include persistence of severe pain beyond 5-7 days, bloody diarrhea, and ascites. ${ }^{35}$ Acidosis and renal or respiratory dysfunction are also suggestive of intestinal infarction. ${ }^{37}$ In the absence of treatment, intestinal perforation, peritonitis, shock, and death from multiorgan failure occur. 37

Clinical features of pylephlebitis include a high, spiking fever with chills, a painful liver, and sometimes shock. Blood cultures usually grow Bacteroides species, with or without other enteric species. Multiple, small liver abscesses are common in this setting. Acute septic PVT is always associated with an abdominal focus of infection. 7,12,32 This primary focus can be easily overlooked clinically and, therefore, detected only by careful review of the CT scan or magnetic resonance imaging (MRI). ${ }^{38}$ Sepsis-related cholestasis can be present.

\section{Imaging Features and Diagnosis.}

In most patients, the diagnosis of acute PVT can be rapidly established using noninvasive imaging. ${ }^{39-43}$ Sonography can show hyperechoic material in the vessel lumen with distension of the portal vein and its tributaries. Doppler imaging shows the absence of flow in part or all of the lumen. ${ }^{44} \mathrm{~A} \mathrm{CT}$ scan without contrast can show hyperattenuating material in the portal vein. After injection of contrast agent, lack of luminal enhancement, increased hepatic enhancement in the arterial phase, and decreased hepatic enhancement in the portal phase are shown. ${ }^{45,46}$ For the assessment of thrombus extension within the portal venous system, CT or MR angiography are more sensitive techniques than Doppler sonography, because the mesenteric veins are more difficult to visualize with ultrasound.

Thinning of the intestinal wall or lack of mucosal enhancement of a thickened intestinal wall after intravenous contrast injection are further pieces of evidence for intestinal infarction. ${ }^{47}$ Enlargement of pre-existing veins in the porta hepatis are seen as early as a few days after the onset of acute PVT. This is particularly conspicuous in the gallbladder wall, which is thickened and enhances after contrast injection, and should not be confused with acute cholecystitis. $^{48}$

Recommendations for diagnosis of acute PVT:

5. Consider a diagnosis of acute PVT in any patient with abdominal pain of more than 24 hours duration, whether or not there is also fever or ileus (Class I, Level B).

6. If acute PVT is suspected, CT scan, before and after injection of vascular contrast agent, should be obtained for early confirmation of diagnosis. If CT scan is not rapidly available, obtain Doppler-sonography (Class I, Level B).

Hepatology. Author manuscript; available in PMC 2019 August 16. 
7. In patients with acute PVT and high fever and chills, septic pylephlebitis should be considered, whether or not an abdominal source of infection has been identified, and blood cultures should be routinely obtained (Class I, Level B).

8. In acute PVT, the possibility of intestinal infarction should be considered from presentation until resolution of pain. The presence of ascites, thinning of the intestinal wall, lack of mucosal enhancement of the thickened intestinal wall, or the development of multiorgan failure indicate that intestinal infarction is likely and surgical exploration should be considered (Class I, Level B).

\section{Treatment.}

The goal of treatment of acute PVT is to recanalize the obstructed veins, which will prevent intestinal infarction and portal hypertension. Correction of the causal factors, which should be achieved as soon as possible, is beyond the scope of these guidelines. In the presence of fever or leukocytosis, antibiotics have been used, whether bacterial infection was eventually documented. There are reports of recanalization of pylephlebitis with antibiotic therapy alone. ${ }^{12,49}$

Anticoagulation therapy is of proven benefit in patients with acute DVT. ${ }^{50}$ Extrapolation to patients with acute PVT is logical but still not firmly validated. There have been no controlled studies of anticoagulation therapy in patients with acute PVT. Four retrospective surveys-all reported before 2000 - included consecutive patients. Their combined data show that when initiated immediately, 6 months of anticoagulation therapy was associated with complete recanalization in 50\% of patients, partial recanalization in about $40 \%$ of patients, and no recanalization in $10 \%$ of patients. ${ }^{7}$ Spontaneous recanalization appears to occur infrequently in unselected patients not given anticoagulation therapy. ${ }^{7}$ High recanalization rates have also been reported in patients given anticoagulation therapy for postsplenectomy $\mathrm{PVT}^{51}$ or for acute thrombosis involving the superior mesenteric vein. 7,34,49,52 Major complications of anticoagulation therapy were reported in less than 5\% of treated patients. ${ }^{7}$

The optimal duration of anticoagulation therapy for acute PVT has not been determined. Complete recanalization can be delayed until the sixth month of anticoagulation therapy. 7,34,41 A panel of international experts has recommended that in patients with acute PVT, anticoagulation be given for at least 3 months, and permanent anticoagulation therapy be considered for patients with permanent prothrombotic conditions. ${ }^{53}$ In patients with DVT, a lack of complete recanalization indicates a high risk of recurrence after cessation of anticoagulation therapy. ${ }^{54}$ It remains to be assessed whether this is also true for patients with acute PVT.

The reported experience with other treatment modalities (surgical thrombectomy, systemic or in situ thrombolysis, or transjugular intrahepatic portosystemic stent shunt [TIPS]) in the treatment of acute PVT is extremely limited. ${ }^{55,56}$ One study analyzed the outcome in 20 patients treated with thrombolysis administered into the superior mesenteric artery or, through transhepatic puncture, in the portal vein. ${ }^{55}$ There was complete recanalization in three patients (15\%), partial recanalization in $12(60 \%)$, and no recanalization in five 
patients (25\%). Twelve patients (60\%) developed major procedure-related complications, and one patient died as a result. ${ }^{55}$ In another retrospective survey, patients treated with thrombolytic agents had significantly increased mortality. ${ }^{57}$ There has been no formal comparison of the risk/benefit ratio of these procedures with that of anticoagulation alone. However, compared to anticoagulation alone, invasive procedures appear not to be more effective while being more dangerous.

When clinical and radiological features indicate that a patient has intestinal infarction, emergency laparotomy for resection of the overtly necrotic parts of the gut should be performed. ${ }^{35,58}$ The risk of postoperative malabsorption is related to the extent of intestinal resection. Moreover, the extent of irreversible lesions can be overestimated at gross inspection. Therefore, various procedures have been proposed to limit the extent of intestinal resection while coping with the risk of necrosis after operation. ${ }^{58}$ This aspect is beyond the scope of the present guidelines. Surgical thrombectomy can be performed at the time of the resection/laparotomy. Anticoagulation therapy appears to improve the survival of patients who undergo surgery. ${ }^{58,59}$

\section{Outcome and Prognosis.}

When acute PVT is recognized and treated before intestinal infarction occurs, the outcome is good. ${ }^{7,34,49,52,57,60}$ Abdominal pain and systemic inflammatory syndrome start subsiding within a few hours to a few days after initiation of anticoagulation. Intestinal infarction is prevented when the superior mesenteric vein remains patent or has recanalized. Portal hypertension is prevented when the portal vein trunk and at least one of its two branches remains patent or has recanalized. Among 31 patients given prolonged anticoagulation therapy for acute PVT, bleeding occurred in two patients: from ruptured esophageal varices in one patient whose portal vein had not recanalized, and from an ovarian cyst in the other. ${ }^{7}$ A few patients may develop delayed intestinal obstruction as a result of intestinal ischemia and stricturing. ${ }^{60,61}$ Overall mortality rate appears to have decreased from $30 \%$ to about $10 \%$ during the last decade, and currently most deaths are related to postoperative complications or underlying disease. ${ }^{37}$

Recommendations for the treatment of acute PVT (see also Table 6):

9. Give anticoagulation therapy for at least 3 months to all patients with acute PVT. Start with low molecular weight heparin in order to achieve rapid anticoagulation. Shift to oral anticoagulation as soon as the patient's condition has stabilized, when no invasive procedure is planned (Class I, Level B).

10. Continue on long-term anticoagulation therapy in patients with acute PVT and permanent thrombotic risk factors that are not correctable other wise (Class I, Level B).

11. In the absence of contraindication, also consider long term anticoagulation for patients with acute PVT and thrombus extension distal into the mesenteric veins (Class IIa, Level C).

12. Initiate antibiotics promptly in patients with acute PVT and any evidence of infection (Class I, Level C). 


\section{Chronic Portal Vein Thrombosis}

\section{Definitions.}

In patients with chronic PVT, also known as portal cavernoma, the obstructed portal vein is replaced by a network of hepatopetal collateral veins connecting the patent portion of the vein upstream from the thrombus to the patent portion downstream. The number, size, and location of collaterals is extremely variable from patient to patient. With occlusion of the trunk of the portal vein, antral, duodenal and biliary veins are markedly enlarged. This enlargement can produce compression and deformation of large bile ducts, so-called portal cholangiopathy or portal biliopathy. ${ }^{62,63}$ With occlusion at the origin of the portal vein, pancreatic veins are enlarged.

Complete occlusion of the portal vein trunk, or of its two main branches is virtually always associated with portal hypertension and the development of portosystemic collaterals.

\section{Clinical and Laboratory Manifestations.}

In developed countries, there is a clear time trend for earlier recognition of PVT at the acute stage. ${ }^{7}$ Moreover, the classical presentation of cavernoma with ruptured esophageal or gastric varices is now rare. At present, diagnosis is commonly made after a fortuitous finding of hypersplenism or portal hypertension. Biliary symptoms related to portal cholangiopathy (jaundice, biliary pain, cholangitis, cholecystitis, or pancreatitis) rarely reveal a cavernoma. 62,63 Gastrointestinal bleeding is regarded as better tolerated than in other forms of portal hypertension probably because patients are usually younger and have no liver dysfunction. The occurrence of ascites or encephalopathy in patients with chronic PVT is uncommon, and is usually encountered only transiently following gastrointestinal bleeding or when there is unrelated renal failure or marked sepsis in older patients. ${ }^{64}$ Features of subclinical encephalopathy, however, can be demonstrated in half of the patients. ${ }^{65}$

Liver tests are typically normal in patients with portal cavernoma in the absence of underlying liver disease. Coagulation factor levels can be moderately altered. Portal cholangiopathy should be considered when there are cholestatic features. Hepatopulmonary syndrome is present in about $10 \%$ of patients. ${ }^{66}$

\section{Imaging Features and Diagnosis.}

A diagnosis of cavernoma is readily made by abdominal imaging with ultrasound, CT or MRI which shows serpiginous structures while the main portal vein and/or its main branches are not visible. ${ }^{40,46,67}$ Hepatic arteries are usually enlarged. In the absence of cirrhosis, there might be an enlarged caudate lobe, together with an atrophic left lateral segment or right lobe of the liver. Typically, the umbilical vein is not dilated as it connects to the left portal vein branch down stream of the obstruction.

In some patients a large, prominent collateral vein at the porta hepatis can be mistaken for a normal portal vein. A cavernoma that has developed in the pancreatic area might be confused with an enlarged pancreas. Portal cholangiopathy, which mimics the bead-like appearance of primary sclerosing cholangitis, is much more commonly seen on biliary tract 
imaging than clinical or laboratory features of biliary disease would suggest. ${ }^{62} \mathrm{~A}$ tumor-like cavernoma can be confused with carcinoma of the main bile duct. This particular and rare form of chronic PVT is characterized by tiny collateral channels forming a mass that encases the main bile duct, and enhances at the portal phase of contrast injection. ${ }^{62}$ Endosonography and MR angiography and cholangiography appear to be of great help in clarifying these differential diagnoses. ${ }^{68,69}$

Recommendations for diagnosis of chronic PVT:

13. Consider a diagnosis of chronic PVT in any patient with newly diagnosed portal hypertension (Class I, Level B).

14. Obtain Doppler-sonography, then either CT scan or MRI, before and after a vascular contrast agent, to make a diagnosis of chronic PVT.

15. Base the diagnosis on the absence of a visible normal portal vein and its replacement with serpiginous veins (Class I, Level B).

\section{Treatment.}

Therapy for chronic PVT can be separated into three areas: prevention and treatment of gastro-intestinal bleeding; prevention of recurrent thrombosis; and treatment of portal cholangiopathy.

\section{Prevention and Treatment of Gastrointestinal Bleeding.}

There have been no controlled studies of beta-adrenergic blockers or endoscopic therapy in patients with chronic PVT. Nevertheless, screening for gastro esophageal varices, and betaadrenergic blockers or endoscopic therapy for patients with large varices might be carried out for patients with portal cavernoma, as is done for patients with cirrhosis. ${ }^{53,70}$ Indeed, retrospective multivariate analyses found that their application reduced the risk of first bleed or recurrent bleeding, ${ }^{64}$ or improved survival. ${ }^{71}$ Endoscopic sclerotherapy has achieved eradication of varices and a reduction in the number of bleeding episodes in uncontrolled surveys. ${ }^{72,73}$ Data on endoscopic ligation are lacking in adult patients with chronic PVT. For primary prophylaxis of variceal bleeding there are insufficient data on whether beta-blockers or endoscopic therapy should be preferred. Contrasting findings have been reported regarding the feasibility and the outcome of surgical portosystemic shunting, which suggests differences in patient selection or referral. ${ }^{74,75}$ Data on splenectomy and devascularization are limited. There are anecdotal reports of successful TIPS insertion in patients with a portal cavernoma in the absence of cirrhosis. ${ }^{76}$ However, this procedure is not technically feasible in most patients.

\section{Prevention of Recurrent Thrombosis.}

Randomized controlled trials of anticoagulation therapy for the prevention of recurrent thrombosis are lacking. The frequent association with permanent prothombotic disorders on the one hand and the risk of intestinal infarction on the other support the use of anticoagulation. However, an increased risk of bleeding from portal hypertension raises concerns. In a retrospective multivariate analysis of a large cohort including patients with chronic or acute PVT, it was found that anticoagulation therapy significantly decreased the 
risk of recurrent thrombosis without increasing the risk of gastrointestinal bleeding. ${ }^{64}$ The severity of bleeding was similar with or without anticoagulation therapy and there were no bleeding-related deaths in patients receiving anticoagulation. Owing to the scarcity of data, however, an expert panel recommended that anticoagulation therapy be considered only in patients with a documented permanent prothrombotic condition. ${ }^{53}$ Recently, a retrospective study showed that warfarin administration independently improved survival of patients with chronic portomesenteric venous thrombosis, most of whom had a risk factor for thrombosis.

${ }^{71}$ Another uncontrolled retrospective survey found a decreased incidence of gastrointestinal bleeding following initiation of anticoagulation therapy. ${ }^{77}$

\section{Treatment of Portal Cholangiopathy.}

In patients with jaundice or recurrent biliary symptoms due to cholangiopathy, insertion of a biliary endoprosthesis after endoscopic extraction of secondary stones resulted in half the patients having no recurrence when the prosthesis was removed after some time. ${ }^{68}$ The procedure needs to be repeated when symptoms recur. Portosystemic shunting primarily performed to address the biliary complications, has been used where feasible in a limited number of patients; bilioenteric anastomosis was necessary in two of the eight shunted patients. ${ }^{78}$ Biliary surgery without portal decompression is extremely hazardous.

\section{Outcome.}

Recurrent bleeding from portal hypertension is the most common complication, followed by recurrent thrombosis at splanchnic or extrasplanchnic sites. ${ }^{64,71}$ However, the current outcome for treated patients with chronic PVT is good. In patients followed up for 5 years, less than 5\% died from the classical complications of PVT (intestinal infarction or gastrointestinal bleeding) ${ }^{64}$ Mortality is related mainly to age, cause of PVT, or unrelated diseases. The long-term prognosis in patients with portomesenteric venous obstruction might be poorer than in those with obstruction limited to the portal vein. ${ }^{71}$ Prolongation of life expectancy due to better control of bleeding and thrombotic risks probably explains why long term complications are predominantly related to cholangiopathy 62,63 and to transformation of underlying myeloproliferative disease into myelofibrosis or acute leukemia. $^{22}$

Recommendations for treatment of chronic PVT (See also Table 6):

16. Screen all patients with chronic PVT for gastroesophageal varices, and apply treatment for active variceal hemorrhage and for primary and secondary prophylaxis according to guidelines for patients with cirrhosis (Class I, Level B).

17. Consider long-term anticoagulation therapy in patients with chronic PVT, without cirrhosis, and with a permanent risk factor for venous thrombosis that cannot be corrected otherwise, provided there is no major contraindication. In patients with gastroesophageal varices, do not initiate anticoagulation until after adequate prophylaxis for variceal bleeding has been instituted (Class IIa, Level C). 


\section{Extrahepatic Portal Vein Obstruction in Children}

The theory that extrahepatic portal vein obstruction in this age group always results from thrombosis, as opposed to a congenital origin, has not been fully documented and is still debated. ${ }^{79,80}$ The prevalence of underlying pro-thrombotic diseases was high in most but not all studies. ${ }^{81-86}$ Primary protein $\mathrm{C}$, protein S, or antithrombin deficiency may be overdiagnosed, as these inhibitors are nonspecifically decreased in many affected children with a negative family screening. ${ }^{81,82}$ These low plasma levels are further decreased by portosystemic shunting, ${ }^{82}$ but corrected by surgical restoration of portal venous inflow. ${ }^{87}$ Occult myeloproliferative diseases have not been assessed in this age group. Umbilical cannulation, omphalitis, and abdominal infections are the most commonly incriminated factors. However, the role of a properly placed, uninfected umbilical catheter, in the absence of underlying thrombophilia ${ }^{84}$ is probably minimal. In this situation, a portal vein thrombus occurs frequently but full portal vein patency is restored in most infants. The probability of full recanalization is inversely related to the size of the thrombus. ${ }^{88}$ There are few features of extrahepatic portal vein obstruction that are specific for children. It is unclear whether growth retardation occurs in the absence of recurrent bleeding. ${ }^{89}$

Band ligation of esophageal varices may be the optimal therapy to prevent first bleed or recurrent bleeding. ${ }^{90}$ Surgical shunts, when a central vein (mesenteric or splenic vein) is available, have achieved good results, ${ }^{74,91}$ in contrast to other, atypical shunts, which have invariably thrombosed ${ }^{75}$ Recently, mesenteric-to-left portal vein bypass has been reported by several groups with good results in terms of feasibility, prevention of rebleeding, restoration of portal inflow and hepatic function, and improvement in cognitive function. 87,92 Recurrent thrombosis has not been mentioned. Anticoagulation has rarely been considered in children with extrahepatic portal vein obstruction. Outcome may be mostly jeopardized by cholangiopathy in patients whose recurrent bleeding is well controlled with endoscopic therapy. ${ }^{63}$

Recommendations for the management of chronic PVT in children:

18. When possible, refer children with extrahepatic portal venous obstruction to an expert surgical center for consideration of a mesenteric-to-left portal vein bypass (Class I, Level B).

19. If a mesenteric to left portal vein bypass is not possible in a child with chronic PVT, use band ligation of large esophageal varices for prophylaxis of gastrointestinal bleeding. If band ligation is not feasible, consider a central portosystemic shunt when either the superior mesenteric or splenic vein is patent (Class I, Level B).

\section{PVT in Patients with Cirrhosis}

PVT is most common in patients with pre-existing cirrhosis. The prevalence of PVT increases with the severity of the cirrhosis, being less than $1 \%$ in patients with compensated cirrhosis ${ }^{93}$ but $8 \%-25 \%$ in candidates for liver transplantation. ${ }^{94}$ In patients with cirrhosis, portal venous obstruction is commonly related to invasion by hepatocellular carcinoma. ${ }^{30,95}$ 
Neoplastic obstruction should always be considered, especially when serum alpha fetoprotein levels are increased, when the portal vein is larger than $23 \mathrm{~mm}$ in diameter, when endoluminal material enhances during the arterial phase of contrast injection, ${ }^{95}$ or when an arterial-like pulsatile flow is seen on Doppler ultrasound. ${ }^{96}$ Needle biopsy of an obstructed intrahepatic portal vein is specific but relatively insensitive for diagnostic purposes. ${ }^{31}$ PVT in patients with cirrhosis is often accompanied by gastrointestinal bleeding, ascites, or encephalopathy ${ }^{29,97}$ In many patients, the thrombus is partial, and changes in aspect and location at follow-up imaging. When the thrombus extends to the superior mesenteric vein, the risk of intestinal infarction is high. ${ }^{29}$

Even in patients with well compensated cirrhosis, an underlying prothrombotic condition is difficult to detect because of a nonspecific decrease in the plasma levels of coagulation inhibitors. In cirrhotic patients with PVT, compared with those without PVT, however, molecular testing shows an increased prevalence of the factor V Leiden, MTHFR, and prothrombin gene mutations, the latter being particularly common. ${ }^{29,98,99}$ Unlike TIPS, splenectomy and surgical portosystemic shunting strongly increase the risk of PVT in cirrhotic patients. Endoscopic therapy of esophageal varices has been suggested to precipitate the development of PVT, although this has been debated. ${ }^{99}$ However, the data could also be interpreted as suggesting that endoscopic therapy is an indicator of severe portal hypertension, which might be a risk factor for PVT.

Thus, in patients with well-compensated cirrhosis and acute or chronic PVT, there are limited data on the utility of screening for an underlying prothrombotic condition, and on the benefits of anticoagulation. In the absence of robust data, recommendations for or against routine anticoagulation cannot be made. Decisions will need to be made on a case-by-case basis. For example, it is reasonable to consider anticoagulation in the setting of a known prothrombotic condition, or in the setting of SMV thrombosis, but only after adequate prophylaxis for gastrointestinal bleeding has been instituted.

There also is limited information on anticoagulation therapy in patients who develop PVT while waiting for a liver transplant. Among 19 such patients given anticoagulation, 10 had recanalization, whereas among 10 historical controls, none had recanalization. ${ }^{94}$ Posttransplant outcome may be compromised by pretransplant complete PVT. ${ }^{94}$ Discussion of the techniques that can be employed to cope with complete PVT at transplantation is beyond the scope of these guidelines.

\section{PVT After Liver Transplantation}

PVT is a rare but serious complication following orthotopic liver transplantation. In this setting, the incidence has been reported to be $1.16 \%-2.7 \% .{ }^{100,101}$ Risk factors that have been identified include modification of the standard end-to-end veno-venous anastomosis of the portal vein due to pathological changes of the vessel wall (mainly in relationship to preexisting PVT); splenectomy during transplantation; and donor/recipient portal vein diameter mismatch. ${ }^{100,101}$ Possible consequences of PVT include graft dysfunction, graft loss, portal hypertension and death. Graft loss appears to be particularly associated with complete PVT in the early post-transplant course. Treatment of patients with PVT has usually been 
regarded as necessary when additional complications such as arterial occlusion or bile duct injuries have occurred. PVT occurring after liver transplantation has been managed surgically by thrombectomy, retransplantation, splenorenal shunt or Wall-stent placement at laparotomy; or non surgically by angioplasty, local high-dose infusion of thrombolytic agents or systemic thrombolytic therapy. ${ }^{100,101}$ Systematic postoperative screening with duplex Doppler-sonography and multidisciplinary approaches to the treatment of vascular complications (including PVT) after liver transplantation has considerably reduced graft loss and patient mortality. ${ }^{100}$

Areas for future studies:

Tests for improved identification of primary deficiency in protein $\mathrm{C}$, protein $\mathrm{S}$ and antithrombin, and antiphospholipid syndrome in the context of liver disease have to be developed. Predictive factors for recanalization of acute portal vein thrombosis treated with anticoagulation have to be identified. Invasive procedures for portal/mesenteric vein recanalization have to be evaluated in patients predictably nonresponsive to anticoagulation alone. The risk-benefit ratio of anticoagulation in patients with chronic portal vein thrombosis has to be assessed, ideally by means of randomized controlled trials.

More studies are needed on the feasibility and long-term results of mesenteric-to-left portal vein bypass in pediatric and adult patient populations.

\section{Sinusoidal Obstruction Syndrome (Hepatic Venoocclusive Disease)}

In North America, Western Europe, and Asia, sinusoidal obstruction syndrome (SOS, previously known as hepatic venooclusive disease) occurs most commonly as a complication of myeloablative regimens that are used to prepare patients for hematopoietic stem cell transplantation (previously known as bone marrow transplantation), particularly when the transplant is for a malignancy. These "conditioning regimens" are combinations of high-dose chemotherapy drugs or chemotherapy drugs plus total body irradiation. Other causes of SOS include chemotherapeutic agents at more conventional doses, chronic immunosuppression with azathioprine or 6-thioguanine, and ingestion of herbal teas made with pyrrolizidine alkaloids or food sources contaminated by pyrrolizidme alkaloids. Table 7 lists various chemotherapeutic drugs that are associated with SOS. These recommendations focus on the diagnosis and management of SOS after myeloablative conditioning for hematopoietic cell transplantation.

Because the incidence of SOS depends on patient risk factors and on choice of conditioning regimen, there is a wide range in incidence between hematopoietic cell transplantation units from $0 \%-50 \%$. For the more liver-toxic regimens, the incidence is around $20 \%-40 \%$, which has lead many centers to abandon extremely high-dose conditioning regimens. Regimens known to cause liver injury are those that contain cyclophosphamide in combination with either busulfan or total body irradiation or regimens that include $\mathrm{N}, N$-bis(2-chloroethyl)- $N$ nitrosourea (BCNU) or multiple alkylating agents. Reduced-intensity conditioning regimens carry little or no risk for SOS and with the ever-increasing use of these regimens, the incidence of SOS continues to drop. Other factors that have contributed to the decline in 
incidence include avoidance of cyclophosphamide-containing regimens, lower doses of total body irradiation, exclusion of patients with hepatitis $\mathrm{C}$ and avoidance of drugs that increase the risk of SOS, such as norethisterone.

\section{Pathogenesis.}

In patients with SOS, evidence of circulatory obstruction precedes liver dysfunction, indicating that this is a primary circulatory disorder. Clinico-pathological studies in patients with SOS after myeloablative conditioning for hematopoietic cell transplantation have demonstrated that SOS occurs in the absence of central vein occlusion in a significant fraction of the patients. Occlusion of the central veins was observed in only $55 \%$ of patients with mild or moderate SOS and only $75 \%$ of patients with severe SOS. ${ }^{102}$ These clinical findings suggest that SOS is due to circulatory obstruction at the level of the sinusoid and that involvement of the central vein is associated with more severe disease. Experimental studies in the monocrotaline rat model of SOS also demonstrate that loss of sinusoidal integrity with consequent sinusoidal obstruction is a prerequisite for the development of SOS. Monocrotaline is a pyrrolizidine alkaloid, the group of plant toxins associated with SOS. Monocrotaline is directly toxic to sinusoidal endothelial cells. ${ }^{103}$ In this model monocrotaline induces rounding up of sinusoidal endothelial cells, which leads to dissection of sinusoidal lining cells that embolize and block the sinusoids. ${ }^{103,104}$ The experimental model has the same signs, symptoms and histology seen in SOS in humans.

\section{Clinical Presentation and Diagnosis.}

The clinical signs and symptoms of SOS are weight gain with or without ascites, right upper quadrant pain of liver origin, hepatomegaly and jaundice. SOS presents with a wide spectrum of severity and is conventionally divided into mild, moderate and severe disease. 105 Mild SOS is considered disease that meets diagnostic criteria, that does not require treatment for fluid excess or medication for hepatic pain, and that has a self-limiting course. Moderate SOS is disease with evidence of liver injury and that requires treatment for fluid excess or medication for hepatic pain, but that resolves completely. Severe SOS is defined as disease that leads to death or that does not resolve by day 100. Because this classification of severity depends on the clinical course, this retrospective definition is useful for clinical research but is not helpful for management decisions in real time. For regimens containing cyclophosphamide, onset is most commonly between 10 and 20 days after initiation of therapy, ${ }^{105}$ but in other regimens onset can be more than 30 days after myeloablative therapy is started. ${ }^{106,107}$

SOS is a clinical diagnosis with all the accompanying uncertainty and need for clinical judgment. For the purposes of patient care, a diagnosis can be made with reasonable certainty in a patient who has received a conditioning regimen known to cause liver injury, who has the clinical signs and symptoms of SOS, and who has had a work-up to exclude other likely causes. Conversely, the diagnosis can be ruled out with reasonable certainty in a patient with some of the signs and symptoms of SOS but who is at no or low risk for SOS; for example, SOS is highly unlikely in a patient who has received a reduced-intensity conditioning regimen. Confounding diagnoses that are relatively common in this population include cholestatic jaundice due to sepsis, drug-induced cholestasis, fluid overload due to 
renal failure or congestive heart failure, liver involvement by viral or fungal infections seen during immunosuppression, and (hyper)acute graft-versus-host disease. The diagnosis becomes more difficult in patients with more than one cause for the signs and symptoms described above and it may be difficult to determine which of the ongoing processes is the predominant cause of illness. As many as $10 \%-20 \%$ of patients with liver dysfunction in the first 20 days after transplant cannot be diagnosed with certainty on clinical grounds. ${ }^{105,108}$

Clinical criteria used for defining populations for research (Table 8) have been published by investigators in Seattle and Baltimore. ${ }^{105,109}$ By the Seattle criteria, two of three findings must occur within 20 days of transplantation: bilirubin $>2 \mathrm{mg} / \mathrm{dL}$, tender hepatomegaly, and greater than $2 \%$ weight gain due to fluid accumulation, with the proviso that other causes of these findings are absent. The original Seattle criteria, developed largely for patients receiving myeloablative regimens containing cyclophosphamide, have a temporal criterion that does not apply to some regimens that do not contain cyclophosphamide. The temporal criteria should be modified for patients receiving regimens known to cause late-onset disease, such as regimens containing thio-TEPA. ${ }^{106}$ The Baltimore criteria require hyperbilirubinemia $>2 \mathrm{mg} / \mathrm{dL}$ plus two of three other findings: (usually painful) hepatomegaly, greater than $5 \%$ weight gain and ascites. As described in the previous paragraph on diagnosis made for purely clinical purposes, other confounding diagnoses need to be ruled out.

How reliable are the clinical criteria for the diagnosis of SOS? First one needs to distinguish the overall incidence of SOS from the incidence of clinically apparent disease. In a study of transplantation patients who were prospectively evaluated by the Seattle criteria and who died by day $100,50 \%$ of patients with liver dysfunction that did not meet the Seattle criteria had evidence on autopsy of SOS. ${ }^{102}$ Thus it appears likely that some degree of sinusoidal injury occurs in most patients who receive liver-toxic conditioning regimens, even in the absence of the characteristic symptoms. The current gold standard for confirming the diagnosis of clinically apparent SOS is measurement of the wedged hepatic venous pressure gradient using an occlusive balloon technique and liver histology (obtained by a transvenous route). Studies that examine the reliability of clinical criteria with confirmation by liver biopsy suffer from the problem that disease can be patchy and liver biopsy can be falsely negative. Since biopsies are typically performed only in patients who meet clinical criteria, it is not possible to assess false negatives by clinical criteria and therefore not possible to assess sensitivity or negative predictive value. More patients fit the Seattle criteria, whereas the Baltimore criteria identify patients with more severe disease. ${ }^{110}$

The diagnosis may be supported by imaging, which will demonstrate the presence of hepatomegaly and ascites and rule out biliary obstruction due to benign or malignant causes, but imaging is currently not diagnostic by itself. The best-studied modality is gray-scale and color Doppler ultrasonography. The majority of studies suggest that no single ultrasound parameter is diagnostic for SOS. ${ }^{111-113}$ Findings that are highly suggestive of SOS are reversal of portal venous flow, attenuation of hepatic venous flow, gallbladder wall edema, and perhaps increased resistive indices to hepatic artery flow. A composite score of grayscale and color Doppler ultrasound criteria has been proposed, but may be too cumbersome for routine clinical use. ${ }^{114,115}$ One study has suggested that the presence of flow in the para- 
umbilical vein is more common in moderate and severe SOS, but this will need to be validated by other investigators. ${ }^{115}$

When the diagnosis is uncertain in a moderately or severely ill patient, further evaluation by transvenous liver biopsy with hepatic venous pressure gradient measurement can establish the diagnosis. Percutaneous liver biopsy is often contraindicated in this population because of thrombocytopenia, coagulopathy or ascites. Transvenous liver biopsy with hepatic venous pressure gradient using the occlusive balloon technique may be particularly helpful in distinguishing SOS from graft-versus-host disease. In the setting of hematopoietic cell transplantation, hepatic venous pressure gradient $>10 \mathrm{~mm} \mathrm{Hg}$ has specificity greater than $90 \%$ and positive predictive value greater than $85 \%$ for the diagnosis of SOS, ${ }^{116}$ using the liver biopsy as the gold standard. Reported complications in this population range from $7 \%-18 \%$ and deaths from $0 \%-3 \% .{ }^{116}, 117$

Recommendations:

1. Consider the diagnosis of SOS inpatients in the appropriate clinical scenario who present with tender hepatomegaly, fluid retention and weight gain, and elevated serum bilirubin (Class I, level B).

2. Rule out other common causes of jaundice (such as biliary tract obstruction, hemolysis, sepsis, drug-induced liver injury and viral and fungal infections involving the liver) and weight gain (for example due to fluid overload, renal insufficiency or congestive heart failure) in this population (Class I, Level C).

3. Image the liver with Doppler ultrasound or another modality to rule out other causes and to demonstrate features consistent with SOS (Class I, Level C).

4. In complicated cases, perform a transvenous liver biopsy with hepatic venous pressure gradient to confirm the diagnosis. In hematopoietic cell transplantation patients, a hepatic venous pressure gradient of greater than $10 \mathrm{~mm} \mathrm{Hg}$ is highly specific for SOS (Class I, Level C).

\section{Prognosis}

One of the reasons for trying to predict outcome is the risk of some of the therapeutic strategies used for SOS. Using mathematical modeling, the severity of SOS due to cyclophosphamide-containing regimens can be predicted based on the slope of bilirubin levels and weight gain over time ${ }^{118}$ : these predictive nomograms are simple to use, but have not been validated for regimens without cyclophosphamide. Other predictors of poor prognosis are higher serum alanine aminotransferase levels, ${ }^{119}$ higher hepatic venous pressure gradient, ${ }^{117}$ and multiorgan failure. ${ }^{105}$

Published incidence rates for SOS after myeloablative conditioning regimens have varied from $0 \%-50 \%$, largely due to variation in conditioning regimens. ${ }^{105,109,120-123}$ Case fatality rates vary depending on the diagnostic criteria used for SOS and fatal SOS. Case fatality rates are currently in the range of $15 \%-20 \%$ following high-dose myeloablative conditioning regimens.

Hepatology. Author manuscript; available in PMC 2019 August 16. 


\section{Prophylaxis}

The major strategy for preventing SOS is identification of patients with risk factors for toxic liver injury and avoidance of liver-toxic conditioning regimens in these patients. The major identifiable risk factors in patients are recent treatment with gemtuzumab ozogamicin, ${ }^{124}$ previous history of SOS, and some forms of pre-existing liver disease. ${ }^{105,122,125,126}$ Hepatitis $C^{127,128}$ and hepatic fibrosis predispose to SOS. Cirrhosis is a contraindication to high-dose myeloablative conditioning regimens. Regimens with a lower risk of causing toxic liver injury and strategies to reduce toxicity in high-risk regimens are listed below.

Reduced-intensity conditioning regimens, i.e., regimens that do not ablate the bone marrow, are low-intensity immunosuppressive regimens that permit host-donor hematopoietic chimerism; their utility in treating patients with malignancy is through a graft-versus-tumor effect. Reduced-intensity regimens include fludarabine with low dose total body irradiation or fludarabine with busulfan and antithymocyte globulin. These regimens seem to carry little risk for SOS and reduce immediate transplant-related mortality, although they may be associated with more late complications than myeloablative regimens. ${ }^{129,130}$ For patients at high-risk for SOS, reduced-intensity regimens are the lowest risk option. However there is increased risk of death from liver decompensation in patients with cirrhosis who undergo conditioning with reduced-intensity regimens. ${ }^{130}$

Other choices that have been reported to reduce the risk of SOS and which should be considered for patients at high-risk for toxic liver injury are lower doses of total body irradiation (12 Gy or lower) ${ }^{131}$ and targeted dosing of the more toxic drugs. When high-dose cyclophosphamide is used without other hepatotoxic drugs in conditioning regimens for nonmalignant indications for hematopoietic cell transplantation, there is little risk of SOS. However in combination with other hepatotoxic drugs or with total body irradiation, cyclophosphamide is one of the most significant risk factors for SOS. ${ }^{132,133}$ Metabolismbased dosing of cyclophosphamide has been shown by one group to be feasible, but it remains to be seen whether this approach will be more widely used and whether it then indeed lowers the risk of fatal SOS. ${ }^{134,135}$ Numerous studies over the years have attempted to reduce the risk of SOS by modification of busulfan dosing, including pharmacokineticdirected dosing of busulfan, ${ }^{136-139}$ reversal of the order of drugs in the busulfancyclophosphamide regimen with treatment with cyclophosphamide preceding busulfan ${ }^{140}$ and use of intravenous busulfan instead of oral busulfan. ${ }^{138,141-143}$ It remains unclear whether adjusting dosing of oral busulfan based on drug disposition reduces the risk of SOS: some studies have shown benefit ${ }^{139,144,145}$ and others have not. ${ }^{137,146,147}$ Studies that found a reduction in SOS with intravenous busulfan used historical controls and the benefit of the intravenous formulation remains to be established. One study that used the intravenous formulation found no relationship between systemic exposure to busulfan and risk of SOS. 148

The highest risk regimens are cyclophosphamide-total body irradiation with total body irradiation greater than $12 \mathrm{~Gy}$ and oral busulfan-cyclophosphamide without targeted dosing. These regimens are best avoided in individuals at high-risk for liver injury. Substituting 
fludarabine for cyclophosphamide (a busulfan/fludarabine conditioning regimen) results in a low incidence of SOS with improved transplant outcome. ${ }^{149,150}$

Norethisterone was used to prevent menstrual hemorrhage in thrombocytopenic women after hematopoietic cell transplantation. This proved to be a significant risk factor for $\operatorname{SOS}^{151}$ and the use of noresthisterone is now avoided in this population.

\section{Prophylactic Medical Therapy}

Heparin, prostaglandin E1, ursodeoxycholic acid, and pentoxifylline have been examined in randomized controlled trials for their ability to prevent SOS.

Heparin infusions or low-molecular weight heparin can be given safely in this patient population and some centers use intravenous heparin or subcutaneous low-molecular weight heparin routinely as prophylaxis for SOS. Two randomized studies found a reduction in nonfatal SOS, but were not powered to show a benefit in reducing fatal SOS. ${ }^{152,153}$ Four additional studies found no benefit. ${ }^{120,151,154,155}$ A meta-analysis concluded that there is a statistically nonsignificant decrease in the risk of nonfatal SOS with prophylactic anticoagulation, but concluded that methodological weaknesses and inconsistencies precluded meaningful conclusions from the pooled analysis. ${ }^{156} \mathrm{~A}$ randomized control trial of high-risk patients is needed to determine whether heparin does indeed reduce the risk of SOS overall and, more importantly, of fatal SOS.

The use of defibrotide for either prophylaxis or treatment of established SOS is described below in the following section on Management of Established Disease.

There are four randomized trials in adults that have examined the effect of ursodeoxycholic acid. Ursodeoxycholic acid was reported to reduce the incidence of SOS in two randomized trials. ${ }^{157,158}$ Subsequently, one large randomized trial found no effect on the incidence of $\operatorname{SOS}^{159}$ and one trial that randomized patients to heparin versus heparin plus ursodeoxycholic acid found no benefit from the addition of ursodeoxycholic acid. ${ }^{160} \mathrm{~A}$ meta-analysis of three of these randomized trials, notably the three that examined the effect of ursodeoxycholic acid alone, suggested that prophylactic use is an effective prophylaxis for SOS. ${ }^{161}$ All of the randomized studies on ursodeoxy-cholate, including those in the meta-analysis, share the problem that there are no exclusionary criteria for confounding liver diseases common in this population, notably sepsis, graft-versus-host disease, and druginduced liver disease. Other concerns are that the endpoint was not fatal SOS but all SOS, including medically trivial cases, and, in some studies, the use of poorly defined criteria for SOS . However the largest randomized trial, which did not find any benefit for SOS, did find that prophylactic use of ursodeoxycholate decreased the frequency of jaundice and lowered peak alanine aminotransferase levels. ${ }^{159}$ It is therefore now standard practice around the world to use ursodeoxycholate prophylactically in this setting.

Prostaglandin E1 was shown to reduce the risk of SOS in one study, although no data were provided on reduction of fatalities from SOS. ${ }^{162}$ A subsequent study found no suggestion that prostaglandin E1 lowered the risk of severe SOS, but could not fully evaluate this 
because of severe toxicity from the prostaglandin E1 treatment. ${ }^{163}$ Prostaglandin E1 also increased cyclosporine levels.

Two placebo-controlled randomized trials found no benefit from pentoxifylline in preventing SOS. ${ }^{152,164}$ One randomized trial showed no benefit from intravenous $N$-acetylcysteine in preventing SOS, but the incidence of SOS in the untreated group may have been too low to find a real difference. ${ }^{165}$

Recommendations:

5. Consider regimens that are less likely to cause toxic liver injury in patients with extensive hepatic fibrosis, viral hepatitis, myelofibrosis with extramedullary hematopoeisis, recent treatment with gemtuzumab ozogamicin or a previous history of SOS. Regimens that are less liver toxic include reduced-intensity regimens, regimens without cyclophosphamide, and regimens with lower doses of total body irradiation (Class I, Level B).

6. Although widely used, no recommendation can be made for or against the use of prophylactic pharmacological strategies because none examined to date have consistently shown a reduction in the overall risk of SOS or the risk of fatal SOS in randomized controlled trials (Class IIB, Level A).

\section{Management of Established Disease}

SOS is an iatrogenic complication with significant mortality and thus a discouraging problem for the medical team. Perhaps as a result of this, prophylactic therapy and management of established disease have sometimes been adopted based on improvement compared to historical controls rather than after randomized trials have been performed. The incidence of SOS can change substantially in a given center ${ }^{126}$ and the reason for the change may remain obscure. This variability in incidence of SOS over time and the risk of selection bias makes the use of historical controls for prophylactic and therapeutic trials of SOS particularly unreliable.

Patients with severe SOS are deeply jaundiced, but commonly lack some signs of liver failure, such as hyper ammonemia, cerebral edema, and prolonged INR. The cause of death is most commonly multiorgan failure with pulmonary and renal failure. Supportive care for SOS requires maintenance of fluid and electrolyte balance. Intravascular volume and renal perfusion need to be maintained while treating extravascular fluid overload. Diuretic therapy is used for reduction of extravascular volume, in conjunction with paracentesis, hemofiltration and hemodialysis to alleviate respiratory impairment by ascites as needed.

The use of tissue plasminogen activator with or without heparin has been reported in numerous case reports and some case series, but there are no randomized controlled studies. Response rates in case series vary widely. In the two largest case series of 42 and 17 patients, respectively, $29 \%$ of patients survived. ${ }^{166,167}$ Patients with multiorgan failure requiring supplemental oxygen, dialysis or mechanical ventilation did not respond to tissue plasminogen activator. ${ }^{166}$ The risk of fatal intracerebral and pulmonary bleeding in 
thrombocytopenic patients is a major limitation. ${ }^{166,168,169}$ At this point, thrombolytic therapy is seldom used because of the risk of fatal bleeding.

Defibrotide is a mixture of the single-stranded oligode-oxyribonucleotides derived from depolymerization of porcine intestinal mucosa DNA. It has been under study for proposed antishock, anti-ischemic, and endothelium protective activities since the mid-1980s. A wide variety of mechanisms have been suggested including increased endothelial cell release of eicosanoids, nitric oxide, or tissue plasminogen activator, reduced endothelial cell release of plasminogen activator inhibitor 1 (PAI-1), interference with platelet, neutrophil or monocyte adhesion to endothelium, and agonist action through the adenosine receptor. ${ }^{170-180}$ In the 1990s, it was examined for its cardioprotective effects. Defibrotide has been examined in four uncontrolled trials for therapy with SOS. ${ }^{181-185}$ Three of the four therapeutic trials were multicenter trials. Three of the studies were performed in patients with moderate to severe SOS, many of whom had multiorgan failure, with day 100 survival of 31\%-43\%. 181-183 One trial in children examined the benefit of defibrotide in mild, moderate and severe SOS; in the severe group, with patients with multiorgan failure, $36 \%$ survived to day 100. ${ }^{185}$ These uncontrolled trials suggest that unlike tissue plasminogen activator, defibrotide may be useful in patients with multiorgan failure without the high-risk side effect of bleeding. An uncontrolled trial of prophylaxis with defibrotide in pediatric hematopoietic cell transplantation also suggested a benefit compared to historical controls. ${ }^{184}$

TIPS and surgical shunting preserve hepatocyte function in BCS, but TIPS does not affect outcome in SOS. ${ }^{186,187}$ In BCS syndrome, hepatocyte necrosis is due to congestion that is alleviated by decompressing the hepatic vasculature. However in SOS damage to hepatocytes is caused by ischemia due to obstruction at the sinusoidal level: protection of the sinusoidal endothelium by various interventions completely prevents sinusoidal obstruction and hepatocyte necrosis. ${ }^{104,188-190}$ Venous de-compression does not improve blood flow to the hepato-cytes. Although TIPS in SOS does reduce ascites, there is no benefit in survival and this is therefore not considered an appropriate indication for TIPS. ${ }^{186,187}$

Successful liver transplantation for SOS has been described in case reports. ${ }^{191-193}$ SOS is usually a complication of the conditioning regimen for hematopoietic cell transplantation for patients with malignancy and the underlying malignancy itself is a contraindication to the liver transplantation. Liver transplantation may be a consideration for patients who receive hematopoietic cell transplantation for a benign condition or in whom the underlying malignancy has a favorable prognosis after transplant.

Recommendations:

7. Fluid overload in SOS should be managed with diuretics, paracentesis, hemofiltration, and hemodialysis as needed (Class I, Level C).

8. With the absence of randomized controlled trials, no recommendation can be made for or against defibrotidefor the treatment of established SOS (Class IIb, Level B). 
9. Patients who undergo hematopoietic cell transplantation for a condition with a favorable prognosis may be considered for liver transplantation (Class I, Level C).

10. Transjugular intrahepatic portosystemic stent shunts (TIPS) or tissue plasminogen activator are not recommended for the therapy of SOS (Class III, Level B).

Areas for future studies:

Randomized controlled trials in patients at high risk for toxic liver injury would establish that there is indeed benefit from the therapeutic use of defibrotide and determine the true frequency of a therapeutic response. Similarly, a placebo-controlled randomized study would establish the potential for primary prophylactic use of defibrotide, i.e., defibrotide given before a liver-toxic conditioning regimen.

\section{Budd-Chiari Syndrome}

Definition.

International expert panels have agreed that "Budd-Chiari syndrome" be used as an eponym for "hepatic venous outflow tract obstruction", independent of the level or mechanism of obstruction. ${ }^{53,194}$ Cardiac and pericardial diseases and sinusoidal obstruction syndrome are excluded from this definition. BCS is a rare disease in population groups with a high standard of living. By contrast, it is a leading cause for liver-related hospital admission in populations with a lower standard of living. ${ }^{195,196}$

Obstruction of the hepatic venous outflow tract can be classified according to its location: small hepatic veins (HV), large HV, inferior vena cava (IVC) and any combination thereof. ${ }^{197}$ Indeed, there are differences in presentation and geographical distribution among these different categories. As a rule, pure IVC or combined IVC/HV block predominates in Asia, whereas pure $\mathrm{HV}$ block predominates in Western countries. ${ }^{196}$

\section{Causes.}

BCS is further divided into "secondary" BCS when related to compression or invasion by a lesion originating outside the veins (benign or malignant tumor, abscess, cyst, etc.); and "primary" BCS when related to a primarily venous disease (thrombosis or phlebitis).

\section{Secondary Budd-Chiari Syndrome.}

Hepatocellular carcinoma, renal and adrenal adenocarcinoma, primary hepatic hemangiosarcoma, epithelioid hemangioendothelioma, sarcoma of the IVC, right atrial myxoma, and alveolar hydatid disease may cause BCS through invasion of the venous outflow. ${ }^{196}$ Parasitic and nonparasitic cysts and abscesses can produce compression and thrombosis of the hepatic venous outflow tract. ${ }^{198,199}$ Large nodules of focal nodular hyperplasia in a central location may cause compression of the hepatic veins. ${ }^{200}$ Compression or kinking of the hepatic veins can occur following hepatic resection or transplantation. ${ }^{201,202}$ BCS may occur following blunt abdominal trauma, either from 
compression by intrahepatic hematoma, inferior vena cava thrombosis related to trauma, or herniation of the liver through a ruptured diaphragm. ${ }^{203-205}$ Blunt abdominal trauma, amoebic and pyogenic hepatic abscess, and polycystic liver disease account only for a small minority of patients with HV or IVC thrombosis. ${ }^{11,206}$

\section{Primary Budd-Chiari syndrome.}

By contrast with PVT, the local factors that determine thrombosis of the hepatic venous outflow tract remain unidentified in most patients.

Routine investigation for general thrombotic risk factors have yielded consistent results in Asia and in Western countries. ${ }^{9}, 11,16,207-212$ Main causal factors are presented in Table 4. Similar to PVT, BCS has been related to myelo proliferative diseases in a majority of patients when the diagnosis has been based on sensitive criteria, regardless of whether peripheral blood cell counts were suggestive or not. Clusters of dystrophic megakaryocytes at bone marrow biopsy, ${ }^{22}$ endogenous erythroid colony formation in culture of bone marrow or circulating progenitors ${ }^{208,210,213}$ and, recently, detection of V617F activating mutation of JAK2 tyrosine kinase in blood cells ${ }^{26,27,214,215}$ have been used as sensitive markers. It is noteworthy that these markers are not simultaneously present in all patients with myeloproliferative diseases. ${ }^{26,27,214}$

Factor V Leiden mutation and G20210A prothrombin gene mutation are associated with odds ratio for BCS of about 12 and 2, respectively. In patients with BCS, liver disease makes it extremely difficult to distinguish primary deficiency in protein $\mathrm{C}$, protein $\mathrm{S}$, or antithrombin, from low plasma levels secondary to decreased hepatic synthetic function. Antiphospholipid antibodies are found in about 10\%-30\% of patients with BCS, ${ }^{216,217}$ whereas lupus anticoagulant or anti-beta-2 glycoprotein 1 antibodies are found in about 4\%-5\%. Elevated anticardiolipin antibodies can be found in a similar proportion (20\%-31\%) of patients with chronic liver disease, suggesting that these antibodies have poor specificity in this context. ${ }^{218}$ Hyper-homocysteinemia, as a risk factor for BCS, is similarly difficult to assess, because raised homocysteine levels are extremely frequent in patients with liver disease whatever its cause. ${ }^{219}$ Studies on the prevalence of C677T homozygous state for MTHFR are limited and their results are not consistent. ${ }^{11,220}$ Other rare acquired diseases, namely paroxysmal nocturnal hemoglobinuria, ${ }^{221,222}$ Behçet's disease, ${ }^{207}$ hypereosinophilic syndrome, ${ }^{223}$ granulomatous venulitis, ${ }^{224}$ and ulcerative colitis ${ }^{225}$ appear to be risk factors for BCS. The association of BCS with oral contraceptive use has been evaluated in two casecontrol studies spanning the years 1970-1983 (odds ratio 2.37, 95\% confidence interval [CI] 1.05-5.34, $P<0.02)^{226}$ and 1985-2000 (odds ratio 2.4; 95\% CI, 0.9-6.2). ${ }^{9}$ Pregnancy also appears to be a risk factor for BCS, based on the temporal association between both conditions, ${ }^{206,227}$ although no case-control study has been performed to quantify this risk.

Overall, an underlying risk factor for thrombosis is found in up to $87 \%$ of patients with BCS. ${ }^{11}$ A combination of several causal factors is demonstrated in about $25 \%$ of patients, where routinely investigated. ${ }^{9,11,210}$ A combination with another causal factor is particularly common in patients with heterozygous factor V Leiden, ${ }^{209}$ or in oral contraceptive users or pregnant women. ${ }^{226}$ It is remarkable that a local factor responsible for development of 
thrombosis in the hepatic venous outflow tract, a highly unusual site, remains unidentified in most patients.

Recommendations for investigating causes of primary BCS:

1. Rule out space occupying lesions, or malignant tumors, compressing or invading the hepatic venous outflow tract with sonography, CT scan or MRI (Class I, Level B).

2. Seek clinical evidence for ulcerative colitis, celiac disease, and for systemic diseases (Class I, Level B).

3. Routinely check for multiple, concurrent risk factors for thrombosis, as indicated in Table 5 (Class I, Level B).

(a) Do not rule out a diagnosis of myeloproliferative disease solely on the basis of normal or low peripheral blood cell counts (Class I, Level B).

(b) When coagulation factor levels are below the normal range, do not regard decreased levels of protein $\mathrm{C}$, protein $\mathrm{S}$ or antithrombin as a primary, possibly inherited, deficiency in the absence of a positive family history or screening (Class I, Level C).

(c) Do not regard relatively weak thrombotic risk factors (factor V Leiden mutation, prothrombin gene mutation, hyperhomocysteinemia, or oral contraceptive use) as the only risk factor for BCS until other causes have been ruled out (Class I, Level B).

\section{Clinical and Laboratory Features}

In most cases, the underlying disorders causing thrombosis of the hepatic venous outflow are unrecognized at presentation. Presentation ranges from complete absence of symptoms to fulminant hepatic failure, through acute (rapid) or chronic (progressive) development of symptoms over weeks to months before diagnosis is made. The apparent age of the macroscopic and microscopic damage to the veins of the liver may differ from the apparent duration of symptoms. ${ }^{206,228}$ Asymptomatic BCS accounts for up to $20 \%$ of cases. ${ }^{229}$ The absence of symptoms is strongly associated with large hepatic vein collaterals. ${ }^{229}$ Classical signs and symptoms of BCS include fever, abdominal pain, ascites, lower extremity edema, gastrointestinal bleeding, and hepatic encephalopathy, ${ }^{206,230,231}$ each of which may be absent in patients with overt BCS. Jaundice is relatively uncommon. Marked dilation of subcutaneous veins on the trunk has a high specificity but a low sensitivity for IVC block. Serum aminotransferases and alkaline phosphatase can be normal or increased. Levels of serum albumin, serum bilirubin, and prothrombin can be normal or abnormal, and in some patients are markedly abnormal. The protein level in ascitic fluid varies from patient to patient. Ascites protein content above $3.0 \mathrm{~g} / \mathrm{dL}$ and serum-ascites albumin concentration gradient $\geq 1.1 \mathrm{~g} / \mathrm{dL}$ are suggestive of BCS, cardiac disease, or pericardial disease. Serum creatinine level can be elevated, usually due to prerenal dysfunction. The course of these manifestations can be steadily progressive, or marked by exacerbations and remissions. The disease can run a long insidious course, or a short period of prodrome followed by a rapid 
downhill course. Portal venous obstruction is common in patients with severe forms of the disease. ${ }^{230,232-234}$

\section{Imaging Features}

$\mathrm{X}$-ray venography has been the gold standard for the evaluation of the hepatic veins. Hepatic venograms can be obtained after cannulation of the veins through the retrograde approach using the transjugular, cephalic, or femoral route, ${ }^{235}$ or through the direct approach using percutaneous transhepatic puncture. ${ }^{236}$ Three patterns of opacification have been regarded as specific at retrograde catheterization ${ }^{235}$ : (1) a fine "spider-web" network pattern without filling of venous radicals; (2) a coarse network of collateral veins which arch outward from the catheter tip and then come together again near the site of entry of the HV into the IVC; and (3) a patent vein upstream from a stricture. Direct percutaneous venography can show a localized obstruction in the vicinity of the ostia when the HVs cannot be entered using retrograde cannulation. ${ }^{236,237}$ Inferior venacavography allows for demonstration of caval stenosis or occlusion. In many patients with pure hepatic vein thrombosis, the IVC appears narrowed at its intrahepatic portion, in relationship to the enlargement of the caudate lobe. ${ }^{238}$ When complete or near complete obstruction of the suprahepatic vena cava is present, insertion of two catheters allows for delineation of the obstacle, one above and one below the obstruction. ${ }^{239}$

Sonography findings are highly correlated with pathological examination ${ }^{240}$ and direct or retrograde venography. ${ }^{241-243}$ Features considered specific for hepatic vein obstruction on color Doppler imaging and pulse Doppler are: (1) a large hepatic vein with an absent flow signal, or with a reversed, or turbulent flow; (2) large intrahepatic or subcapsular collaterals with continuous flow connecting the hepatic veins or the diaphragmatic or intercostal veins; (3) a spider-web appearance usually located in the vicinity of hepatic vein ostia, together with the absence of a normal hepatic vein in the area; (4) an absent or flat hepatic vein wave form without fluttering; (5) a hyperechoic cord replacing a normal vein.

Spin-echo and gradient-echo MRI sequences, and intravenous gadolinium injection allows visualization of obstructed HVs and IVC, intrahepatic or subcapsular collaterals, as well as spider web network pattern. ${ }^{240,244}$ With computed X-ray tomography, failure to visualize the $\mathrm{HVs}$ is considered suggestive of $\mathrm{HV}$ obstruction.

Caudate lobe hypertrophy is found in about $75 \%$ of patients. ${ }^{240,245}$ This change is due to the separate venous drainage of this liver lobe into the inferior vena cava allowing for sparing of the outflow and compensatory hypertrophy. ${ }^{228}$ A characteristic pattern of parenchymal perfusion can be demonstrated using CT or MRI following bolus intravenous injection of contrast medium. This pattern consists of early homogeneous central enhancement (particularly at the level of the caudate lobe) together with delayed patchy enhancement of the periphery of the liver and prolonged retention of the contrast medium in the periphery. $240,244,246$ This heterogeneity is related to uneven portal perfusion. ${ }^{247,248}$

Macroregenerative nodules (enhancing at the arterial phase of contrast injection) are common in patients with longstanding BCS (see below). ${ }^{232,234}$ 


\section{Histopathological Features}

Thrombosis of small veins is uncommonly observed in small liver biopsy specimens.

Congestion, liver cell loss, and fibrosis in the centrilobular area are considered characteristic features for BCS. ${ }^{197}$ Central to central fibrosis develops in areas where there has been bridging necrosis. Ultimately, a cirrhotic pattern may be seen. However, there may be considerable variation in the degree of these changes from one area to the other. Thrombosis of intrahepatic portal veins is common in the most advanced cases and is associated with fibrous enlargement of the portal tracts. Portovenous and portoportal bridging fibrosis may develop. Parenchymal extinction refers to an area where liver cells have disappeared and are replaced by connective tissue. This change is found in areas where the corresponding hepatic veins and portal veins are simultaneously obliterated.

Nodular regenerative hyperplasia, and macroregenerative nodules are common in patients with longstanding BCS. ${ }^{232,234}$ These architectural changes appear to be related to the obstruction of an intrahepatic portal vein branch and to increased arterial inflow in the corresponding area. ${ }^{232,234}$ Macroregenerative nodules may strongly resemble focal nodular hyperplasia, histopathologically and at imaging.

\section{Diagnosis}

For providing direct evidence of an obstructed hepatic venous outflow tract, Dopplersonography, MRI and CT scan have the advantages of being non invasive or minimally invasive. The examiner's experience and awareness of a clinical suspicion of BCS appear to be key factors for a high diagnostic yield at Doppler sonography. However, there may be limitations to the study related to the patient's body habitus. Absence of visualization, or tortuosity of the hepatic veins at gray-scale real-time sonography albeit with flow signals at Doppler imaging are common but not specific, being also observed in advanced cirrhosis of other origins. However, a distinctive feature for BCS is the association with intrahepatic or subcapsular hepatic venous collaterals, which is found in more than $80 \%$ of the cases. MRI is not as effective as sonography in demonstrating intrahepatic collaterals. ${ }^{240}$ MRI might be more accurate than direct inferior venacavagraphy for characterizing solid endoluminal material. In the assessment of hepatic veins uisng CT scan, there are problems of false positive and indeterminate results in approximately $50 \%$ of the cases. ${ }^{240}$ There have been no clinical studies using the most recent techniques for computed tomography. Other limitations of CT scan are irradiation and potential renal toxicity from iodinated contrast agents.

Direct X-ray venography is needed for establishing a diagnosis of BCS in difficult cases, and also for precise delineation of obstructive lesions before planning treatment. Diagnostic pitfalls include failure to cannulate the hepatic vein ostia, and a distorted appearance of the hepatic veins. Complications of venous cannulation with thromboembolism appear uncommon although this statement needs to be verified. Anticoagulation likely increases the risk of hematoma at the puncture site. Percutaneous venous puncture should delay initiation of thrombolytic therapy. 
Indirect evidence for the diagnosis of BCS can be derived from an altered perfusion pattern at MRI or CT scan, or from caudate lobe enlargement. However, these two features are encountered in patients with other chronic liver diseases. ${ }^{247} \mathrm{An}$ altered perfusion pattern is also observed in other situations where portal venous perfusion is compromised. ${ }^{247,248}$ One of these situations, constrictive pericarditis, mimics hepatic venous obstruction, clinically, and can be missed at echocardiography. ${ }^{249}$

In the patient presenting with acute or chronic liver disease, Doppler sonography by an experienced operator has sufficed to establish or rule out BCS in most patients when the operator was aware of the diagnostic suspiscion. The role of MRI or CT scan has then been mainly to give images that are more appropriate for multidisciplinary discussion than sonography. When the patient with unexplained liver disease has had MRI or CT scan that suggests BCS, then Doppler sonography by an experienced operator is used as a confirmatory procedure for a detailed characterization of venous anomalies.

As venous thrombosis is rarely seen at liver biopsy, the main yield of this procedure is to show indirect, but strong, evidence for hepatic venous outflow tract obstruction in the form of congestion, liver cell loss, and fibrosis in the centrilobular area. The main differential diagnoses for these features are heart failure, constrictive pericarditis, circulatory failure, and SOS. Sinusoidal dilatation, with or without predominance in the centrilobular area, can be found in a number of systemic and hepatic conditions in the absence of hepatic venous obstruction. ${ }^{250}$ Although venular and perivenular fibrosis without congestion is occasionally found in patients with longstanding suprahepatic IVC obstruction, ${ }^{251}$ the absence of congestion in the centrilobular area is a strong argument against the diagnosis of $\mathrm{HV}$ thrombosis. ${ }^{206,228}$ At a late stage, hepatic vein thrombosis complicated by cirrhosis is difficult to differentiate from cardiac cirrhosis, or from cirrhosis complicated by hepatic vein thrombosis. ${ }^{252}$ Liver biospy remains the only means to diagnose the rare form of BCS due to involvement of the small hepatic veins with patent large veins, ${ }^{197}$ although differentiation of this form from sinusoidal obstruction syndrome is not always feasible. ${ }^{197,253}$

Considerable sample variation, ${ }^{232,234}$ and lack of independent prognostic value when tested together with simple clinical and laboratory data, ${ }^{230,254,255}$ make liver needle biopsy useless for prognostication and therapeutic indications. The risk of bleeding from the liver biopsy puncture site may delay the initiation of anticoagulation or thrombolytic therapy. Therefore the diagnostic yield of liver biopsy should be balanced against its impact on therapy.

When a confirmation is needed because Doppler sonography, MRI, or CT scan does not establish a diagnosis of BCS, liver biopsy may be used first when the large HVs and IVC appear clearly patent. Venography may be preferred as a first procedure when the aspect of the HVs is abnormal but not diagnostic, as may occur in patients with cirrhosis. In such patients, demonstration of patent HVs at transjugular venography may be followed by transvenous liver biopsy in the same session.

Recommendations for diagnosis of BCS:

4. Consider a diagnosis of BCS in the following settings: 
(a) An acute or chronic illness occurs with upper abdominal pain, ascites, or liver enlargement;

(b) A liver disease occurs in a patient with known risk factors for thrombosis;

(c) A liver disease occurs in a patient with an extensive network of subcutaneous veins of the trunk suggesting inferior vena cava obstruction;

(d) A liver disease remains unexplained after other common or uncommon causes have been excluded (Class I, Level C).

5. Consider only direct visualization of obstruction, and/or collaterals, of a hepatic vein or inferior vena cava, as definite evidence for the diagnosis ( Class I, Level C).

6. Consider Doppler-sonography by an experienced examiner, aware of the diagnostic suspicion, as a most effective and reliable diagnostic means. Consider MRI or CT scan as a confirmatory study or, if an experienced Dopplersonography examiner is not available, as an alternative (Class I, Level C).

7. Consider performing a liver biopsy only when an obstructed hepatic venous outflow tract has not been demonstrated with noninvasive imaging (Class I, Level C).

8. Consider $\mathrm{X}$-ray venography as a diagnostic procedure in patients where the diagnosis remains uncertain (Class I, Level B).

9. When making a decision regarding whether or not to perform an invasive diagnostic procedure, consider the potential renal toxicity of iodinated contrast agents and a possible need for rapid anticoagulation and/or pharmacological thrombolysis following the invasive procedure (Class I, Level C).

10. Do not regard liver nodules enhancing at the arterial phase of contrast injection as hepatocellular carcinoma without additional support for this diagnosis (Class I, Level C).

\section{Therapy}

This section will focus on treatment for primary BCS.

\section{Medical Therapy}

Underlying Risk Factors for Thrombosis.-Oral contraceptives are generally contraindicated in patients with BCS. It is not clear whether pregnancy should be considered contraindicated in patients whose underlying risk factors for thrombosis are well controlled, as there are reports of successful and uncomplicated pregnancies in patients with BCS given anticoagulation throughout the pregnancy. ${ }^{256}$

It is logical to treat underlying myeloproliferative diseases. The cell count threshold where treatment should be initiated, as well as the target counts to be reached with therapy, have not been assessed. Low-dose acetyl salicylic acid has been shown to be beneficial to prevent 
arterial disease in patients with polycythemia vera, but data on venous thrombosis are less clear. ${ }^{257}$ For most other risk factors for BCS, the only available treatment is anticoagulation.

Anticoagulation Therapy.-Indefinite anticoagulation therapy is generally recommended after an episode of idiopathic DVT in patients in whom a permanent risk factor is present and when thrombophilia is not curable. ${ }^{50}$ This might be extrapolated to patients with BCS. However, there have been no prospective randomized controlled trials of anticoagulation in patients with BCS. Two retrospective studies with multivariate analysis have attempted to evaluate the impact of anticoagulation on mortality from BCS. In a multicenter French study, 120 patients admitted to the hospital from 1970-1992 were enrolled. ${ }^{255}$ Permanent anticoagulation was systematically administered to patients who were admitted starting in 1985. Analysis by year of admission disclosed a sharp increase in survival starting in 1985, and no other change in referral or management pattern taking place in 1985 could be identified. In a recently reported international study, 237 patients were enrolled. ${ }^{230}$ Overall, 171 patients $(72 \%)$ were treated with anticoagulants. The use of anticoagulants did not yield a significant beneficial effect on survival in the total population (relative risk, 1.05; 95\% CI, 0.62-1.76). Results did not change when the group with portosystemic shunting was taken as a separate category (relative risk, 0.80 ; $95 \% \mathrm{CI}, 0.61-$ 1.05). Separate analyses of the effect of anticoagulation on survival for three classes of prognosis suggested a nonsignificant trend toward improved survival for patients with a good prognosis (relative risk, $0.14 ; 95 \% \mathrm{CI}, 0.02-1.21$ ), but not for those with an intermediate (relative risk, 0.88 ; 95\% CI, $0.39-2.01$ ) and poor prognosis (relative risk, 1.3; $95 \%$ CI, 0.50-3.04). Neither of these two studies included the presence of an underlying risk factor for thrombosis in the analysis.

Some data on anticoagulation are derived from the experience in liver transplantation for BCS. Two early reports have suggested a beneficial effect of long term anticoagulation. 258,259 Overall, 118 instances of transplantation combined with permanent anticoagulation have been reported from single centers. ${ }^{258-264}$ There were only five cases of recurrence, two of which required retransplantation. However, anticoagulation did not prevent posttransplant hepatic artery thrombosis or PVT in 15 of these 118 patients (13\%), including seven with PVT treated conservatively, ${ }^{258,261,262}$ three with hepatic artery thrombosis treated with retransplantation, ${ }^{258,264}$ one with pharmacological thrombolysis and exploratory laparotomy, ${ }^{260}$ and four patients reported without details. ${ }^{262}$ Bleeding complications were reported in 28 patients (24\%), some of which required an operation. There were no bleeding-related deaths. In a recent European survey on 248 patients who underwent transplantation for BCS, $85 \%$ of patients received anticoagulation after transplantation. ${ }^{265}$ Venous thrombosis at various sites recurred in 27 patients (11\%). Mortality was $40.7 \%$ in patients with recurrence. Hemorrhage attributed to anti-coagulants was observed in 27 patients (11\%). Two patients with intracranial bleeding died and the mortality attributed to anticoagulants was $1 \% .265$

Other available data are from an experience in percutaneous angioplasty where univariate analysis disclosed that lack of anticoagulation therapy for at least 6 months was associated with reobstruction. ${ }^{266}$ 
There has been no report of bleeding-related death in patients with BCS on anticoagulation, but there have been few studies on this particular issue. A recent study disclosed a high rate of anticoagulation related complications in patients undergoing transhepatic interventional therapy. Moreover, a surprisingly high rate of heparin-induced thrombocytopenia was observed, mainly with unfractionated heparin. ${ }^{267}$

There has been little evaluation of the optimal level of anticoagulation in patients with BCS. The above mentioned studies have used conventional targets for thrombosis in other venous beds, namely anti Xa level $0.5-0.8 \mathrm{IU} / \mathrm{mL}$ for heparins and INR 2 to 3 for vitamin K antagonists. ${ }^{267}$ It remains to be assessed whether current INR for monitoring patients on vitamin $\mathrm{K}$ antagonists without liver disease are appropriate for patients with BCS receiving these agents.

Thrombolysis.-The limited amount of available data on efficacy and tolerance of pharmacologic thrombolysis have been recently reviewed, and found to be inconclusive. ${ }^{268}$ There is some indication that in situ infusion of thrombolytic agents is associated with sustained patency of recently thrombosed veins when thrombolysis is coupled with restoration of a high blood flow velocity by means of angioplasty or stenting. ${ }^{268}$

Medical Treatment for Portal Hypertension.-Guidelines for the management of portal hypertension-related complications in patients with cirrhosis of other causes ${ }^{53,70}$ have usually been followed in BCS patients. However, as circulatory changes seen in patients with BCS differ from those seen in patients with cirrhosis of other causes, ${ }^{269}$ the effects of pharmacological therapy for portal hypertension might differ in these two populations.

Angioplasty and Stenting.-The rationale for recanalization has been to decompress the liver without compromising, and even while restoring, hepatic blood flow. Patients with focal or segmental obstruction of the hepatic venous outflow tract are theoretically eligible for recanalization. Short-length stenosis is present in $25 \%-30 \%$ of patients with pure hepatic vein block ${ }^{270}$; and in up to $60 \%$ of patients with IVC block, most of whom have an associated HV block. ${ }^{271}$

Surgery for HV or IVC angioplasty and for hepatoatrial anastomosis have been abandoned over time. Data on percutaneous maneuvers come from a limited number of retrospective uncontrolled studies. Percutaneous angioplasty has usually been performed through a transvenous route, with or without stent insertion. A transhepatic approach with stenting has also been used when a long segment of the HV was occluded. Data can be analyzed according to the main level of obstruction: HVs or IVC.

With respect to HVs, angioplasty $272-274$ or stenting $266,275-277$ was reported in 14 and 24 patients, respectively, with a follow-up averaging 2 years. The overall technical success rate was unclear. Severe procedure-related complications seem to be rare with percutaneous transluminal approach, ${ }^{237}$ which might not be the case with a percutaneous, transhepatic approach. ${ }^{266,272}$ Immediate improvement in signs, symptoms, and liver function generally occurs. Reobstruction was more common in patients undergoing primary angioplasty alone than in those undergoing primary stenting. Prognostic factors for reobstruction of the hepatic 
veins have not been assessed. Sustained clinical improvement despite reobstruction occurs, although the frequency of this cannot be evaluated. Clinical failure has been treated successfully with surgical mesocaval shunts in selected cases. ${ }^{237}$ No patient was reported to require liver transplantation. Periprocedural and total mortality appear to be low and not related to the procedure. However, no evaluation based on initial severity of the disease is possible. It should be remembered that patients with short-length stenoses of the hepatic veins, eligible for, but untreated with recanalization procedures, have a better outcome than other patients. ${ }^{270}$ Publication biases cannot be ruled out.

IVC angioplasty with ${ }^{266,276,278-280}$ or without ${ }^{272,278,281-293}$ stenting was reported in 296 and 157 patients, respectively. Information on the outcome beyond 36-48 months is limited. The overall technical success rate was about $95 \%$. Severe procedure-related complications were more common when IVC recanalization was combined with hepatic vein recanalization through the transhepatic approach ${ }^{266}$ than when the attempt was limited to a transvenous approach. Immediate improvement in signs, symptoms and liver function generally occurred. Reobstruction was usual after primary angioplasty alone but uncommon after primary stenting. However, the final patency rate (about 85\%) was similar with both techniques (probably owing to revision with stent insertion for reobstruction after angioplasty alone). Factors for reobstruction might be HV stenting (as opposed to IVC stenting), and lack of anticoagulation therapy for at least 6 months, and not the degree or the type of obstruction. ${ }^{266}$ Periprocedural and overall mortality was low and not related to the procedure. Only one patient was reported to undergo subsequent liver transplantation. No evaluation of the outcome based on initial severity of the disease is possible from the available data.

Portosystemic Shunting.-The rationale for side-to-side portosystemic shunting has been to decompress the liver using the portal venous system as an outflow tract, at the expense of decreased portal venous inflow. Depending on the patency of the inferior vena cava, and on technical limitations related to caudate lobe enlargement, several variants of surgical side-to-side shunting have been used. Overall perioperative mortality has been high, averaging 25\% (reviewed by Langlet and Valla ${ }^{294}$ ). The rate of shunt dysfunction due to early or late thrombosis or to late stenosis has reached $30 \%$ in series with long term followup. ${ }^{261,295,296}$ The impact of surgical portosystemic shunting on survival has been assessed in four multicenter, retrospective, multivariate analyses. A study of 45 patients with liver biopsy available at the time of diagnosis found portosystemic shunting to be a significant factor for survival $(P=0.008)$, in addition to Child-Pugh score and prothrombin time. ${ }^{254} \mathrm{~A}$ study of 120 patients with a patent portal vein, found surgical shunting to be of no independent prognostic value after adjustment for Child-Pugh score, response of ascites to diuretics and serum creatinine. ${ }^{255}$ A study of 123 patients seen since 1985 with a patent portal vein disclosed no independent prognostic value of surgical shunting after adjustment for Child-Pugh score, ascites score, serum creatinine, and the clinicopathological form (acute, chronic, or acute on chronic). ${ }^{297}$ The most recent study, of 237 patients diagnosed between 1984 and 2001, found surgical shunting to lack independent prognostic value after adjustment for encephalopathy, ascites, prothrombin time and bilirubin (all independent determinants of survival). ${ }^{230}$ However, in the latter study an improved survival with surgical 
shunting was suggested for patients in prognostic class II (with intermediate prognosis) (RR $0.63 ; 95 \% \mathrm{CI}, 0.26-1.49)$. In these four studies, surgical shunting was considered on an intention-to-treat basis, i.e., without consideration for shunt patency. Recent data in a cohort of 39 patients with BCS treated with a surgical shunt followed for a median of 110 months show that maintenance or reestablishment of good shunt function is crucial for long-term survival. ${ }^{295}$ Shunt dysfunction may be related to stenosis of intrahepatic IVC (which is amenable to stenting), ${ }^{275,295,298}$ to shunt stenosis (amenable to percutaneous transluminal angioplasty and stenting), ${ }^{273,275,295,299}$ and to shunt or PVT (amenable to in situ thrombolysis). ${ }^{299}$ One risk factor for shunt dysfunction appears to be the use of long prosthetic grafts. ${ }^{75,295}$ Routine anticoagulation did not prevent shunt dysfunction from occurring. ${ }^{295,300}$ Whether anticoagulation can still have a protective effect cannot be assessed from the limited data available. ${ }^{75}$

TIPS have been increasingly used for BCS treatment in recent years. TIPS insertion was reported in 195 cases from retrospective surveys on consecutive patients.

267,274,278,288,293,301-313 Indications were generally stated to be manifestations unresponsive to medical therapy, but precise criteria were generally not provided. Where data are available, a TIPS was attempted in 156 of 270 patients with BCS (57.8\%) seen in the corresponding period. Insertion was successful in 141 of 174 cases (81.1\%) reported on an intention-to-treat basis. Median follow-up was approximately 24 months on average. Dysfunction was reported in 100 of 181 cases (55.2\%). One-month mortality rate was $9.0 \%$ in 145 patients. Eighteen of 195 patients (9.2\%) underwent liver transplantation. Overall, 59 patients $(30.2 \%)$ died or were transplanted. In some patients, however, TIPS was used as a bridge to planned liver transplantation whereas other patients, whose condition improved, were not listed or were withdrawn from the transplantation waiting list. In most surviving and nontransplanted patients, control of ascites and rapid improvement in general condition and in liver function were generally reported. There has been no attempt to compare the outcome following TIPS insertion to that following surgical shunting, after adjustment for prognostic factors. TIPS dysfunction was much lower when using polytetrafluoroethylene (PTFE) covered stents (in 17 patients) than uncovered stents (in 41 patients). ${ }^{314}$ Moreover, PTFE covered stents appear to be associated with a lower incidence of clinically significant events than uncovered stents. A higher than expected incidence of bleeding complications has been suggested following TIPS insertion for treatment of BCS as compared with other chronic liver disease. ${ }^{267,307}$ A learning curve effect for success and complication rates, not for mortality, has been observed. ${ }^{267}$ The incidence of post-TIPS encephalopathy appears to be low 313,314 but this finding needs to be confirmed.

Liver Transplantation.-Data from $84 \%$ of the patients transplanted for BCS in the European liver transplant registry between 1988 and 1999 have recently been analyzed. ${ }^{265}$ Half of the patients included in the European transplant survey belonged to Rotterdam prognostic class III (with the worst baseline prognosis ${ }^{230}$ ). Overall actuarial survival was $76 \%$ at 1 year, $71 \%$ at 5 years, and $68 \%$ at 10 years. ${ }^{265}$ This survival is almost identical to that in the intermediate class of risk score (Rotterdam class II) from a contemporary U.S.Dutch-French cohort where a minority of patients underwent transplantation. In surveys of consecutive patients transplanted for BCS, 27 of 142 patients (19\%) had been transplanted 
following portosystemic shunting. ${ }^{56,258-260,262-264,302,309,315,316}$ Likewise, in the European survey, $24 \%$ of patients had undergone TIPS or surgical shunting. ${ }^{265}$ Previous surgical shunting or TIPS, together with high serum creatinine and bilirubin levels, was an independent marker of a poor outcome following transplantation. ${ }^{265}$ Recently reported data from a U.S. registry are in line with these European data. ${ }^{317}$

As discussed above, a favorable impact of early and prolonged anticoagulation on the results of liver transplantation has been suggested. Some data indicate that, for patients with myeloproliferative disease, a strategy combining hydroxyurea and aspirin for prevention of thrombotic events might be as effective as anticoagulation. ${ }^{318}$ There is no indication that within 10 years of transplantation, there is a significant increase in the risk of malignant transformation of underlying myeloproliferative disease as compared to natural history in patients who did not undergo transplantation.

\section{Treatment Strategy}

Consensus statements have been reported by expert panels in $2002^{194}$ and $2005 .{ }^{53}$ In these documents, a strategy was proposed consisting of the following graded approach: (1) anticoagulation, treatment of underlying condition, and symptomatic treatment for complications of portal hypertension in all patients with primary BCS; (2) active search for short-length venous stenoses amenable to angioplasty/stenting; (3) in patients not suited for, or unresponsive to angioplasty/stenting, insertion of a TIPS should be considered; (4) and in patients unresponsive to TIPS, liver transplantation should be considered. The definition for response to therapy was not stated. A recent proposal for such a definition needs validation. 267 Two recent clinical studies provide support to the strategy described above. Between 1984 and 2004 in Birmingham, 61 of 111 primary patients with BCS were treated with anticoagulation plus stent/angioplasty and/or TIPS. The cohort included 33 patients seen after 1999, when a treatment algorithm similar to this strategy came into place. ${ }^{313}$ Between 1997 and 2004 in Clichy, France, 51 patients were treated according to this strategy. ${ }^{267}$ The outcome in these two cohorts (5-year survival greater than $85 \%$ ) may be compared with other cohorts where the distribution of patients according to prognostic classes was reported. Such comparisons have undisputed limitations. However, the outcome was clearly better in these two cohorts than in those managed mainly with medical therapy or surgical shunting. 230,255,297 In particular, the improvement was most marked in patients with the poorest prognostic class. ${ }^{319}$ From the relatively limited but consistent data available, it appears that the first step of the strategy (medical therapy) is associated with steady improvement in 20\% of patients without any need for additional therapy. ${ }^{267,288,320}$ In Western countries where pure hepatic vein block predominates, percutaneous recanalization appears to achieve a complete response in an additional $20 \%$ of patients; TIPS successfully treats an additional $65 \%$; and liver transplantation is performed in the rest. ${ }^{267}$ By contrast, in Asia where suprahepatic IVC block predominates, percutaneous recanalization can be expected to achieve a complete response in $60 \%$ of patients, whereas the place of TIPS, derivative surgery, and transplantation remain unclear. ${ }^{282,288}$

Data on patients with BCS with fulminant hepatic failure are scarce, because this condition appears to be extremely rare. ${ }^{321}$ In these patients, it is unclear whether an attempt at TIPS 
should be used prior to emergency liver transplantation. Furthermore, it remains to be clarified whether TIPS in this setting should be considered only a bridge to liver tansplantation or might be a definitive treatment for those patients who clearly and rapidly improve following TIPS placement. ${ }^{309}$

\section{Current Outcome and Prognosis}

Natural history is poorly known as there has been no cohort study of untreated patients. There has been continued improvement in outcome over the last four decades. In the most recently reported cohorts, overall 5-year survival rates over $80 \%$ have been achieved. $230,267,305,310,313$

Serum albumin, bilirubin, prothrombin, ascites, and encephalopathy, or their combination as Child-Pugh score, have generally been found to be independent prognostic factors. Prognostic scores based on a combination of these factors have been developed. 230,254,255,288,297 These scores are most useful for clinical studies but not relevant to individual management. Histological variables were repeatedly shown to lack independent prognostic value, once components of the Child-Pugh score were taken into account. $230,254,255$ In addition, the site of hepatic venous outflow tract obstruction, and the association with PVT did not appear to bear prognostic value independent of the components of the Child-Pugh score. ${ }^{230,255,288}$

Hepatocellular carcinoma appears to be rare and is mainly observed in patients with longstanding disease, particularly in relationship to suprahepatic IVC obstruction. ${ }^{209,322-324}$ However, its differentiation from benign macroregenerative nodules is challenging. A rising serum alpha fetoprotein level appears to be highly specific for the diagnosis but insufficiently sensitive. ${ }^{322,324,325}$ Patients with splanchnic vein thrombosis and myeloproliferative disease are at risk of subsequent development of leukemia or myelofibrosis. Hematological progression occurred after a mean follow-up of 6.6 years in 7 of 31 such patients versus none of 63 patients without evidence of myeloproliferative disease. ${ }^{22}$ Therefore, in adequately treated patients, long-term prognosis might be jeopardized more by subsequent neoplastic disease than by liver failure. Despite this risk of hematological progression, survival after liver transplantation for BCS has been similar to that for other liver diseases. ${ }^{265}$

Recommendations for therapy of Budd-Chiari syndrome (see also Table 6):

11. Correct without delay the underlying risk factors for venous thrombosis, whenever possible (Class I, Level C).

12. Initiate anticoagulation therapy immediately. Use low molecular weight heparin, targeting anti-Xa activity to $0.5-0.8 \mathrm{IU} / \mathrm{mL}$. Change to an oral anticoagulation agent when clinically appropriate, targeting the INR to between 2-3 (Class I, Level B).

13. Maintain permanent anticoagulation therapy, unless a major contra-indication is present or a complication of anticoagulation therapy occurs (Class I, Level C). 
14. Treat complications of portal hypertension as recommended for other types of liver disease until more data are available (Class I, Level C).

15. Check for a venous obstruction amenable to percutaneous angioplasty/stenting in all symptomatic patients. Treat accordingly (Class I, Level C).

16. In patients without ongoing improvement on anticoagulation therapy (with or without angioplasty), consider TIPS insertion (Class I, Level C).

17. Consider liver transplantation:

(a) if TIPS insertion fails or does not improve the patient's condition.

(b) in patients with fulminant hepatic failure (Class I, Level C).

18. Consider initial management for recently diagnosed BCS in close connection with a transplant center (Class III, Level C).

19. Monitor patients with long-standing, well controlled BCS for late development of hepatocellular carcinoma and transformation of underlying myeloproliferative disease (Class I, Level C).

\section{Special Groups}

Children.

Data on BCS in children are scarce. Series of consecutive cases date back to the early 1990s. 206,326-328 There appears to be a predominance of obstruction at the level of the suprahepatic inferior vena cava. The etiology remains unclear as underlying prothrombotic diseases have not been routinely investigated. There are, however, isolated case reports of an association with factor $\mathrm{V}$ Leiden or prothrombin gene mutation, antiphopholipid syndrome, or celiac disease. Surgical as well as percutaneous therapy (TIPS or recanalization), and thrombolysis have been claimed beneficial in selected cases.

\section{Combined Portal Vein and Hepatic Venous Outflow Tract Obstruction.}

Extrahepatic PVT has been found in about $15 \%$ of unselected patients with BCS. ${ }^{233,329}$ Disease is usually more severe in these patients than in those with a patent extrahepatic portal vein. TIPS, however, has been possible and apparently effective in a handful of patients ${ }^{76}$ whereas surgical portosystemic shunting and liver transplantation apparently had poor results. ${ }^{233,329}$ PVT was present before transplantation in 47 of 248 patients in the European survey on transplantation; however, the impact of PVT on the outcome of liver transplantation was not reported. ${ }^{265}$

Areas requiring future studies:

Tests for improved identification of primary deficiency in protein C, protein S and antithrombin, and antiphopholipid syndrome in a context of liver disesase have to be developed. Accuracy of most recent generation CT technology for BCS diagnosis has to be evaluated and compared with that of Doppler ultrasound and MRI. Risk factors and diagnostic features for hepatocellular carcinoma need assessment, particularly in 
relationship to benign macroregenerative nodules. The risk/benefit ratio of anticoagulation requires further evaluation, particularly in the setting of interventional radiology or surgery. Improved prognostic models are needed for optimal timing and targeting of invasive therapeutic options. Long-term outcome of, and therapy for, underlying blood diseases have to be clarified.

\section{Congenital Vascular Malformations}

Vascular malformations of the liver result in abnormal shunting of blood in or around the liver. They are increasingly being discovered in patients undergoing ultrasonography or other imaging studies of the liver for other reasons. Given the vascular anatomy of the liver, functional shunting can occur from the hepatic artery to the hepatic vein (arteriovenous or arteriohepatic shunt), from the hepatic artery to the portal vein (arterioportal shunt) and/or from the portal vein to the systemic circulation (portosystemic or portohepatic shunt).

Although all these shunts can be acquired, as those associated with cirrhosis and/or hepatocellular carcinoma, or those that occur after blunt or penetrating liver trauma (including liver biopsy, transhepatic cholangiography, or biliary surgery), most are congenital. ${ }^{330}$ In liver involvement by hereditary hemorrhagic telangiectasia (HHT), the three types of shunt may coexist and, although it is a congenital disorder, symptoms appear in adults. Although the condition is rare, there has been a recent interest in pathophysiology, genetics, clinical presentation and management issues, including several international consensus conferences among experts involved in the care of these patients. 331,332 Consensus reached at these conferences form the bases for the recommendations set forward.

Isolated congenital vascular malformations are those not associated with HHT and are usually diagnosed in infants or children. These isolated malformations are very rare and their diagnosis and management have been mostly anecdotal.

Interestingly, liver vascular malformations are associated with nodular lesions of the liver such as nodular regenerative hyperplasia or focal nodular hyperplasia, particularly in patients with isolated congenital portosystemic shunts ${ }^{333-336}$ and in patients with liver involvement by HHT, ${ }^{337-339}$ most probably as a result of heterogenous liver blood perfusion.

\section{Liver Involvement By Hereditary Hemorrhagic Telangiectasia}

HHT, or Rendu-Osler-Weber disease, is a rare (1-2 cases/10,000) genetic disease with an autosomal dominant inheritance pattern, characterized by widespread cutaneous, mucosal and visceral arteriovenous malformations that can involve lung, brain and/or liver. In most HHT families, there is a mutation in one of two genes, endoglin (ENG) and activin receptorlike kinase tpe 1 (ALK-1 and ACVRL1), that encode for transmembrane proteins involved in the transforming growth factor- $\beta$ (TGF- $\beta$ ) signaling pathway and are expressed predominantly on vascular endothelium. ${ }^{340,341}$ 
Liver vascular malformations are widespread and include both microscopic and macroscopic malformations of variable size, ranging from tiny telangiectases to discrete arteriovenous malformations ${ }^{342}$ Functionally they result in three different types of shunting: arteriovenous, portovenous, and arterioportal. Using sensitive imaging techniques, vascular malformations in the liver are demonstrable in more than $75 \%$ of patients with HHT; ${ }^{343,344}$ however, most of them are asymptomatic. Symptomatic liver vascular malformations (LVMs) occurs in about $8 \%$ of the patients with HHT who have hepatic imaging abnormalities. ${ }^{337,343}$ A recent review of the English literature spanning 29 years revealed only 89 unique patients with HHT with symptomatic LVMs. ${ }^{345}$ LVMs are more common and are more often symptomatic in families of patients with the ALK-1 mutation ${ }^{346-350}$

Symptoms of LVMs in HHT appear around age 30 and occur predominantly in females. The three most common initial clinical presentations are high-output heart failure, portal hypertension, and biliary ischemia. ${ }^{338,345}$ The most common presentation is high output heart failure characterized by shortness of breath, dyspnea on exertion, ascites, or edema; the next most common presentation is portal hypertension, presenting most commonly with ascites, but also with varices and variceal hemorrhage; and the least common, but potentially most lethal (particularly when associated with high-output heart failure) is biliary disease characterized by biliary strictures/dilation, and bile cysts presenting with abdominal pain, cholestasis with or without cholangitis. ${ }^{345}$ These presentations may occur concurrently or successively and may have spontaneous exacerbations and remissions. ${ }^{338}$

High-output heart failure results from arteriohepatic and/or portohepatic shunting leading to a hyperdynamic circulatory state that eventually leads to heart failure. Portal hypertension results either from arterioportal shunting (with subsequent development of portal fibrosis) or from nodular regenerative hyperplasia (NRH) that in turn results from an irregular blood flow through the liver. The biliary presentation likely results from shunting of blood away from the peribiliary plexus leading to biliary ischemia. In its extreme, biliary ischemia can lead to bile duct necrosis and liver necrosis, a catastrophic event that has been termed "hepatic disintegration" 351 , characterized by sudden right upper quadrant pain and development of cholangitis, sepsis and/or liver hemorrhage. Other, less common presentations are hepatic encephalopathy, due to portovenous shunting and abdominal angina due to mesenteric arterial "steal" through pancreaticoduodenal arteries.

Biochemically, the most common abnormalities are elevations of the alkaline phosphatase and of the gamma-glutamyl-transpeptidase that, as expected, are mostly observed in the biliary type although they can also be seen in the other clinical presentations. Notably, liver synthetic function and platelet count are normal (even in the portal hypertension type) because these patients do not have cirrhosis and therefore they do not develop liver insufficiency 338,345

\section{Diagnosis}

The diagnosis of liver involvement by HHT has to be made in the context of a symptomatic patient with clinical characteristics that suggest the presence of HHT such as epistaxis, cutaneous or mucosal telangiectases, family history of HHT and a personal or family history

Hepatology. Author manuscript; available in PMC 2019 August 16. 
of stroke or intracerebral hemorrhage (from pulmonary and cerebral AVMs, respectively). ${ }^{332}$ In patients with diffuse liver AVMs who do not meet clinical diagnostic criteria for HHT, genetic testing for the two most common coding sequence mutations (ENG and ALK-1) can be performed to assist in establishing a diagnosis of HHT. ${ }^{331}$ Liver involvement is suspected by finding a thrill/bruit in the abdominal right upper quadrant. Although angiography is the gold standard in the diagnosis of LVMs, the diagnosis can be readily established using less invasive methods such as Doppler ultrasonography and multiphase CT. On Doppler ultrasonography the abnormalities that have the highest diagnostic accuracy are enlarged hepatic artery and intrahepatic hypervascularization ${ }^{352}$ whereas on CT, all patients with symptomatic liver involvement have a markedly dilated hepatic artery and diffuse liver telangiectases that lead to a markedly heterogeneous hepatic enhancement pattern. ${ }^{353}$

On imaging studies, the liver may appear nodular mostly due to the presence of NRH and is often misinterpreted as cirrhosis. Focal nodular hyperplasia, a focal benign liver lesion akin $\mathrm{NRH}$, is frequent in patients with HHT, with a prevalence of $2.9 \%$ (100-fold greater than in the general population). ${ }^{337}$ Its presence can lead to further confusion, as finding a mass in a nodular liver can lead to a misdiagnosis of hepatocellular carcinoma, which has not been described in HHT. Liver biopsy in the diagnosis of liver vascular malformations in HHT is unnecessary as it is often misinterpreted, it does not provide as much information as an imaging study and may be dangerous. ${ }^{338,345}$

Screening for LVMs in patients with HHT who have no clinical evidence of liver involvement is not recommended because the prevalence of liver involvement is high and there is no effective treatment for asymptomatic VMs. Screening should only be done in the context of research studies or when the presence of liver involvement is a decisive factor in establishing a diagnosis of "definite" HHT in patients who only meet one or two HHT diagnostic criteria or in whom genetic testing is inconclusive or unavailable. ${ }^{331,332}$

Recommendations:

1. Screening for liver involvement in patients with HHT is not recommended except in patients in whom the presence of liver vascular malformations would be key in establishing a definite diagnosis of HHT (Class III, Level C).

2. The diagnosis of liver involvement in HHT should be made radiographically: by Doppler ultrasound, CT scan or angiography (Class I, Level C). The diagnosis is based on finding heterogeneous enhancement or hypervascularization of the liver and common hepatic artery enlargement (class I, Level B). Liver biopsy should be avoided, as it is not useful in the diagnosis of liver involvement by HHT and could be complicated by bleeding (class III, Level B).

3. Isolated liver masses in patients with HHT should not be regarded as hepatocellular carcinoma without additional support for the diagnosis (Class I, Level B). 


\section{Treatment.}

No treatment is recommended for patients with asymptomatic liver involvement by HHT. In patients with symptomatic liver involvement, management depends on the type of clinical presentation. ${ }^{354}$ The majority of patients with high-output heart failure respond to standard therapy with salt restriction, diuretics, beta-blockers, digoxin and angiotensin-converting enzyme inhibitors, and includes correction of anemia and arrhythmias that often trigger symptomatic heart failure. Complications of portal hypertension (bleeding from gastroesophageal varices, ascites) should follow the same recommendations put forward for cirrhotic patients. ${ }^{71,345,355}$ Abdominal pain from biliary ischemia is treated with analgesics with the addition of systemic antibiotics when associated with cholangitis. To avoid cholangitis, patients with biliary abnormalities should not be subjected to invasive biliary imaging procedures such as endoscopic retrograde cholangiography. ${ }^{338}$ As in any cholestatic disease, urosdeoxycholic acid can be used although there is no evidence demonstrating a beneficial effect. In patients with active biliary ischemia/necrosis with developing or growing biliary cysts whose pain is not responding to analgesics and/or who develop signs of infection, biliary drainage should be considered with chronic administration of antibiotics. 354

Transarterial embolization or surgical ligation of the hepatic artery has been used mostly in the therapy of high-output heart failure, but also in cases of portal hypertension and mesenteric "steal" syndrome. Amelioration or resolution of symptoms is transient and treatment is associated with significant morbidity and mortality mostly in the form of biliary and/or hepatic necrosis. Over a third of patients who have undergone this procedure have experienced complications that led to liver transplantation or death. ${ }^{345}$ Hepatic artery embolization should be considered mainly in nontransplant candidates who have failed maximal medical therapy. The procedure is contraindicated in patients with portovenous shunts and in those with biliary symptoms/signs. ${ }^{331}$

Orthotopic liver transplant has been proposed as the only definitive curative option for liver involvement in HHT. Until recently, most published accounts of liver transplantation for HHT had been single-case reports, the most common reason for liver transplantation being hepatobiliary necrosis after hepatic artery embolotherapy. In these cases, the survival was $90 \%$ in a median followup of 24 months. ${ }^{345}$ The analysis of 40 patients with liver HHT who underwent liver transplantation reported to the European Liver Transplant Registry were recently published. ${ }^{356}$ Although the procedure is demanding and associated with large intraoperative bleeding, the overall survival rate is $80 \%$ in a median follow-up of 58 months. 356 The majority (58\%) of patients transplanted had the heart failure clinical presentation, either alone or in combination with other presentations. Survival in this subgroup appeared to be the best with an overall median survival of $87 \%$ in a median followup period of 47 months (93\% in those with isolated heart failure). ${ }^{354}$ However, it is uncertain whether maximal medical therapy had been attempted in these patients. Conversely, the worst posttransplant survival appears to occur in patients with the portal hypertension presentation with an overall median survival of $63 \%$ in a median followup period of 47 months. ${ }^{354}$

In a recent conference on Model for End-Stage Liver Disease (MELD) exceptions for liver transplantation in the United States, it was proposed that patients with HHT should continue 
to be addressed by the Regional Review Boards and additional priority for liver transplantation be assigned on a case-by-case basis. ${ }^{357}$ Given the fast and catastrophic evolution of acute biliary necrosis associated with liver failure, ${ }^{358-360}$ it was suggested that patients with acute biliary necrosis be assigned a MELD score of 40, while those with highoutput heart failure that are symptomatic despite maximal medical therapy could be assigned a MELD score of 22. If an increased MELD score is provided, the MELD score should increase by an incremental $10 \%$ mortality risk score at 3-month intervals on a case-by-case basis after the regional review board has evaluated all of the information defined above for each 3-month cycle. ${ }^{357}$ Right heart catheterization should always be performed in patients with HHT being evaluated for liver transplantation to exclude significant pulmonary hypertension and allowed in those with a pulmonary vascular resistance $<240$ dynes.sec.cm $-5.331$

Anecdotal reports of bevacizumab, an antibody to vascular endothelial growth factor (VEGF) have shown that 3-month courses of this antiangiogenic drug are associated with amelioration $^{361}$ and even normalization of cardiac output ${ }^{362}$ as well as reduction in liver volume and LVMs and improvement in liver enzymes and performance status. ${ }^{362}$ Further experimental and human studies are needed before this therapy can be widely recommended in these patients but it indicates that active angiogenesis may play a role in the growth and regression of liver vascular malformations in HHT.

\section{Recommendations:}

4. Treatment is not indicated in patients with HHT who have asymptomatic liver involvement (Class III, Level C).

5. In patients with HHT who have symptomatic liver involvement, treatment depends on presentation:

a. Heart failure and portal hypertension are treated according to standards of care (Class I, Level A).

b. Biliary disease is treated with ursodeoxycholic acid and with analgesics for right upper quadrant pain (Class I, Level C).

6. Hepatic artery embolization should be avoided in patients with liver involvement by HHT, as it is a palliative measure associated with significant morbidity. It is also contraindicated in patients with portosystemic shunting and in those with biliary presentation. (Class III-Level B) It can be considered in nontransplant candidates with intractable heart failure and hepatic artery "steal" syndrome (Class IIa, Level C).

7. Liver transplantation is the only curative treatment and should be considered for acute biliary necrosis syndrome and intractable heart failure or portal hypertension (Class I, Level C). 


\section{Isolated Congenital Liver Shunts}

Congenital Arteriovenous (Hepatic Artery to Hepatic Vein) Malformations are very rare and consist of discrete abnormalities that, unlike arteriovenous malformations associated with hemangioendotheliomas, do not grow or regress. ${ }^{363}$ The usual clinical presentation is that of high-output heart failure occurring in a neonate. Magnetic resonance imaging appears to be the most useful tool to make the diagnosis. ${ }^{363}$ Treatment initially consists of the conservative management of heart failure. In patients who fail to respond to this therapy, embolization and surgical resection are treatment options.

Congenital Arterioportal Malformations are also very rare and cause portal hypertension manifested within the first year of life with splenomegaly, hypersplenism and/or variceal hemorrhage. Doppler ultrasound is the single most useful diagnostic method. ${ }^{363}$ Lesions should be treated as soon as they are diagnosed, by embolization of the feeding artery with or without resection. Liver transplantation has been mentioned as a therapeutic option if embolization is unsuccessful.

Congenital Portosystemic Shunts are very rare anomalies that result from developmental abnormalities of the portal venous system. Two types of congenital portosystemic shunt have been described: extrahepatic ${ }^{364,365}$ and intrahepatic (includes patent ductus venosus). ${ }^{366}$ Most portosystemic shunts are discovered incidentally. Portosystemic shunting, by bypassing the liver where ammonia is metabolized, causes an increase in plasma ammonia that will ultimately affect cognition. Patients with congenital portosystemic shunt may develop symptoms early in life or remain asymptomatic until the sixth or seventh decades. Symptoms include fatigue, mental retardation, and bouts of portosystemic encephalopathy. Neuropsychological tests may reveal cognitive deficits similar to those present in patients with cirrhosis and minimal hepatic encephalopathy. ${ }^{367}$ It has been suggested that the diameter of the shunt could determine the clinical course: patients with large shunts may have persistent manifestations starting from childhood, while those with small in-trahepatic shunts may develop recurrent episodes of portosystemic encephalopathy that initiate in adult-hood ${ }^{367}$ Mental retardation would result from hyperammonemia during brain development. Nephrolithiasis can also develop as a result of hyperammonemia. MRI is recommended in the diagnosis and classification of portosys-temic shunt. Treatment in symptomatic patients consists of surgical or laparoscopic ligation of the shunt or obliteration by interventional radiology using metallic coils, although this last procedure carries the risk of coil migration into pulmonary arteries. Preoperative evaluation of portal vein patency, portal pressure (before and after ligation) and determination of the type of portosystemic shunt by angiography is crucial. ${ }^{365}$ Orthotopic liver transplantation may be the only treatment option when there is an absent portal vein or with intractable portosystemic encephalopathy. ${ }^{368}$

Recommendation:

8. Congenital portosystemic shunting should be investigated in patients with unexplained hyperammonemia, mental retardation and/or clinical picture compatible with hepatic encephalopathy in the absence of cirrhosis (Class I, Level C). 


\section{Acknowledgment:}

This guideline was produced in collaboration with the Practice Guidelines Committee of the AASLD. This committee in concert with George B. McDonald, M.D., supplied extensive peer-review of the manuscript. Members of the AASLD Practice Guidelines Committee include Margaret C. Shuhart, M.D., M.S., (Committee Chair), Gary L. Davis, M.D. (Board Liaison), Kiran Bambha, M.D., Andres Cardenas, MD, MMSc., Timothy J. Davern, M.D., José Franco, M.D., Steven-Huy B. Han, M.D., Stephen A. Harrison, M.D., Charles D. Howell, M.D., Simon C. Ling, MBChB, MRCP, Lawrence U. Liu, M.D., Paul Martin, M.D., Robert S. O'Shea, M.D., Nancy Reau, M.D., Bruce A. Runyon, M.D., Jayant A. Talwalkar, M.D., MPH, John B. Wong, M.D., and Colina Yim, R.N., M.N.

\section{Abbreviations}

$\begin{array}{ll}\text { AASLD } & \text { American Association for the Study of Liver Diseases } \\ \text { BCS } & \text { Budd-Chiari syndrome } \\ \text { CT } & \text { computed tomography } \\ \text { DVT } & \text { deep vein thrombosis } \\ \text { HHT } & \text { hereditary hemorrhagic telangiectasia } \\ \text { HV } & \text { hepatic vein } \\ \text { IVC } & \text { inferior vena cav } \\ \text { LVM } & \text { liver vascular malformation } \\ \text { MELD } & \text { Model for End-Stage Liver Disease } \\ \text { MRI } & \text { magnetic resonance imaging } \\ \text { NRH } & \text { nodular regenerative hyperplasia } \\ \text { PVT } & \text { portal vein thrombosis } \\ \text { SOS } & \text { sinusoidal obstruction syndrome } \\ \text { TIPS } & \text { transjugular intrahepatic portosystemic stent shunt }\end{array}$

\section{References}

1. Eddy DM. A Manual for Assessing Health Practices and Designing Practice Guidelines. Philadelphia, PA:American College of Physicians; 1996: 1-126.

2. Position and policy statement: American Gastroenterological Association policy statement on the use of medical practice guidelines by managed care organizations and insurance carriers. Gastroenterology 1995;108: 925-926. [PubMed: 7875497]

3. Shiffman RN, Shekelle P, Overhage JM, Slutsky J, Grimshaw J, Deshpande AM. Standardized reporting of clinical practice guidelines: a proposal from the conference on guideline standardization. Ann Intern Med 2003;139:493-498. [PubMed: 13679327]

4. American Heart Association. Methodology Manual. http://www.heart.org/presenter.jhtml? identifier=3039683. Accessed December 2008.

5. Ogren M, Bergqvist D, Bjorck M, Acosta S, Eriksson H, Sternby NH. Portal vein thrombosis: prevalence, patient characteristics and lifetime risk: a population study based on 23,796 consecutive autopsies. World J Gastroenterol 2006;12:2115-2119. [PubMed: 16610067] 
6. Arora NK, Lodha R, Gulati S, Gupta AK, Mathur P, Joshi MS, et al. Portal hypertension in north Indian children. Indian J Pediatr 1998;65: 585-591. [PubMed: 10773909]

7. Condat B, Pessione F, Denninger MH, Hillaire S,Valla D. Recent portal or mesenteric venous thrombosis: increased recognition and frequent recanalization on anticoagulant therapy. HePATOLOGy 2000;32:466-470. [PubMed: 10960436]

8. Chamouard P, Pencreach E, Maloisel F, Grunebaum L, Ardizzone JF, Meyer A, et al. Frequent factor II G20210A mutation in idiopathic portal vein thrombosis. Gastroenterology 1999;116:144-148. [PubMed: 9869612]

9. Janssen HL, Meinardi JR, Vleggaar FP, van Uum SH, Haagsma EB, van Der Meer FJ, et al. Factor $\mathrm{V}$ Leiden mutation, prothrombin gene mutation, and deficiencies in coagulation inhibitors associated with Budd-Chiari syndrome and portal vein thrombosis: results of a case-control study. Blood 2000;96:2364-2368. [PubMed: 11001884]

10. Primignani M, Martinelli I, Bucciarelli P, Battaglioli T, Reati R, Fabris F, et al. Risk factors for thrombophilia in extrahepatic portal vein obstruction. HEPATOLOGY2005;41:603-608. [PubMed: 15726653]

11. Denninger MH, Chait Y, Casadevall N, Hillaire S, Guillin MC, Bezeaud A, et al. Cause of portal or hepatic venous thrombosis in adults: the role of multiple concurrent factors. HEPATOLOGY 2000;31:587-591. [PubMed: 10706547]

12. Plemmons RM, Dooley DP, Longfield RN. Septic thrombophlebitis of the portal vein (pylephlebitis): diagnosis and management in the modern era. Clin Infect Dis 1995;21:1114-1120. [PubMed: 8589130]

13. Webb LJ, Sherlock S. The aetiology, presentation and natural history of extra-hepatic portal venous obstruction. Q J Med 1979;48:627-639. [PubMed: 538223]

14. Bhattacharyya M, Makharia G, Kannan M, Ahmed RP, Gupta PK, Saxena R. Inherited prothrombotic defects in Budd-Chiari syndrome and portal vein thrombosis: a study from North India. Am J Clin Pathol 2004;121:844-847. [PubMed: 15198356]

15. Mahmoud AE, Elias E, Beauchamp N, Wilde JT. Prevalence of the factor V Leiden mutation in hepatic and portal vein thrombosis. Gut 1997;40: 798-800. [PubMed: 9245936]

16. Mohanty D, Shetty S, Ghosh K, Pawar A,Abraham P. Hereditary thrombophilia as a cause of Budd-Chiari syndrome: a study from Western India. HePATOLOGY2001;34:666-670. [PubMed: 11584361]

17. Ahuja V, Marwaha N, Chawla Y, Dilawari JB. Coagulation abnormalities in idiopathic portal venous thrombosis. J Gastroenterol Hepatol 1999; 14:1210-1211. [PubMed: 10634159]

18. Amitrano L, Brancaccio V, Guardascione MA, Margaglione M, Iannaccone L, Dandrea G, et al. High prevalence of thrombophilic genotypes in patients with acute mesenteric vein thrombosis. Am J Gastroenterol 2001;96:146-149. [PubMed: 11197244]

19. Egesel T, Buyukasik Y, Dundar SV, Gurgey A, Kirazli S, Bayraktar Y. The role of natural anticoagulant deficiencies and factor $\mathrm{V}$ Leiden in the development of idiopathic portal vein thrombosis. J Clin Gastroenterol 2000;30:66-71. [PubMed: 10636214]

20. Fennerty A. Venous thromboembolic disease and cancer. Postgrad MedJ 2006;82:642-648. [PubMed: 17068274]

21. Aird WC. Sepsis and coagulation. Crit Care Clin 2005;21:417-431. [PubMed: 15992665]

22. Chait Y, Condat B, Cazals-Hatem D, Rufat P,Atmani S, Chaoui D, et al. Relevance of the criteria commonly used to diagnose myeloproliferative disorder in patients with splanchnic vein thrombosis. Br J Haematol 2005;129:553-560. [PubMed: 15877740]

23. Valla D, Casadevall N, Huisse MG, Tulliez M, Grange JD, Muller O, et al. Etiology of portal vein thrombosis in adults. A prospective evaluation of primary myeloproliferative disorders. Gastroenterology 1988;94: 1063-1069. [PubMed: 3345875]

24. Colaizzo D, Amitrano L, Tiscia GL, Scenna G, Grandone E, Guardascione MA, et al. The JAK2 V617F mutation frequently occurs in patients with portal and mesenteric venous thrombosis. $\mathrm{J}$ Thromb Haemost 2007; 5:55-61.

25. De Stefano V, Fiorini A, Rossi E, Za T, Farina G, Chiusolo P, et al. Prevalence of the JAK2(V617F) mutation among patients with splanchnic or cerebral venous thrombosis and without overt chronic myeloproliferative disorders. J Thromb Haemost 2007;5:708-714. [PubMed: 17263783] 
26. Kiladjian JJ, Cervantes F, Leebeek FW, Marzac C, Cassinat B, Chevret S, et al. The impact of JAK2 and MPL mutations on diagnosis and prognosis of splanchnic vein thrombosis. A report on 241 cases. Blood 2008;111: 4022-4029. [PubMed: 18256322]

27. Primignani M, Barosi G, Bergamaschi G, Gianelli U, Fabris F, Reati R, et al. Role of the JAK2 mutation in the diagnosis of chronic myeloproliferative disorders in splanchnic vein thrombosis. Hepatology 2006;44: 1528-1534. [PubMed: 17133457]

28. Fisher NC, Wilde JT, Roper J, Elias E. Deficiency of natural anticoagulant proteins C, S, and antithrombin in portal vein thrombosis: a secondary phenomenon? Gut 2000;46:534-539. [PubMed: 10716684]

29. Amitrano L, Guardascione MA, Brancaccio V, Margaglione M, Manguso F, Iannaccone L, et al. Risk factors and clinical presentation of portal vein thrombosis in patients with liver cirrhosis. $\mathrm{J}$ Hepatol 2004;40:736-741. [PubMed: 15094219]

30. Duchmann JC, Joly JP, Biny JP, Sevestre H, Capron JP. Portal thrombosis and liver cirrhosis. Value of ultrasound-guided puncture-biopsy of the thrombus. [in French] Gastroenterol Clin Biol 1995;19:581-586. [PubMed: 7590023]

31. Tarantino L, Francica G, Sordelli I, Esposito F, Giorgio A, Sorrentino P, et al. Diagnosis of benign and malignant portal vein thrombosis in cirrhotic patients with hepatocellular carcinoma: color Doppler US, contrast-enhanced US, and fine-needle biopsy. Abdom Imaging 2006;31: 537-544. [PubMed: 16865315]

32. Trum JW, Valla D, Cohen G, Degott C, Rueff B, Santoni P, et al. Bacteroides bacteremia of undetermined origin: strong association with portal vein thrombosis and cryptogenic pylephlebitis. Eur J Gastroenterol Hepatol 1993;5:655-659.

33. Grendell JH, Ockner RK. Mesenteric venous thrombosis. Gastroenterology 1982;82:358-372. [PubMed: 7033036]

34. Sheen CL, Lamparelli H, Milne A, Green I, Ramage JK. Clinical features, diagnosis and outcome of acute portal vein thrombosis. Q J Med 2000; 93:531-534.

35. Clavien PA. Diagnosis and management of mesenteric infarction. Br J Surg 1990;77:601-603. [PubMed: 2200547]

36. Valla DC, Condat B. Portal vein thrombosis in adults: pathophysiology, pathogenesis and management. J Hepatol 2000;32:865-871. [PubMed: 10845677]

37. Kumar S, Sarr M, Kamath PS. Mesenteric venous thrombosis. N Engl J Med 2001;345:1683-1688. [PubMed: 11759648]

38. Dourakis SP, Tsochatzis E, Alexopoulou A, Archimandritis AJ. Pylephlebitis complicating silent diverticulitis. Lancet 2006;368:422. [PubMed: 16876671]

39. Haddad MC, Clark DC, Sharif HS, al Shahed M, Aideyan O, Sammak BM. MR, CT, and ultrasonography of splanchnic venous thrombosis. Gastrointest Radiol 1992;17:34-40. [PubMed: 1544556]

40. Kreft B, Strunk H, Flacke S, Wolff M, Conrad R, Gieseke J, et al. Detection of thrombosis in the portal venous system: comparison of contrast-enhanced MR angiography with intraarterial digital subtraction angiography. Radiology 2000;216:86-92. [PubMed: 10887231]

41. Rahmouni A, Mathieu D, Golli M, Douek P,Anglade MC, Caillet H, et al. Value of CT and sonography in the conservative management of acute splenoportal and superior mesenteric venous thrombosis. Gastrointest Radiol 1992;17:135-140. [PubMed: 1551509]

42. Tessler FN, Gehring BJ, Gomes AS, Perrella RR, Ragavendra N, Busuttil RW, et al. Diagnosis of portal vein thrombosis: value of color Doppler imaging. AJR Am J Roentgenol 1991;157:293 296. [PubMed: 1853809]

43. Wiersema MJ, Chak A, Kopecky KK, Wiersema LM. Duplex Doppler endosonography in the diagnosis of splenic vein, portal vein, and portosystemic shunt thrombosis. Gastrointest Endosc 1995;42:19-26. [PubMed: 7557171]

44. Van Gansbeke D, Avni EF, Delcour C, Engelholm L, Struyven J. Sonographic features of portal vein thrombosis. AJR Am J Roentgenol 1985; 144:749-752. [PubMed: 3883708]

45. Bach AM, Hann LE, Brown KT, Getrajdman GI, Herman SK, Fong Y, et al. Portal vein evaluation with US: comparison to angiography combined with CT arterial portography. Radiology 1996;201:149-154. [PubMed: 8816536] 
46. Mathieu D, Vasile N, Grenier P. Portal thrombosis: dynamic CT features and course. Radiology 1985;154:737-741. [PubMed: 3881793]

47. Chou CK, Mak CW, Tzeng WS, Chang JM. CT of small bowel ischemia. Abdom Imaging 2004;29:18-22. [PubMed: 15160748]

48. Cerri GG, Habr-Gama A, Paranagua-Vezozzo D, Machado MC, Pinotti HW, Magalhaes A. Doppler demonstration of cystic vein dilatation secondary to portal vein thrombosis. Surg Endosc 1991;5:92-93. [PubMed: 1948622]

49. Baril N, Wren S, Radin R, Ralls P, Stain S. The role of anticoagulation in pylephlebitis. Am J Surg 1996;172:449-452; discussion 452-443. [PubMed: 8942542]

50. Bates SM, Ginsberg JS. Clinical practice. Treatment of deep-vein thrombosis. N Engl J Med 2004;351:268-277. [PubMed: 15254285]

51. Hassn AM, Al-Fallouji MA, Ouf TI, Saad R. Portal vein thrombosis following splenectomy. Br J Surg 2000;87:362-373.

52. Lagasse JP, Bahallah ML, Salem N, Debillon G, Labarriere D, Serve MP, et al. Acute thrombosis of the portal system. Treatment with alteplase and heparin or with heparin alone in 10 patients. [in French] Gastroenterol Clin Biol 1997;21:919-923. [PubMed: 9587554]

53. de Franchis R Evolving consensus in portal hypertension. Report of the Baveno IV consensus workshop on methodology of diagnosis and therapy in portal hypertension. J Hepatol 2005;43:167-176. [PubMed: 15925423]

54. Prandoni P, Lensing AWA, Prins MH, Bernardi E, Marchiori A, Bagatella P, et al. Residual venous thrombosis as a predictive factor of recurrent venous thromboembolism. Ann Intern Med 2002;137:955-960. [PubMed: 12484710]

55. Hollingshead M, Burke CT, Mauro MA, Weeks SM, Dixon RG, Jaques PF. Transcatheter thrombolytic therapy for acute mesenteric and portal vein thrombosis. J Vasc Interv Radiol 2005;16:651-661. [PubMed: 15872320]

56. Malkowski P, Pawlak J, Michalowicz B, Szczerban J, Wroblewski T, Leowska E, et al. Thrombolytic treatment of portal thrombosis. Hepatogastroenterology2003;50:2098-2100. [PubMed: 14696472]

57. Grisham A, Lohr J, Guenther JM, Engel AM. Deciphering mesenteric venous thrombosis: imaging and treatment. Vasc Endovascular Surg 2005;39:473-479. [PubMed: 16382268]

58. Brunaud L,Antunes L, Collinet-Adler S, Marchal F,Ayav A, Bresler L, et al. Acute mesenteric venous thrombosis: case for nonoperative management. J Vasc Surg 2001;34:673-679. [PubMed: 11668323]

59. Abdu RA, Zakhour BJ, Dallis DJ. Mesenteric venous thrombosis-1911 to 1984. Surgery 1987;101:383-388. [PubMed: 3563882]

60. Joh JH, Kim DI. Mesenteric and portal vein thrombosis: treated with early initiation of anticoagulation. Eur J Vasc Endovasc Surg 2005;29: 204-208. [PubMed: 15649730]

61. Eugene C, Valla D, Wesenfelder L, Fingerhut A, Bergue A, Merrer J, et al. Small intestinal stricture complicating superior mesenteric vein thrombosis. A study of three cases. Gut 1995;37:292-295. [PubMed: 7557585]

62. Condat B, Vilgrain V, Asselah T, O’Toole D, Rufat P, Zappa M, et al. Portal cavernoma-associated cholangiopathy: a clinical and MR cholangiography coupled with MR portography imaging study. HePATOLOGY 2003;37:1302-1308. [PubMed: 12774008]

63. Khuroo MS, Yattoo GN, Zargar SA, Javid G, Dar MY, Khan BA, et al. Biliary abnormalities associated with extrahepatic portal venous obstruction. HEPATOLOGY 1993;17:807-813. [PubMed: 8491448]

64. Condat B, Pessione F, Hillaire S, Denninger MH, Guillin MC, Poliquin M, et al. Current outcome of portal vein thrombosis in adults: risk and benefit of anticoagulant therapy. Gastroenterology 2001;120:490-497. [PubMed: 11159889]

65. Minguez B, Garcia-Pagan JC, Bosch J, Turnes J,Alonso J, Rovira A, et al. Noncirrhotic portal vein thrombosis exhibits neuropsychological and MR changes consistent with minimal hepatic encephalopathy. HEPATOLOGY 2006;43:707-714. [PubMed: 16557541] 
66. Gupta D, Vijaya DR, Gupta R, Dhiman RK, Bhargava M, Verma J, et al. Prevalence of hepatopulmonary syndrome in cirrhosis and extrahepatic portal venous obstruction. Am J Gastroenterol 2001;96:3395-3399. [PubMed: 11774955]

67. Ueno N, Sasaki A, Tomiyama T, Tano S, Kimura K. Color Doppler ultrasonography in the diagnosis of cavernous transformation of the portal vein. J Clin Ultrasound 1997;25:227-233. [PubMed: 9314103]

68. Dumortier J, Vaillant E, Boillot O, Poncet G, Henry L, Scoazec JY, et al. Diagnosis and treatment of biliary obstruction caused by portal cavernoma. Endoscopy 2003;35:446-450. [PubMed: 12701019]

69. Palazzo L, Hochain P, Helmer C, Cuillerier E, Landi B, Roseau G, et al. Biliary varices on endoscopic ultrasonography: clinical presentation and outcome. Endoscopy 2000;32:520-524. [PubMed: 10917183]

70. Garcia-Tsao G, Sanyal AJ, Grace ND, Carey W. Prevention and management of gastroesophageal varices and variceal hemorrhage in cirrhosis. HEPATOLOGY 2007;46:322-338.

71. Orr DW, Harrisson PM, Karani J, Rela M, Heaton ND, O’Grady JG, et al. Chronic portomesenteric and portosplenomesenteric venous thrombosis: evaluation of long term follow-up and determinants of survival [Abstract]. HEPATOLOGY 2005;42:212A.

72. Kahn D, Krige JE, Terblanche J, Bornman PC, Robson SC. A 15-year experience of injection sclerotherapy in adult patients with extrahepatic portal venous obstruction. Ann Surg 1994;219:34-39. [PubMed: 8297173]

73. Vleggaar FP, van Buuren HR, Schalm SW. Endoscopic sclerotherapy for bleeding oesophagogastric varices secondary to extrahepatic portal vein obstruction in an adult Caucasian population. Eur J Gastroenterol Hepatol 1998;10:81-85. [PubMed: 9512958]

74. Orloff MJ, Orloff MS, Girard B, Orloff SL. Bleeding esophagogastric varices from extrahepatic portal hypertension: 40 years' experience with portal-systemic shunt. J Am Coll Surg 2002;194:717-728; discussion 728-730. [PubMed: 12081062]

75. Warren WD, Henderson JM, Millikan WJ, Galambos JT, Bryan FC. Management of variceal bleeding in patients with noncirrhotic portal vein thrombosis. Ann Surg 1988;207:623-634. [PubMed: 3259859]

76. Senzolo M, Tibbals J, Cholongitas E, Triantos CK, Burroughs AK, Patch D. Transjugular intrahepatic portosystemic shunt for portal vein thrombosis with and without cavernous transformation. Aliment Pharmacol Ther 2006;23:767-775. [PubMed: 16556179]

77. Kitchens CS, Weidner MH, Lottenberg R. Chronic oral anticoagulant therapy for extrahepatic visceral thrombosis is safe. J Thromb Thrombolysis 2007;23:223-228. [PubMed: 17221331]

78. Chaudhary A, Dhar P, Sarin SK, Sachdev A, Agarwal AK, Vij JC, et al. Bile duct obstruction due to portal biliopathy in extrahepatic portal hypertension: surgical management. Br J Surg 1998;85:326-329. [PubMed: 9529484]

79. Sarin SK, Sollano JD, Chawla YK, Amarapurkar D, Hamid S, Hashizume M, et al. Consensus on extra-hepatic portal vein obstruction. Liver Int 2006;26:512-519. [PubMed: 16761994]

80. Shinohara T, Ando H, Watanabe Y, Seo T, Harada T, Kaneko K. Extrahepatic portal vein morphology in children with extrahepatic portal hypertension assessed by 3-dimensional computed tomographic portography: a new etiology of extrahepatic portal hypertension. J Pediatr Surg 2006;41:812-816. [PubMed: 16567199]

81. Balta G, Altay C, Gurgey A. PAI-1 gene 4G/5G genotype: A risk factor for thrombosis in vessels of internal organs. Am J Hematol 2002;71:89-93. [PubMed: 12353306]

82. Dubuisson C, Boyer-Neumann C, Wolf M, Meyer D, Bernard O. Protein C, protein S and antithrombin III in children with portal vein obstruction. J Hepatol 1997;27:132-135. [PubMed: 9252086]

83. El-Karaksy H, El-Koofy N, El-Hawary M, Mostafa A, Aziz M, El-Shabrawi M, et al. Prevalence of factor V Leiden mutation and other hereditary thrombophilic factors in Egyptian children with portal vein thrombosis: results of a single-center case-control study. Ann Hematol 2004;83:712715. [PubMed: 15309526]

84. Heller C, Schobess R, Kurnik K, Junker R, Gunther G, Kreuz W, et al. Abdominal venous thrombosis in neonates and infants: role of prothrombotic risk factors - a multicentre case-control 
study. For the Childhood Thrombophilia Study Group. BrJ Haematol 2000;111:534-539. [PubMed: 11122096]

85. Pinto RB, Silveira TR, Rosling L, Bandinelli E. Thrombophilic disorders in children and adolescents with portal vein thrombosis. [in Portugese] J Pediatr (Rio J) 2003;79:165-172.

86. Yachha SK, Aggarwal R, Sharma BC, Misra RN, Aggarwal A, Naik SR. Functional protein C and anti-cardiolipin antibody in children with portal vein thrombosis. Indian J Gastroenterol 2001;20:47-49. [PubMed: 11305488]

87. Mack CL, Superina RA, Whitington PF. Surgical restoration of portal flow corrects procoagulant and anticoagulant deficiencies associated with extrahepatic portal vein thrombosis. J Pediatr 2003;142:197-199. [PubMed: 12584545]

88. Morag I, Epelman M, Daneman A, Moineddin R, Parvez B, Shechter T, et al. Portal vein thrombosis in the neonate: risk factors, course, and outcome. J Pediatr 2006;148:735-739. [PubMed: 16769378]

89. Bellomo-Brandao MA, Morcillo AM, Hessel G, Cardoso SR, Servidoni Mde F, da-Costa-Pinto EA. Growth assessment in children with extra-hepatic portal vein obstruction and portal hypertension. Arq Gastroenterol 2003;40:247-250. [PubMed: 15264047]

90. Zargar SA, Javid G, Khan BA, Yattoo GN, Shah AH, Gulzar GM, et al. Endoscopic ligation compared with sclerotherapy for bleeding esophageal varices in children with extrahepatic portal venous obstruction. HePATOLOGy 2002;36:666-672. [PubMed: 12198659]

91. Pande GK, Reddy VM, Kar P, Sahni P, Berry M, Tandon BN, et al. Operations for portal hypertension due to extrahepatic obstruction: results and 10 year follow up. Br Med J (Clin Res Ed) 1987;295:1115-1117.

92. Superina R, Bambini DA, Lokar J, Rigsby C, Whitington PF. Correction of extrahepaticportalvein thrombosis bythe mesenteric to leftportalvein bypass. Ann Surg 2006;243:515-521. [PubMed: 16552203]

93. Okuda K, Ohnishi K, Kimura K, Matsutani S, Sumida M, Goto N, et al. Incidence of portal vein thrombosis in liver cirrhosis. An angiographic study in 708 patients. Gastroenterology 1985;89:279-286. [PubMed: 4007419]

94. Francoz C, Belghiti J, Vilgrain V, Sommacale D, Paradis V, Condat B, et al. Splanchnic vein thrombosis in candidates for liver transplantation: usefulness of screening and anticoagulation. Gut 2005;54:691-697. [PubMed: 15831918]

95. Tublin ME, Dodd GD 3rd, Baron RL. Benign and malignantportal vein thrombosis: differentiation by CT characteristics. AJR Am J Roentgenol 1997;168:719-723. [PubMed: 9057522]

96. Rossi S, Rosa L, Ravetta V, Cascina A, Quaretti P, Azzaretti A, et al. Contrast-enhanced versus conventional and color Doppler sonography for the detection of thrombosis of the portal and hepatic venous systems. AJR Am J Roentgenol 2006;186:763-773. [PubMed: 16498104]

97. Nonami T, Yokoyama I, Iwatsuki S, Starzl TE. The incidence of portal vein thrombosis at liver transplantation. HePATOLOGY 1992;16:1195-1198. [PubMed: 1427658]

98. Amitrano L, Brancaccio V, Guardascione MA, Margaglione M, Iannaccone L, D'Andrea G, et al. Inherited coagulation disorders in cirrhotic patients with portal vein thrombosis. HEPATOLOGY 2000;31:345-348. [PubMed: 10655256]

99. Amitrano L, Brancaccio V, Guardascione MA, Margaglione M, Sacco M, Martino R, et al. Portal vein thrombosis after variceal endoscopic sclerotherapy in cirrhotic patients: role of genetic thrombophilia. Endoscopy 2002;34:535-538. [PubMed: 12170404]

100. Cavallari A, Vivarelli M, Bellusci R, Jovine E, Mazziotti A, Rossi C. Treatment of vascular complications following liver transplantation: multidisciplinary approach. Hepatogastroenterology 2001;48:179-183. [PubMed: 11268960]

101. Settmacher U, Nussler NC, Glanemann M, Haase R, Heise M, Bechstein WO, et al. Venous complications after orthotopic liver transplantation. Clin Transplant 2000;14:235-241. [PubMed: 10831082]

102. Shulman HM, Fisher LB, Schoch HG, Henne KW, McDonald GB. Venoocclusive disease of the liver after marrow transplantation: histological correlates of clinical signs and symptoms. Hepatology 1994;19: 1171-1180. [PubMed: 8175139] 
103. DeLeve LD, Wang X, Kuhlenkamp JF, Kaplowitz N. Toxicity of azathio-prine and monocrotaline in murine sinusoidal endothelial cells and hepatocytes: the role of glutathione and relevance to hepatic venooclusive disease. HePATOLOGY 1996;23:589-599. [PubMed: 8617441]

104. DeLeve LD, Ito I, Bethea NW, McCuskey MK, Wang X, McCuskey RS. Embolization by sinusoidal lining cell obstructs the microcirculation in rat sinusoidal obstruction syndrome. Am J Physiol Gastrointest Liver Physiol 2003;284:G1045-G1052. [PubMed: 12584111]

105. McDonald GB, Hinds MS, Fisher LD, Schoch HG, Wolford JL, Banaji M, et al. Veno-occlusive disease of the liver and multiorgan failure after bone marrow transplantation - a cohort study of 355 patients. Ann Intern Med 1993;118:255-267. [PubMed: 8420443]

106. Lee JL, Gooley T, Bensinger W, Schiffman K, McDonald GB. Veno-occlusive disease of the liver after busulfan, melphalan, and thiotepa conditioning therapy: incidence, risk factors, and outcome. Biol Blood Marrow Transplant 1999;5:306-315. [PubMed: 10534061]

107. Carreras E, Rosinol L, Terol MJ, Alegre A, de Arriba F, Garcia-Larana J, et al. Veno-occlusive disease of the liver after high-dose cytoreductive therapy with busulfan and melphalan for autologous blood stem cell transplantation in multiple myelomapatients. Biol Blood Marrow Transplant 2007;13:1448-1454. [PubMed: 18022574]

108. McDonald GB. Liver disease of uncertain cause. Bone Marrow Transplant 2004;33:977-978. [PubMed: 15129235]

109. Jones RJ, Lee KS, Beschorner WE, Vogel VG, Grochow LB, Braine HG, et al. Venoocclusive disease of the liver following bone marrow transplantation. Transplantation 1987;44:778-783. [PubMed: 3321587]

110. Blostein MD, Paltiel OB, Thibault A, Rybka WB. A comparison of clinical criteria for the diagnosis of veno-occlusive disease of the liver after bone marrow transplantation. Bone Marrow Transplant 1992;10:439-443. [PubMed: 1464007]

111. Hommeyer SC, Teefey SA, Jacobson AF, Higano CS, Bianco JA, Colacurcio CJ, et al. Venocclusive disease of the liver: prospective study of US evaluation. Radiology 1992;184:683686. [PubMed: 1509050]

112. Teefey SA, Brink JA, Borson RA, Middleton WD. Diagnosis of venoocclusive disease of the liver after bone marrow transplantation: value of duplex sonography. Am J Roentgenol 1995;164:1397-1401. [PubMed: 7754881]

113. McCarville MB, Hoffer FA, Howard SC, Goloubeva O, Kauffman WM. Hepatic veno-occlusive disease in children undergoing bone-marrow transplantation: usefulness of sonographic findings. Pediatr Radiol 2001; 31:102-105. [PubMed: 11214676]

114. Lassau N, Leclere J, Auperin A, Bourhis JH, Hartmann O, Valteau-Couanet D, et al. Hepatic veno-occlusive disease after myeloablative treatment and bone marrow transplantation: value of gray-scale and Doppler US in 100 patients. Radiology 1997;204:545-552. [PubMed: 9240551]

115. Lassau N, Auperin A, Leclere J, Bennaceur A, Valteau-Couanet D, Hartmann O. Prognostic value of doppler-ultrasonography in hepatic veno-occlusive disease. Transplantation 2002;74:60-66. [PubMed: 12134100]

116. Shulman HM, Gooley T, Dudley MD, Kofler T, Feldman R, Dwyer D, et al. Utility of transvenous liver biopsies and wedged hepatic venous pressure measurements in sixty marrow transplant recipients. Transplantation 1995;59:1015-1022. [PubMed: 7709437]

117. Carreras E, Granena A, Navasa M, Bruguera M, Marco V, Sierra J, et al. Transjugular liver biopsy in BMT. Bone Marrow Transplant 1993;11: 21-26. [PubMed: 8431707]

118. Bearman SI, Anderson GL, Mori M, Hinds MS, Shulman HM, McDonald GB. Venoocclusive disease of the liver: development of a model for predicting fatal outcome after marrow transplantation. J Clin Oncol 1993;11:1729-1736. [PubMed: 8355040]

119. McDonald GB, Sharma P, Matthews DE, Shulman HM, Thomas ED. The clinical course of 53 patients with venocclusive disease of the liver after marrow transplantation. Transplantation 1985;36:603-608.

120. Carreras E, Bertz H,Arcese W,Vernant JP, Tomas JF, Hagglund H, et al. Incidence and outcome of hepatic veno-occlusive disease after blood or marrow transplantation: a prospective cohort study of the European Group for Blood and Marrow Transplantation. European Group for Blood and 
Marrow Transplantation Chronic Leukemia Working Party. Blood 1998;92:3599-3604.

[PubMed: 9808553]

121. Ganem G, Saint-Marc Girardin MF, Kuentz M, Cordonnier C, Morinello G, Teboul C, et al.Venocclusive disease of the liver after allogeneic bone marrow transplantation in man. Int $\mathrm{J}$ Radiat Oncol Biol Phys 1988; 14:879-884. [PubMed: 3283084]

122. Hasegawa S, Horibe K, Kawabe T, Kato K, Kojima S, Matsuyama T, et al. Veno-occlusive disease of the liver after allogeneic bone marrow transplantation in children with hematologic malignancies: incidence, onset time and risk factors. Bone Marrow Transplant 1998;22:11911197. [PubMed: 9894723]

123. McDermott WV, Stone MD, Bothe A Jr, Trey C. Budd-Chiari syndrome. Historical and clinical review with an analysis of surgical corrective procedures. Am J Surg 1984;147:463-467. [PubMed: 6324603]

124. Wadleigh M, Richardson PG, Zahrieh D, Lee SJ, Cutler C, Ho V, et al. Prior gemtuzumab ozogamicin exposure significantly increases the risk of veno-occlusive disease in patients who undergo myeloablative allogeneic stem cell transplantation. Blood 2003;102:1578-1582. [PubMed: 12738663]

125. Dulley FL, Kanfer EJ,Appelbaum FR,Amos D, Hill RS, Buckner CD, et al. Venocclusive disease of the liver after chemoradiotherapy and autologous bone marrow transplantation. Transplantation 1987;43:870-873. [PubMed: 3296355]

126. Reiss U, Cowan M, McMillan A, Horn B. Hepatic venoocclusive disease in blood and bone marrow transplantation in children and young adults: incidence, risk factors, and outcome in a cohort of 241 patients. J Pediatr Hematol Oncol 2002;24:746-750. [PubMed: 12468917]

127. Frickhofen N, Wiesneth M, Jainta C, Hertenstein B, Heymer B, Bianchi L, et al. Hepatitis C virus infection is a risk factor for liver failure from veno-occlusive disease after bone marrow transplantation. Blood 1994; 83:1998-2004. [PubMed: 7511444]

128. Strasser SI, Myerson D, Spurgeon CL, Sullivan KM, Storer B, Schoch HG, et al. Hepatitis C virus infection and bone marrow transplantation: a cohort study with 10-year follow-up. HEPATOLOGY 1999;29:1893-1899. [PubMed: 10347135]

129. Cordonnier C, Maury S, Esperou H, Pautas C, Beaune J, Rodet M, et al. Do minitransplants have minicosts? A cost comparison between myeloa-blative and nonmyeloablative allogeneic stem cell transplant in patients with acute myeloid leukemia. Bone Marrow Transplant 2005;36:649-654. [PubMed: 16044135]

130. Hogan WJ, Maris M, Storer B, Sandmaier BM, Maloney DG, Schoch HG, et al. Hepatic injury after nonmyeloablative conditioning followed by allogeneic hematopoietic cell transplantation: a study of 193 patients. Blood 2004;103:78-84. [PubMed: 12969980]

131. Clift RA, Buckner CD, Appelbaum FR, Bearman SI, Petersen FB, Fisher LD, et al. Allogeneic marrow transplantation in patients with acute myeloid leukemia in first remission: a randomized trial of two irradiation regimens. Blood 1990;76:1867-1871. [PubMed: 2224134]

132. DeLeve LD. Cellular target of cyclophosphamide toxicity in the murine liver: role of glutathione and site of metabolic activation. HePATOLOGY 1996;24:830-837. [PubMed: 8855185]

133. McDonald GB, Slattery JT, Bouvier ME, Ren S, Batchelder AL, Kalhorn TF, et al. Cyclophosphamide metabolism, liver toxicity, and mortality following hematopoietic stem cell transplantation. Blood 2003;101: 2043-2048. [PubMed: 12406916]

134. McDonald GB, McCune JS, Batchelder A, Cole SL, Phillips B, Ren AG, et al. Metabolism-based cyclophosphamide dosing for hematopoietic cell transplant. Clin Pharmacol Ther 2005;78:298308. [PubMed: 16153400]

135. Salinger DH, McCune JS, Ren AG, Shen DD, Slattery JT, Phillips B, et al. Real-time dose adjustment of cyclophosphamide in a preparative regimen for hematopoietic cell transplant: a Bayesian pharmacokinetic approach. Clin Cancer Res 2006;12:4888-4898. [PubMed: 16914577]

136. Grochow LB. Busulfan disposition: the role of therapeutic monitoring in bone marrow transplantation induction regimens. Semin Oncol 1993; 20:18-25.

137. Demirer T, Buckner CD, Appelbaum FR, Bensinger WI, Sanders J, Lambert K, et al. Busulfan, cyclophosphamide and fractionated total body irradiation for autologous or syngeneic marrow transplantation for acute and chronic myelogenous leukemia: phase I dose escalation of busulfan 
based on targeted plasma levels. Bone Marrow Transplant 1996; 17:491-495. [PubMed: 8722344]

138. Vaughan WP, Carey D, Perry S, Westfall AO, Salzman DE. A limited sample strategy for pharmacokinetic therapy with intravenous busulfan. Biol Blood Marrow Transplant 2002;8:619624. [PubMed: 12463481]

139. Hassan M, Ehrsson H, Ljungman P. Aspects concerning busulfan pharmacokinetics and bioavailability. Leuk Lymphoma 1996;22:395-407. [PubMed: 8882952]

140. Méresse V, Hartmann O, Vassal G, Benhamou E, Valteau-Couanet D, Brugieres L, et al. Risk factors for hepatic veno-occlusive disease after high-dose busulfan-containing regimens followed by autologous bone marrow transplantation: a study in 136 children. Bone Marrow Transplant 1992;10:135-141.

141. Shimoni A, Bielorai B, Toren A, Hardan I, Avigdor A, Yeshuran, et al. Intravenous busulfanbased conditioning prior to allogeneic hematopoietic stem cell transplantation: myeloablation with reduced toxicity. Exp Hematol 2003;31:428-434. [PubMed: 12763142]

142. Lee J-H, Choi S-J, Lee J-H, Kim S-E, Park C-J, Chi H-S, et al. Decreased incidence of hepatic veno-occlusive disease and fewer hemostatic derangements associated with intravenous busulfan vs oral busulfan in adults conditioned with busulfan + cyclophosphamide for allogeneic bone marrow transplantation. Ann Hematol 2005;84:321-330. [PubMed: 15580502]

143. Kashyap A, Wingard J, Cagnoni P, Roy J, Tarantolo S, Hu W, et al. Intravenous versus oral busulfan as part of a busulfan/cyclophosphamide preparative regimen for allogeneic hematopoietic stem cell transplantation: decreased incidence of hepatic venoocclusive disease (HVOD), HVOD-related mortality, and overall 100-day mortality. Biol Blood Marrow Transplant 2002;8:493-500. [PubMed: 12374454]

144. Grochow LB,Jones RJ, Brundrett RB, Braine HG, Chen TL, Saral R, et al. Pharmacokinetics of busulfan: correlation with veno-occlusive disease in patients undergoing bone marrow transplantation. Cancer Chemother Pharmacol 1989;25:55-61. [PubMed: 2591002]

145. Bleyzac N, Souillet G, Magron P, Janoly A, Martin P, Bertrand Y, et al. Improved clinical outcome of paediatric bone marrow recipients using a test dose and Bayesian pharmacokinetic individualization of busulfan dosage regimens. Bone Marrow Transplant 2001;28:743-751. [PubMed: 11781625]

146. Schuler US, Ehrsam M, Schneider A, Schmidt H, Deeg J, Ehninger G. Pharmacokinetics of intravenous busulfan and evaluation of the bioavailability of the oral formulation in conditioning for haematopoietic stem cell transplantation. Bone Marrow Transplant 1998;22:241-244. [PubMed: 9720736]

147. Slattery JT, Clift RA, Buckner CD, Radich J, Storer B, Bensinger WI, et al. Marrow transplantation for chronic myeloid leukemia: the influence of plasma busulfan levels on the outcome of transplantation. Blood 1997; 89:3055-3060. [PubMed: 9108427]

148. Zwaveling J, Bredius RGM, Cremers SCLM, Ball LM, Lankester AC, Teepe-Twiss IM, et al. Intravenous busulfan in children prior to stem cell transplantation: study of pharmacokinetics in association with early clinical outcome and toxicity. Bone Marrow Transplant 2005;35:17-23. [PubMed: 15502853]

149. Bornhauser M, Storer B, Slattery JT, Appelbaum FR, Deeg HJ, Hansen J, et al. Conditioning with fludarabine and targeted busulfan for transplantation of allogeneic hematopoietic stem cells. Blood 2003;102:820-826. [PubMed: 12676781]

150. DeLima M, Ghaddar H, Pierce S, Estey E. Treatmentof newly-diagnosed acute myelogenous leukaemia in patients aged 80 years and above. Br J Haematol 1996;93:89-95. [PubMed: 8611481]

151. Hagglund H, Remberger M, Klaesson S, Lonnqvist B, Ljungman P, Ringden O. Norethisterone treatment, a major risk-factor for veno-occlusive disease in the liver after allogeneic bone marrow transplantation. Blood 1998;92:4568-4572. [PubMed: 9845522]

152. Attal M, Huguet F, Ruble H, Charlet JP, Schlaifer D, Huynh A, et al. Prevention of regimenrelated toxicities after bone marrow transplantation by pentoxifylline - a prospective, randomized trial. Blood 1993;82: 732-736. [PubMed: 8338943] 
153. Rosenthal J, Sender L, Secola R, Killen R, Millerick M, Murphy L, et al. Phase II trial of heparin prophylaxis for veno-occlusive disease of the liver in children undergoing bone marrow transplantation. Bone Marrow Transplant 1996;18:185-191. [PubMed: 8832013]

154. Bearman SI, Hinds MS, Wolford JL, Petersen FB, Nugent DL, Slichter SJ, et al. A pilot study of continuous infusion heparin for the prevention of hepatic veno-occlusive disease after bone marrow transplantation. Bone Marrow Transplant 1990;5:407-411. [PubMed: 2369681]

155. Marsa-Vila L, Gorin NC, Laporte JP, Labopin M, Dupuy-Montbrun MC, Fouillard L, et al. Prophylactic heparin does not prevent liver veno-occlusive disease following autologous bone marrow transplantation. Eur J Haematol 1991;47:346-354. [PubMed: 1761121]

156. Imran H, Tleyjeh IM, Zirakzadeh A, Rodriguez V, Khan SP. Use of prophylactic anticoagulation and the risk of hepatic veno-occlusive disease in patients undergoing hematopoietic stem cell transplantation: a systematic review and meta-analysis. Bone Marrow Transplant 2006;37: 677686. [PubMed: 16489362]

157. Essell JH, Schroeder MT, Harman GS, Halvorson R, Lew V, Callander N,et al. Ursodiol prophylaxis against hepatic complications of allogeneic bone marrow transplantation. A randomized, double-blind, placebo-controlled trial. Ann Intern Med 1998;128:975-981. [PubMed: 9625683]

158. Ohashi K, Tanabe J, Watanabe R, Tanaka T, Sakamaki H, Maruta A, et al. The Japanese multicenter open randomized trial of ursodeoxycholic acid prophylaxis for hepatic venoocclusive disease after stem cell transplantation. Am J Hematol 2000;64:32-38. [PubMed: 10815785]

159. Ruutu T, Eriksson B, Remes K,Juvonen E,Volin L, Remberger M, et al. Ursodeoxycholic acid for the prevention of hepatic complications in allogeneic stem cell transplantation. Blood 2002;100:1977-1983. [PubMed: 12200355]

160. Park SH, Lee MH, Lee H, Kim HS, Kim K, Kim WS, et al.Arandomized trial of heparin plus ursodiol vs. heparin alone to prevent hepatic veno-occlusive disease after hematopoietic stem cell transplantation. Bone Marrow Transplant 2002;29:137-143. [PubMed: 11850708]

161. Tay J, Tinmouth A, Fergusson D, Huebsch L, Allan DS. Systematic review of controlled clinical trials on the use of ursodeoxycholic acid for the prevention of hepatic veno-occlusive disease in hematopoietic stem cell transplantation. Biol Blood Marrow Transplant 2007;13:206-217. [PubMed: 17241926]

162. Gluckman E, Jolivet I, Scrobohaci ML, Devergie A, Traineau R, Bourdeau-Esperou H, et al. Role of PGE1 to prevent veno-occlusive disease of the liver after bone marrow transplantation. Nouv Rev Fr Hematol 1990;32:1-3.

163. Bearman SI, Shen DD, Hinds MS, Hill HA, McDonald GB. A phase-I phase-II study of prostaglandin $\mathrm{E} 1$ for the prevention of hepatic venoocclusive disease after bone marrow transplantation. Br J Haematol 1993; 84:724-730. [PubMed: 8217833]

164. Clift RA, Bianco JA, Appelbaum FR, Buckner CD, Singer JW, Bakke L, et al. A randomized controlled trial of pentoxifylline for the prevention of regimen-related toxicities in patients undergoing allogeneic marrow transplantation. Blood 1993;82:2025-2030. [PubMed: 8400255]

165. Barkholt L, Remberger M, Hassan Z, Fransson K, Omazic B, Svahn BM, et al. A prospective randomized study using $\mathrm{N}$-acetyl-L-cysteine for early liver toxicity after allogeneic hematopoietic stem cell transplantation. Bone Marrow Transplant 2008;41:785-790. [PubMed: 18176610]

166. Bearman SI, Lee JL, Baron AE, McDonald GB. Treatment of hepatic venocclusive disease with recombinant human tissue plasminogen activator and heparin in 42 marrow transplant patients. Blood 1997;89:1501-1506. [PubMed: 9057629]

167. Kulkarni S, Rodriguez M, Lafuente A, Mateos P, Mehta J, Singhal S, et al. Recombinant tissue plasminogen activator (rtPA) for the treatment of hepatic veno-occlusive disease (VOD). Bone Marrow Transplant 1999; 23:803-807. [PubMed: 10231143]

168. Hagglund H, Ringden O, Ljungman P, Winiarski J, Ericzon B, Tyden G. No beneficial effects, but severe side effects caused by recombinant human tissue plasminogen activator for treatment of hepatic veno-occlusive disease after allogeneic bone marrow transplantation. Transplant Proc 1995;27:3535. [PubMed: 8540088] 
169. Hagglund H, Ringden O, Ericzon BG, Duraj F, Ljungman P, Lonnqvist B, et al. Treatment of hepatic venoocclusive disease with recombinant human tissue plasminogen activator or orthotopic liver transplantation after allogeneic bone marrow transplantation. Transplantation 1996;62: 1076-1080. [PubMed: 8900305]

170. Hohlfeld T, Strobach H, Schror K. Stimulation of prostacyclin synthesis by defibrotide: improved contractile recovery from myocardial "stunning". J Cardiovasc Pharmacol 1991;17:108-115. [PubMed: 1708043]

171. Biagi G, Legnani C, Rodorigo G, Coccheri S. Modulation of arachidonate metabolite generation in human blood by oral defibrotide. Arzne-imittelforschung 1991;41:511-514.

172. San T, Moini H, Emerk K, Bilsel S. Protective effect of defibrotide on perfusion induced endothelial damage. Thromb Res 2000;99:335-341. [PubMed: 10963784]

173. Masini E, Lupini M, Mugnai L, Raspanti S, Mannaioni PF. Polydeoxyri-bonucleotides and nitric oxide release from guinea-pig hearts during ischaemia and reperfusion. Br J Pharmacol 1995;115:629-635. [PubMed: 7582482]

174. Berti F, Rossoni G, Della Bella D, Villa LM, Buschi A, Trento F, et al. Nitric oxide and prostacyclin influence coronary vasomotor tone in perfused rabbit heart and modulate endothelin-1 activity. J Cardiovasc Pharmacol 1993;22:321-326. [PubMed: 7692176]

175. Pellegatta F, Lu Y, Radaelli A, Zocchi MR, Ferrero E, Chierchia S, et al. Drug-induced in vitro inhibition of neutrophil-endothelial cell adhesion. Br J Pharmacol 1996;118:471-476. [PubMed: 8762067]

176. Klocking HP. Acute t-PA release by defibrotide. Thromb Res 1992;66: 779-785. [PubMed: 1519236]

177. Bianchi G, Barone D, Lanzarotti E, Tettamanti R, Porta R, Moltrasio D, et al. Defibrotide, a single-stranded polydeoxyribonucleotide acting as an adenosine receptor agonist. Eur J Pharmacol 1993;238:327-334. [PubMed: 8405101]

178. Abbate R, Gori AM, Martini F,Attanasio M, Comeglio, Giusti B, et al. Defibrotide reduces monocyte PAI-2 and procoagulant activity. Semin Thromb Hemost 1995;21:245-250. [PubMed: 7660147]

179. Falanga A, Vignoli A, Marchetti M, Barbui T. Defibrotide reduces procoagulant activity and increases fibrinolytic properties of endothelial cells. Leukemia 2003;17:1636-1642. [PubMed: 12886253]

180. Lefer AM, Aoki N, Mulloy D. Coronary endothelium-protective effects of defibrotide in ischaemia and reperfusion. Naunyn Schmiedebergs Arch Pharmakol 1990;341:246-250.

181. Richardson PG, Elias AD, Krishnan A, Wheeler C, Nath R, Hoppen-steadt D, et al. Treatment of severe veno-occlusive disease with defib-rotide: compassionate use results in response without significant toxicity in a high-risk population. Blood 1998;92:737-744. [PubMed: 9680339]

182. Chopra R, Eaton JD, Grass! A, Potter M, Shaw B, Salat C, et al. Defib-rotide for the treatment of hepatic veno-occlusive disease: results of the European compassionate-use study. Br J Haematol 2000;111:1122-1129. [PubMed: 11167751]

183. Richardson PG, Murakami C, Jin Z, Warren D, Momtaz P, Hoppensteadt D, et al. Multiinstitutional use of defibrotide in 88 patients after stem cell transplantation with severe venoocclusive disease and multisystem organ failure: response without significant toxicity in a highrisk population and factors predictive of outcome. Blood 2002;100:4337-4343. [PubMed: 12393437]

184. Chalandon Y, Roosnek E, Mermillod B, Newton A, Ozsahin H, Wacker P, et al. Prevention of veno-occlusive disease with defibrotide after allogeneic stem cell transplantation. Biol Blood Marrow Transplant 2004; 10:347-354. [PubMed: 15111934]

185. Corbacioglu S, Greil J, Peters C, Wulffraat N, Laws HJ, Dilloo D, et al. Defibrotide in the treatment of children with veno-occlusive disease (VOD): a retrospective multicentre study demonstrates therapeutic efficacy upon early intervention. Bone Marrow Transplant 2004;33:189-195. [PubMed: 14661036]

186. Fried MW, Connaghan DG, Sharma S, Martin LG, Devine S, Holland K, et al. Transjugular intrahepatic portosystemic shunt for the management of severe venoocclusive disease following bone marrow transplantation. HEPATOLOGY 1996;24:588-591. [PubMed: 8781329] 
187. Azoulay D, Castaing D, Lemoine A, Hargreaves GM, Bismuth E. Transjugular intrahepatic portosystemic shunt (TIPS) for severe veno-occlusive disease of the liver following bone marrow transplantation. Bone Marrow Transplant 2000;25:987-992. [PubMed: 10800068]

188. Wang X, Kanel G, DeLeve LD. Support of sinusoidal endothelial cell glutathione prevents hepatic venoocclusive disease in vivo. HePATOLOGY 2000;31:428-434. [PubMed: 10655267]

189. DeLeve LD, Wang X, Kanel GC, Tokes ZA, Tsai J, Ito Y, et al. Decreased Hepatic Nitric Oxide Production Contributes to the Development of Rat Sinusoidal Obstruction Syndrome. HePATOLOGY 2003;38:900-908. [PubMed: 14512877]

190. DeLeve LD, Wang X, Tsai J, Kanel GC, Strasberg SM, Tokes ZA. Prevention of sinusoidal obstruction syndrome (hepatic venoocclusive disease) in the rat by matrix metalloproteinase inhibitors. Gastroenterology 2003;125:882-890. [PubMed: 12949732]

191. Koenecke C, Kleine M, Schrem H, Krug U, Nashan B, Neipp M, et al. Sinusoidal obstruction syndrome of the liver after hematopoietic stem cell transplantation: decision making for orthotopic liver transplantation. Int J Hematol 2006;83:271-274. [PubMed: 16720562]

192. Mellgren K, Fasth A, Saalman R, Olausson M, Abrahamsson J. Liver transplantation after stem cell transplantation with the same living donor in a monozygotic twin with acute myeloid leukemia. Ann Hematol 2005; 84:755-757. [PubMed: 16001242]

193. Kim I-D, Egawa H, Marui Y, Kaihara S, Haga H, Lin Y-W, et al. A successful liver transplantation for refractory hepatic veno-occlusive disease originating from cord blood transplantation. Am J Transplant 2002; 2:796-800. [PubMed: 12243502]

194. Janssen HL, Garcia-Pagan JC, Elias E, Mentha G, Hadengue A, Valla DC. Budd-Chiari syndrome: a review by an expert panel. J Hepatol 2003;38:364-371. [PubMed: 12586305]

195. Shrestha SM, Okuda K, Uchida T, Maharjan KG, Shrestha S, Joshi BL, et al. Endemicity and clinical picture of liver disease due to obstruction of the hepatic portion of the inferior vena cava in Nepal. J Gastroenterol Hepatol 1996;11:170-179. [PubMed: 8672764]

196. Valla D Hepatic venous outflow tract obstruction etipathogenesis: Asia versus the West. J Gastroenterol Hepatol 2004;19:S204-S211.

197. Ludwig J, Hashimoto E, McGill D, Heerden Jv. Classification of hepatic venous outflow obstruction:ambiguous terminology of the Budd-Chiari syndrome. Mayo Clin Proc 1990;65:5155. [PubMed: 2296212]

198. Mehrotra G, Singh RP, Krishna A, Singh BK. Pyogenic liver abscess causing acute Budd-Chiari syndrome. Ann Trop Paediatr 1992;12:451-453. [PubMed: 1283677]

199. Uddin W, Ramage JK, Portmann B, Wilson P, Benjamin I, Tan KC, et al. Hepatic venous outflow obstruction in patients with polycystic liver disease: pathogenesis and treatment. Gut 1995;36:142-145. [PubMed: 7890219]

200. Rangheard AS,Vilgrain V,Audet P, O’Toole D,Vullierme MP,Valla D, et al. Focal nodular hyperplasia inducing hepatic vein obstruction. AJR Am J Roentgenol 2002;179:759-762. [PubMed: 12185058]

201. Kubo T, Shibata T, Itoh K, Maetani Y, Isoda H, Hiraoka M, et al. Outcome of percutaneous transhepatic venoplasty for hepatic venous outflow obstruction after living donor liver transplantation. Radiology 2006;239:285-290. [PubMed: 16567488]

202. Wang SL, Sze DY, Busque S, Razavi MK, Kee ST, Frisoli JK, et al. Treatment of hepatic venous outflow obstruction after piggyback liver transplantation. Radiology 2005;236:352-359. [PubMed: 15955856]

203. Balian A, Valla D, Naveau S, Musset D, Coue O, Lemaigre G, et al. Post-traumatic membranous obstruction of the inferior vena cava associated with a hypercoagulable state. J Hepatol 1998;28:723-726. [PubMed: 9566843]

204. Kim PN, Mitchell DG, Outwater EK. Budd-Chiari syndrome: hepatic venous obstruction byan elevated diaphragm. Abdom Imaging 1999;24: 267-271. [PubMed: 10227891]

205. Markert DJ, Shanmuganathan K, Mirvis SE, Nakajima Y, Hayakawa M. Budd-Chiari syndrome resulting from intrahepatic IVC compression secondaryto blunt hepatic trauma. Clin Radiol 1997;52:384-387. [PubMed: 9171794] 
206. Dilawari JB, Bambery P, Chawla Y, Kaur U, Bhusnurmath SR, Malhotra HS, et al. Hepatic outflow obstruction (Budd-Chiari syndrome). Experience with 177 patients and a review of the literature. Medicine (Baltimore) 1994;73:21-36. [PubMed: 8309360]

207. Bayraktar Y, Balkanci F, Bayraktar M, Calguneri M. Budd-Chiari syndrome: a common complication of Behcet's disease. Am J Gastroenterol 1997;92:858-862. [PubMed: 9149201]

208. Dayal S, Pati HP, Pande GK, Sharma MP, Saraya AK. Multilineage hemopoietic stem cell defects in Budd Chiari syndrome. J Hepatol 1997; 26:293-297. [PubMed: 9059949]

209. Deltenre P, Denninger MH, Hillaire S, Guillin MC, Casadevall N, Briere J, et al. Factor V Leiden related Budd-Chiari syndrome. Gut 2001;48: 264-268. [PubMed: 11156651]

210. Hirshberg B, Shouval D, Fibach E, Friedman G, Ben-Yehuda D. Flow cytometric analysis of autonomous growth of erythroid precursors in liquid culture detects occult polycythemia vera in the Budd-Chiari syndrome. J Hepatol 2000;32:574-578. [PubMed: 10782905]

211. Kumar SI, Kumar A, Srivastava S, Saraswat VA, Aggarwal R. Low frequency of factor V Leiden and prothrombin G20210A mutations in patients with hepatic venous outflow tract obstruction in northern India: a case-control study. Indian J Gastroenterol 2005;24:211-215. [PubMed: 16361766]

212. Lin GL, Xu PQ, Qi H, Lian JH, Zheng H, Dang XW. Relations of Budd-Chiari syndrome to prothrombin gene mutation. Hepatobiliary Pancreat Dis Int 2004;3:214-218. [PubMed: 15138112]

213. Valla D, Casadevall N, Lacombe C, Varet B, Goldwasser E, Franco D, et al. Primary myeloproliferative disorder and hepatic vein thrombosis. A prospective study of erythroid colony formation in vitro in 20 patients with Budd-Chiari syndrome. Ann Intern Med 1985;103:329334. [PubMed: 4026081]

214. Patel RK, Lea NC, Heneghan MA, Westwood NB, Milojkovic D, Thanigaikumar M, et al. Prevalence of the activating JAK2 tyrosine kinase mutation V617F in the Budd-Chiari syndrome. Gastroenterology 2006; 130:2031-2038. [PubMed: 16762626]

215. Smalberg JH, Murad SD, Braakman E, Valk PJ, Janssen HL, Leebeek FW. Myeloproliferative disease in the pathogenesis and survival of Budd-Chiari syndrome. Haematologica 2006;91:1712-1713. [PubMed: 17145613]

216. Aggarwal R, Ravishankar B, Misra R, Aggarwal A, Dwivedi S, Naik SR. Significance of elevated IgG anticardiolipin antibody levels in patients with Budd-Chiari syndrome. Am J Gastroenterol 1998;93:954-957. [PubMed: 9647027]

217. Espinosa G, Font J, Garcia-Pagan JC, Tassies D, Reverter JC, Gaig C, et al. Budd-Chiari syndrome secondary to antiphospholipid syndrome: clinical and immunologic characteristics of 43 patients. Medicine (Baltimore) 2001;80:345-354. [PubMed: 11704712]

218. Mangia A, Margaglione M, Cascavilla I, Gentile R, Cappucci G, Facciorusso D, et al. Anticardiolipin antibodies in patients with liver disease. Am J Gastroenterol 1999;94:2983-2987. [PubMed: 10520856]

219. Bosy-Westphal A, Ruschmeyer M, Czech N, Oehler G, Hinrichsen H, Plauth M, et al. Determinants of hyperhomocysteinemia in patients with chronic liver disease and after orthotopic liver transplantation. Am J Clin Nutr2003;77:1269-1277.

220. Li XM, Wei YF, Hao HL, Hao YB, He LS, Li JD, et al. Hyperhomocys-teinemia and the MTHFR C677T mutation in Budd-Chiari syndrome. Am J Hematol 2002;71:11-14. [PubMed: 12221667]

221. Hillmen P, Lewis SM, Bessler M, Luzzatto L, Dacie JV. Natural history of paroxysmal nocturnal hemoglobinuria. N Engl J Med 1995;333:1253-1258. [PubMed: 7566002]

222. Valla D, Dhumeaux D, Babany G, Hillon P, Rueff B, Rochant H, et al. Hepatic vein thrombosis in paroxysmal nocturnal hemoglobinuria. A spectrum from asymptomatic occlusion of hepatic venules to fatal Budd-Chiari syndrome. Gastroenterology 1987;93:569-575. [PubMed: 3609666]

223. Zylberberg H, Valla D, Viguie F, Casadevall N. Budd-Chiari syndrome associated with 5q deletion and hypereosinophilia. J Clin Gastroenterol 1996;23:66-68. [PubMed: 8835906]

224. Young ID, Clark RN, Manley PN, Groll A, Simon JB. Response to steroids in Budd-Chiari syndrome caused by idiopathic granulomatous venulitis. Gastroenterology 1988;94:503-507. [PubMed: 3335322] 
225. Rahhal RM, Pashankar DS, Bishop WP. Ulcerative colitis complicated by ischemic colitis and Budd Chiari syndrome. J Pediatr Gastroenterol Nutr 2005;40:94-97. [PubMed: 15625435]

226. Valla D, Le MG, Poynard T, Zucman N, Rueff B, Benhamou JP. Risk of hepatic vein thrombosis in relation to recent use of oral contraceptives. A case-control study. Gastroenterology 1986;90:807-811. [PubMed: 3949113]

227. Khuroo MS, Datta DV. Budd-Chiari syndrome following pregnancy. Report of 16 cases, with roentgenologic, hemodynamic and histologic studies of the hepatic outflow tract. Am J Med 1980;68:113-121. [PubMed: 7350798]

228. Parker RGF. Occlusion of the hepatic veins in man. Medicine (Baltimore) 1959;38:369-402. [PubMed: 14430507]

229. Hadengue A, Poliquin M, Vilgrain V, Belghiti J, Degott C, Erlinger S, et al. The changing scene of hepatic vein thrombosis: recognition of asymptomatic cases. Gastroenterology 1994;106:1042-1047. [PubMed: 8143970]

230. Murad SD, Valla DC, de Groen PC, Zeitoun G, Hopmans JA, Haagsma EB, et al. Determinants of survival and the effect of portosystemic shunting in patients with Budd-Chiari syndrome. HePatology 2004;39:500-508. [PubMed: 14768004]

231. Okuda H, Yamagata H, Obata H, Iwata H, Sasaki R, Imai F, et al. Epidemiological and clinical features of Budd-Chiari syndrome in Japan. J Hepatol 1995;22:1-9.

232. Cazals-Hatem D, Vilgrain V, Genin P, Denninger MH, Durand F, Belghiti J, et al. Arterial and portal circulation and parenchymal changes in Budd-Chiari syndrome: a study in 17 explanted livers. HePATOLOGY 2003;37:510-519. [PubMed: 12601347]

233. Mahmoud AEA, Helmy AS, Billingham S, Elias E. Poor prognosis and limited therapeutic options in patients with Budd-Chiari syndrome and portal venous system thrombosis. Eur $\mathbf{J}$ Gastroenterol Hepatol 1997;9: 485-489. [PubMed: 9187882]

234. Tanaka M, Wanless IR. Pathology of the liver in Budd-Chiari syndrome: portal vein thrombosis and the histogenesis of veno-centric cirrhosis, veno-portal cirrhosis, andlarge regenerative nodules. HePatology 1998; 27:488-496. [PubMed: 9462648]

235. Kreel L, Freston JW, Clain D. Vascular radiology in the Budd-Chiari syndrome. Br J Radiol 1967;40:755-759. [PubMed: 6047799]

236. Wilson MW, Ring EJ, LaBerge JM, Kerlan RK, Gordon RL. Percutaneous transhepatic hepatic venography in the delineation and treatment of Budd-Chiari syndrome. J Vasc Interv Radiol 1996;7:133-138. [PubMed: 8773988]

237. Fisher NC, McCafferty I, Dolapci M, Wali M, Buckels JA, Olliff SP, et al. Managing Budd-Chiari syndrome: a retrospective review of percutaneous hepatic vein angioplasty and surgical shunting. Gut 1999;44:568-574. [PubMed: 10075967]

238. Tavill AS, Wood EJ, Kreel L, Jones EA, Gregory M, Sherlock S. The Budd-Chiari syndrome: correlation between hepatic scintigraphy and the clinical, radiological, and pathological findings in nineteen cases of hepatic venous outflow obstruction. Gastroenterology 1975;68:509-518. [PubMed: 1112452]

239. Lim JH, Park JH, Auh YH. Membranous obstruction of inferior vena cava: comparison of findings at sonography, CT, and venography. Am J Roentgenol 1992;159:515-520. [PubMed: 1503015]

240. Miller WJ, Federle MP, Straub WH, Davis PL. Budd-Chiari syndrome: imaging with pathologic correlation. Abdom Imaging 1993;18:329-335. [PubMed: 8220030]

241. Chawla Y, Kumar S, Dhiman RK, Suri S, Dilawari JB. Duplex Doppler sonography in patients with Budd-Chiari syndrome. J Gastroenterol Hepatol 1999;14:904-907. [PubMed: 10535473]

242. Grant EG, Perrella R, Tessler FN, Lois J, Busuttil R. Budd-Chiari syndrome: the results of duplex and color Doppler imaging. AJR Am J Roentgenol 1989;152:377-381. [PubMed: 2643267]

243. Millener P, Grant EG, Rose S, Duerinckx A, Schiller VL, Tessler FN, et al. Color Doppler imaging findings in patients with Budd-Chiari syndrome: correlation with venographic findings. AJR Am J Roentgenol 1993;161:307-312. [PubMed: 8333368]

244. Menu Y, Sebag G, Vigrain V, Arrivé L, Nahum H. Budd-Chiari syndrome: MR evaluation. Diagn Interv Radiol 1990;2:23-28. 
245. Gupta S, Barter S, Phillips GW, Gibson RN, Hodgson HJ. Comparison of ultrasonography, computed tomography and $99 \mathrm{mTc}$ liver scan in diagnosis of Budd-Chiari syndrome. Gut 1987;28:242-247. [PubMed: 3552905]

246. Baert AL, Fevery J, Marchal G, Goddeeris P, Wilms G, Ponette E, et al. Early diagnosis of BuddChiari syndrome by computed tomography and ultrasonography: report of five cases. Gastroenterology 1983;84:587-595. [PubMed: 6822327]

247. Mathieu D, Kracht M, Zafrani E, Dhumeaux D, Vasile N. Budd-Chiari syndrome In: Ferrucci JR, Matthieu DG, eds. Advances in Hepatobiliary Radiology. St Louis, MO: C.V. Mosby Co; 1990:3-28.

248. Van Beers B, Pringot J, Trigaux JP, Dautrebande J, Mathurin P. Hepatic heterogeneity on CT in Budd-Chiari syndrome: correlation with regional disturbances in portal flow. Gastrointest Radiol 1988;13:61-66. [PubMed: 3350270]

249. Solano FX, Young E, Talamo TS, Dekker A. Constrictive pericarditis mimicking Budd-Chiari syndrome. Am J Med 1986;80:113-115. [PubMed: 3942142]

250. Kakar S, Kamath PS, Burgart LJ. Sinusoidal dilatation and congestion in liver biopsy: is it always due to venous outflow impairment? Arch Pathol Lab Med 2004;128:901-904. [PubMed: 15270610]

251. Rector WG,Xu YH, Goldstein L, Peters RL, Reynolds TB. Membranous obstruction of the inferior vena cava in the United States. Medicine (Baltimore) 1985;64:134-143. [PubMed: 3871892]

252. Wanless I, Liu J, Butany J. Role of thrombosis in the pathogenesis of congestive hepatic fibrosis (cardiac cirrhosis). HePATOLOGY 1995;21: 1232-2137. [PubMed: 7737628]

253. DeLeve LD, Shulman HM, McDonald GB. Toxic injury to hepatic sinusoids: sinusoidal obstruction syndrome (veno-occlusive disease). Semin Liver Dis 2002;22:27-42. [PubMed: 11928077]

254. Tang TJ, Batts KP, de Groen PC, van Hoek B, Haagsma EB, Hop WC, et al. The prognostic value of histology in the assessment of patients with Budd-Chiari syndrome. J Hepatol 2001;35:338343. [PubMed: 11592594]

255. Zeitoun G, Escolano S, Hadengue A, Azar N, El Younsi M, Mallet A, et al. Outcome of BuddChiari syndrome: a multivariate analysis of factors related to survival including surgical portosystemic shunting. HEPATOLOGY 1999;30:84-89. [PubMed: 10385643]

256. Vons C, Smadja C, Franco D, Valla D, Rueff B, Benhamou JP. Successful pregnancy after BuddChiari syndrome. Lancet 1984;2:975.

257. Landolfi R, Marchioli R, Kutti J, Gisslinger H, Tognoni G, Patrono C, et al. Efficacy and safety of low-dose aspirin in polycythemia vera. N Engl J Med 2004;350:114-124. [PubMed: 14711910]

258. Campbell DA, Rolles K, Jamieson N, O’Grady J, Wight D, Williams R, et al. Hepatic transplantation with perioperative and long term anticoagulation as treatment for Budd-Chiari syndrome. Surg Gynecol Obstet 1988;166:511-518. [PubMed: 3287665]

259. Halff G, Todo S, Tzakis AG, Gordon RD, Starzl TE. Liver transplantation for the Budd-Chiari syndrome. Ann Surg 1990;211:43-49. [PubMed: 2294842]

260. Cruz E, Ascher NL, Roberts JP, Bass NM, Yao FY. High incidence of recurrence and hematologic events following liver transplantation for Budd-Chiari syndrome. Clin Transplant 2005;19:501506. [PubMed: 16008595]

261. Hemming AW, Langer B, Greig P, Taylor BR, Adams R, Heathcote EJ. Treatment of Budd-Chiari syndrome with portosystemic shunt or liver transplantation. Am J Surg 1996;171:176-180; discussion 180-171. [PubMed: 8554136]

262. Ringe B, Lang H, Oldhafer KJ, Gebel M, Flemming P, Georgii A, et al. Which is the best surgery for Budd-Chiari syndrome: venous decompression or liver transplantation? A single-center experience with 50 patients. HePATOlogy 1995;21:1337-1344. [PubMed: 7737640]

263. Shaked A, Goldstein RM, Klintmalm GB, Drazan K, Husberg B, Busuttil RW. Portosystemic shunt versus orthotopic liver transplantation for the Budd-Chiari syndrome. Surg Gynecol Obstet 1992;174:453-459. [PubMed: 1595020]

264. Srinivasan P, Rela M, Prachalias A, Muiesan P, Portmann B, Mufti GJ, et al. Liver transplantation for Budd-Chiari syndrome. Transplantation 2002;73:973-977. [PubMed: 11923703] 
265. Mentha G, Giostra E, Majno PE, Bechstein WO, Neuhaus P, O’Grady J, et al. Liver transplantation for Budd-Chiari syndrome: A European study on 248 patients from 51 centres. $\mathrm{J}$ Hepatol 2006;44:520-528. [PubMed: 16427719]

266. Zhang CQ, Fu LN, Xu L, Zhang GQ, Jia T, Liu JY, et al. Long-term effect of stent placement in 115 patients with Budd-Chiari syndrome. World J Gastroenterol 2003;9:2587-2591. [PubMed: 14606103]

267. Plessier A, Sibert A, Consigny Y, Hakime A, Zappa M, Denninger MH, et al. Aiming at minimal invasiveness as a therapeutic strategy for Budd-Chiari syndrome. HEPATOLOGY 2006;44:13081316. [PubMed: 17058215]

268. Sharma S, Texeira A, Texeira P, Elias E, Wilde J, Olliff SP. Pharmacological thrombolysis in Budd Chiari syndrome: a single centre experience and review of the literature. J Hepatol 2004;40:172-180. [PubMed: 14672630]

269. Hernandez-Guerra M, Lopez E, Bellot P, Piera C, Turnes J, Abraldes JG, et al. Systemic hemodynamics, vasoactive systems, and plasma volume in patients with severe Budd-Chiari syndrome. HePatology 2006;43:27-33. [PubMed: 16374846]

270. Valla D, Hadengue A, elYounsi M,Azar N, Zeitoun G, Boudet MJ, et al. Hepatic venous outflow block caused by short-length hepatic vein stenoses. HePATOLOGY 1997;25:814-819. [PubMed: 9096581]

271. Okuda K Inferior vena cava thrombosis at its hepatic portion (obliterative hepatocavopathy). Semin Liver Dis 2002;22:15-26.

272. Griffith JF, Mahmoud AE, Cooper S, Elias E, West RJ, Olliff SP. Radiological intervention in Budd-Chiari syndrome: techniques and outcome in 18 patients. Clin Radiol 1996;51:775-784. [PubMed: 8937320]

273. Martin LG, Henderson JM, Millikan WJ, Casarella WJ, Kaufman SL. Angioplasty for long-term treatment of patients with Budd-Chiari syndrome. AJR Am J Roentgenol 1990;154:1007-1010. [PubMed: 2138842]

274. Nunez O, de la Cruz G, Molina J, Borrego GM, Marin I, Ponferrada A, et al. Interventional radiology, angioplasty and TIPS in Budd-Chiari syndrome. [in Spanish] Gastroenterol Hepatol 2003;26:461-464. [PubMed: 14534016]

275. Pelage JP, Denys A, Valla D, Sibert A, Sauvanet A, Belghiti J, et al. Budd-Chiari syndrome due to prothrombotic disorder: mid-term patency and efficacy of endovascular stents. Eur Radiol 2003;13:286-293. [PubMed: 12598992]

276. Qiao T, Liu CJ, Liu C, Chen K, Zhang XB, Zu MH. Interventional endovascular treatment for Budd-Chiari syndrome with long-term follow-up. Swiss Med Wkly 2005;135:318-326. [PubMed: 16034686]

277. Witte AM, Kool LJ, Veenendaal R, Lamers CB, van Hoek B. Hepatic vein stenting for BuddChiari syndrome. Am J Gastroenterol 1997;92: 498-501. [PubMed: 9068478]

278. Lee BB, Villavicencio L, Kim YW, Do YS, Koh KC, Lim HK, et al. Primary Budd-Chiari syndrome: outcome of endovascular management for suprahepatic venous obstruction. J Vasc Surg 2006;43:101-108. [PubMed: 16414396]

279. Furui S, Sawada S, Irie T, Makita K, Yamauchi T, Kusano S, et al. Hepatic inferior vena cava obstruction: treatment of two types with Gi-anturco expandable metallic stents. Radiology 1990;176:665-670. [PubMed: 2143840]

280. Baijal SS, Roy S, Phadke RV, Agrawal DK, Kumar S, Choudhuri G. Management of idiopathic Budd-Chiari syndrome with primary stent placement: early results. J Vasc Interv Radiol 1996;7:545-553. [PubMed: 8855534]

281. Guan H. Diagnosis and treatment of membraneous obstruction of the inferior vena cava. [in Chinese] Zhonghua Wai Ke Za Zhi 1990;28:760-763, 783-764. [PubMed: 2150799]

282. Kohli V, Pande GK, Dev V, Reddy KS, Kaul U, Nundy S. Management of hepatic venous outflow obstruction. Lancet 1993;342:718-722. [PubMed: 8103826]

283. Sato M, Yamada R, Tsuji K, Kishi K, Terada M, Shioyama Y, et al. Percutaneous transluminal angioplasty in segmental obstruction of the hepatic inferior vena cava: long-term results. Cardiovasc Intervent Radiol 1990;13:189-192. [PubMed: 2146015] 
284. Yamada R, Sato M, Kawabata M, Nakatsuka H, Nakamura K, Kobayashi N. Segmental obstruction of the hepatic inferior vena cava treated by transluminal angioplasty. Radiology 1983;149:91-96. [PubMed: 6225147]

285. Yang XL, Chen CR, Cheng TO. Nonoperative treatment of membranous obstruction of the inferior vena cava by percutaneous balloon transuminal angioplasty. Am Heart J 1992;124:405412. [PubMed: 1386183]

286. Bilbao JI, Pueyo JC, Longo JM, Arias M, Herrero JI, Benito A, et al. Interventional therapeutic techniques in Budd-Chiari syndrome. Cardiovasc Intervent Radiol 1997;20:112-119. [PubMed: 9030501]

287. De BK, Biswas PK, Sen S, Das D, De KK, Das U, et al. Management of the Budd-Chiari syndrome by balloon cavoplasty. Indian J Gastroenterol 2001;20:151-154. [PubMed: 11497174]

288. Khuroo MS, Al-Suhabani H, Al-Sebayel M, Al Ashgar H, Dahab S, Khan MQ, et al. Budd-Chiari syndrome: long-term effect on outcome with transjugular intrahepatic portosystemic shunt. J Gastroenterol Hepatol 2005;20:1494-1502. [PubMed: 16174064]

289. Mishra TK, Routray SN, Behera M, Patnaik UK, Satapathy C. Percutaneous balloon angioplasty of membranous obstruction of the inferior vena cava. Indian Heart J 2003;55:362-364. [PubMed: 14686667]

290. Tyagi S, Jain BL, Kumar N, Lahoti D, Arora R. Balloon dilatation of inferior vena cava stenosis in Budd-Chiari syndrome. J Assoc Physicians India 1996;44:378-380. [PubMed: 9282554]

291. Wu T, Wang L, Xiao Q, Wang B, Li S, Li X, et al. Percutaneous balloon angioplasty of inferior vena cava in Budd-Chiari syndrome-R1. Int J Cardiol 2002;83:175-178. [PubMed: 12007692]

292. Xiaoming Z, Zhonggao W. Interventional or semi-interventional treatment for Budd-Chiari syndrome. Chin Med Sci J 2003;18:111-115. [PubMed: 12903794]

293. Xu K, Feng B, Zhong H, Zhang X, Su H, Li H, et al. Clinical application of interventional techniques in the treatment of Budd-Chiari syndrome. Chin Med J (Engl) 2003;116:609-615. [PubMed: 12875733]

294. Langlet P, Valla D. Is surgical portosystemic shunt the treatment of choice in Budd-Chiari syndrome? Acta Gastroenterol Belg 2002;65:155-160. [PubMed: 12420607]

295. Bachet JB, Condat B, Hagege H, Plessier A, Consigny Y, Belghiti J, et al. Long-term portosystemic shunt patency as a determinant of outcome in Budd-Chiari syndrome. J Hepatol 2007;46:60-68. [PubMed: 17107735]

296. Panis Y, Belghiti J, Valla D, Benhamou JP, Fekete F. Portosystemic shunt in Budd-Chiari syndrome: long-term survival and factors affecting shunt patency in 25 patients in Western countries. Surgery 1994;115:276-281. [PubMed: 8128351]

297. Langlet P, Escolano S, Valla D, Coste-Zeitoun D, Denie C, Mallet A, et al. Clinicopathological forms and prognostic index in Budd-Chiari syndrome. J Hepatol 2003;39:496-501. [PubMed: 12971957]

298. Feng LS, Peng QP, Li K, Ma XX, Zhao YF, Ye XX, et al. Management of severe Budd-Chiari syndrome: report of 147 cases. Hepatobiliary Pancreat Dis Int 2004;3:522-525. [PubMed: 15567737]

299. Savader SJ, Venbrux AC, Klein AS, Osterman FA. Percutaneous intervention in portosystemic shunts in Budd-Chiari syndrome. J Vasc Interv Radiol 1991;2:489-495. [PubMed: 1839134]

300. Bismuth H, Sherlock DJ. Portasystemic shunting versus liver transplantation for the Budd-Chiari syndrome. Ann Surg 1991;214:581-589. [PubMed: 1953111]

301. Ganger DR, Klapman JB, McDonald V, Matalon TA, Kaur S, Rosenblate H, et al. Transjugular intrahepatic portosystemic shunt (TIPS) for Budd-Chiari syndrome or portal vein thrombosis: review of indications and problems. Am J Gastroenterol 1999;94:603-608. [PubMed: 10086638]

302. Ryu RK, Durham JD, Krysl J, Shrestha R, Shrestha R, Everson GT, et al. Role of TIPS as a bridge to hepatic transplantation in Budd-Chiari syndrome. J Vasc Interv Radiol 1999;10:799_ 805. [PubMed: 10392951]

303. Slakey DP, Klein AS, Venbrux AC, Cameron JL. Budd-Chiari syndrome: current management options. Ann Surg 2001;233:522-527. [PubMed: 11303134]

304. Cejna M, Peck-Radosavljevic M, Schoder M, Thurnher S, Ba-Ssalamah A, Angermayr B,et al. Repeat interventions for maintenance of transjugular intrahepatic portosystemic shunt function in 
patients with Budd-Chiari syndrome. J Vasc Interv Radiol 2002;13:193-199. [PubMed: 11830626]

305. Perello A, Garcia-Pagan JC, Gilabert R, Suarez Y, Moitinho E, Cervantes F, et al. TIPS is a useful long-term derivative therapy for patients with Budd-Chiari syndrome uncontrolled by medical therapy. HePatology 2002;35:132-139. [PubMed: 11786969]

306. Blokzijl H, de Knegt RJ. Long-term effect of treatment of acute Budd-Chiari syndrome with a transjugular intrahepatic portosytemic shunt. HePATOLOGY 2002;35:1551-1552. [PubMed: 12029648]

307. Mancuso A, Fung K, Mela M, Tibballs J, Watkinson A, Burroughs AK, et al. TIPS for acute and chronic Budd-Chiari syndrome: a single-centre experience. J Hepatol 2003;38:751-754. [PubMed: 12763367]

308. Kavanagh PM, Roberts J, Gibney R, Malone D, Hegarty J, McCormick PA. Acute Budd-Chiari syndrome with liver failure: the experience of a policy of initial interventional radiological treatment using transjugular intrahepatic portosystemic shunt. J Gastroenterol Hepatol 2004;19: 1135-1139. [PubMed: 15377290]

309. Attwell A, Ludkowski M, Nash R, Kugelmas M. Treatment of Budd-Chiari syndrome in a liver transplant unit, the role of transjugular intrahepatic porto-systemic shunt and liver transplantation. Aliment Pharmacol Ther 2004;20:867-873. [PubMed: 15479358]

310. Rossle M, Olschewski M, Siegerstetter V, Berger E, Kurz K, Grandt D. The Budd-Chiari syndrome: outcome after treatment with the transjugular intrahepatic portosystemic shunt. Surgery 2004;135:394-403. [PubMed: 15041963]

311. Safka V, Hulek P, Krajina A, Dulicek P, Fejfar T, Jirkovsky V, et al. Budd-Chiari syndrome and TIPS—twelve years' experience. [in Czech] Cas Lek Cesk 2005;144(Suppl 3):38-42.

312. Molmenti EP, Segev DL, Arepally A, Hong J, Thuluvath PJ, Rai R, et al. The utility of TIPS in the management of Budd-Chiari syndrome. Ann Surg 2005;241:978-981; discussion 982-973. [PubMed: 15912047]

313. Eapen CE, Velissaris D, Heydtmann M, Gunson B, Olliff S, Elias E. Favourable medium term outcome following hepatic vein recanalisation and/or transjugular intrahepatic portosystemic shunt for Budd Chiari syndrome. Gut 2006;55:878-884. [PubMed: 16174658]

314. Hernandez-Guerra M, Turnes J, Rubinstein P, Olliff S, Elias E, Bosch J, et al. PTFE-covered stents improve TIPS patency in Budd-Chiari syndrome. HEPATOLOGY2004;40:1197-1202. [PubMed: 15486923]

315. Henderson JM, Nagle A, Curtas S, Geisinger M, Barnes D. Surgical shunts and TIPS for variceal decompression in the 1990s. Surgery 2000; 128:540-547. [PubMed: 11015086]

316. Jamieson NV, Williams R, Calne RY. Liver transplantation for Budd-Chiari syndrome, 19761990. Ann Chir 1991;45:362-365. [PubMed: 2064300]

317. Segev DL, Nguyen GC, Locke JE, Simpkins CE, Montgomery RA, Maley WR, et al. Twenty years of liver transplantation for Budd-Chiari syndrome: a national registry analysis. Liver Transpl 2007;13:1285-1294. [PubMed: 17763380]

318. Melear JM, Goldstein RM, Levy MF, Molmenti EP, Cooper B, Netto GJ, et al. Hematologic aspects of liver transplantation for Budd-Chiari syndrome with special reference to myeloproliferative disorders. Transplantation 2002;74:1090-1095. [PubMed: 12438952]

319. Valla DC. Prognosis in Budd Chiari syndrome after re-establishing hepatic venous drainage. Gut 2006;55:761-763. [PubMed: 16698751]

320. Min AD, Atillasoy EO, Schwartz ME, Thiim M, Miller CM, Bodenheimer HC. Reassessing the role of medical therapy in the management of hepatic vein thrombosis. Liver Transpl Surg 1997;3:423-429. [PubMed: 9346773]

321. Ostapowicz G, Fontana RJ, Schiodt FV, Larson A, Davern TJ, Han SHB, et al. Results of a prospective study of acute liver failure at 17 tertiary care centers in the United States. Ann Intern Med 2002;137:947-954. [PubMed: 12484709]

322. Havlioglu N, Brunt EM, Bacon BR. Budd-Chiari syndrome and hepatocellular carcinoma: a case report and review of the literature. Am J Gastroenterol 2003;98:201-204. [PubMed: 12526959] 
323. Moucari R, Rautou PE, Cazals-Hatem D, Geara A, Bureau C, Consigny Y, et al. Hepatocellular carcinoma in Budd-Chiari syndrome: characteristics and risk factors. Gut 2008;57:828-835. [PubMed: 18218675]

324. Shin SH, Chung YH, Suh DD, Shin JW, Jang MK, Ryu SH, et al. Characteristic clinical features of hepatocellular carcinoma associated with Budd-Chiari syndrome: evidence of different carcinogenic process from hepatitis B virus-associated hepatocellular carcinoma. Eur J Gastroenterol Hepatol 2004;16:319-324. [PubMed: 15195897]

325. Moucari R, Plessier A, Rautou PE, Consigny Y, Denninger MH, Cazals-Hatem D, et al. Hepatocellular carcinoma in Budd-Chiari syndrome: characteristics and risk factors [Abstract]. HePATOLOGY 2006;44:461A.

326. Boudhina T, Ghram N, Ben Becher S, Lakhoua R,Ayachi R, Hammou-Jeddi A, et al. Budd-Chiari syndrome in children. Apropos of 7 cases. [in French] Arch Fr Pediatr 1991;48:243-248. [PubMed: 2069474]

327. Gentil-Kocher S, Bernard O, Brunelle F, Hadchouel M, Maillard JN, Valayer J, et al. Budd-Chiari syndrome in children: report of 22 cases. J Pediatr 1988;113:30-38. [PubMed: 3290415]

328. Odell JA, Rode H, Millar AJ, Hoffman HD. Surgical repair in children with the Budd-Chiari syndrome. J Thorac Cardiovasc Surg 1995;110: 916-923. [PubMed: 7475157]

329. Murad SD, Valla DC, de Groen PC, Zeitoun G, Haagsma EB, Kuipers EJ, et al. Pathogenesis and treatment of Budd-Chiari syndrome combined with portal vein thrombosis. Am J Gastroenterol 2006;101:83-90. [PubMed: 16405538]

330. Gallego C, Velasco M, Marcuello P, Tejedor D, De Campo L, Friera A. Congenital and acquired anomalies of the portal venous system. Radiographics 2002;22:141-159. [PubMed: 11796904]

331. Buscarini E, Plauchu H, Garcia-Tsao G, White RI Jr, Sabba C, Miller F, et al. Liver involvement in hereditary hemorrhagic telangiectasia: consensus recommendations. Liver Int 2006;26:10401046. [PubMed: 17032403]

332. Shovlin CL, Guttmacher AE, Buscarini E, Faughnan ME, Hyland RH, Kjeldsen AD, et al. Diagnostic criteria for hereditary hemorrhagic telangiectasia (Rendu-Osler-Webersyndrome).Am J Med Genet 2000;91:65-66.

333. De Gaetano AM, Gui B, Macis G, Manfredi R, Di Stasi C. Congenital absence of the portal vein associated with focal nodular hyperplasia in the liver in an adult woman: imaging and review of the literature. Abdom Imaging 2004;29:455-459. [PubMed: 14716452]

334. Kim T, Murakami T, Sugihara E, Hori M, Wakasa K, Nakamura H. Hepatic nodular lesions associated with abnormal development of the portal vein. AJR Am J Roentgenol 2004;183:13331338. [PubMed: 15505299]

335. Wanless IR, Lentz JS, Roberts EA. Partial nodular transformation of liver in an adult with persistent ductus venosus. Review with hypothesis on pathogenesis. Arch Pathol Lab Med 1985;109:427-432. [PubMed: 3838656]

336. Grazioli L, Alberti D, Olivetti L, Rigamonti W, Codazzi F, Matricardi L, et al. Congenital absence of portal vein with nodular regenerative hyperplasia of the liver. Eur Radiol 2000;10:820-825. [PubMed: 10823641]

337. Buscarini E, Danesino C, Plauchu H, de Fazio C, Olivieri C, Brambilla G, et al. High prevalence of hepatic focal nodular hyperplasia in subjects with hereditary hemorrhagic telangiectasia. Ultrasound Med Biol 2004; 30:1089-1097. [PubMed: 15550313]

338. Garcia-Tsao G, Korzenik JR, Young L, Henderson KJ, Byrd R, Pollak JS, et al. Liver disease in patients with hereditary hemorrhagic telangiectasia. N Engl J Med 2000;343:931-936. [PubMed: 11006369]

339. Wanless IR, Gryfe A. Nodular transformation of the liver in hereditary hemorrhagic telangiectasia. Arch Pathol Lab Med 1986;110:331-335. [PubMed: 3754122]

340. Johnson DW, Berg JN, Baldwin MA, Gallione CJ, Marondel I, Yoon SJ, et al. Mutations in the activin receptor-like kinase 1 gene in hereditary haemorrhagic telangiectasia type 2. Nat Genet 1996;13:189-195. [PubMed: 8640225]

341. McAllister KA, Grogg KM, Johnson DW, Gallione CJ, Baldwin MA, Jackson CE, et al. Endoglin, a TGF-beta binding protein of endothelial cells, is the gene for hereditary haemorrhagic telangiectasia type 1. Nat Genet 1994;8:345-351. [PubMed: 7894484] 
342. Siddiki H, Doherty MG, Fletcher JG, Stanson AW, Vrtiska TJ, Hough DM, et al. Abdominal findings in hereditary hemorrhagic telangiectasia: pictorial essay on $2 \mathrm{D}$ and $3 \mathrm{D}$ findings with isotropic multiphase CT. Radiographics 2008;28:171-184. [PubMed: 18203937]

343. Ianora AA, Memeo M, Sabba C, Cirulli A, Rotondo A, Angelelli G. Hereditary hemorrhagic telangiectasia: multi-detector row helical CT assessment of hepatic involvement. Radiology 2004;230:250-259. [PubMed: 14645886]

344. Buonamico P, Suppressa P, Lenato GM, Pasculli G, D’Ovidio F, Memeo M, et al. Liver involvement in a large cohort of patients with hereditary hemorrhagic telangiectasia: Echo-colorDoppler vs multislice computed tomography study. J Hepatol 2008;48:811-812. [PubMed: 18321607]

345. Garcia-Tsao G Liver involvement in hereditary hemorrhagic telangiectasia (HHT). J Hepatol 2007;46:499-507. [PubMed: 17239481]

346. Brakensiek K, Frye-Boukhriss H, Malzer M, Abramowicz M, Bahr MJ, von Beckerath N, et al. Detection of a significant association between mutations in the ACVRL1 gene and hepatic involvement in German patients with hereditary haemorrhagic telangiectasia. Clin Genet 2008; 74:171-177. [PubMed: 18498373]

347. Lesca G, Olivieri C, Burnichon N, Pagella F, Carette MF, Gilbert-Dussardier B, et al. Genotypephenotype correlations in hereditary hemorrhagic telangiectasia: datafrom the French-Italian HHT network. Genet Med 2007;9:914-922.

348. Sabba C, Pasculli G, Lenato GM, Suppressa P, Lastella P, Memeo M, et al. Hereditary hemorrhagic telangiectasia: clinical features in ENG and ALK1 mutation carriers. J Thromb Haemost 2007;5:1149-1157. [PubMed: 17388964]

349. Bayrak-Toydemir P, McDonald J, Markewitz B, Lewin S, Miller F, Chou LS, et al. Genotypephenotype correlation in hereditary hemorrhagic telangiectasia: mutations and manifestations. Am J Med Genet 2006; 140:463-470. [PubMed: 16470787]

350. Letteboer TG, Mager HJ, Snijder RJ, Koeleman BP, Lindhout D, Ploos van Amstel HK, et al. Genotype - phenotype relationship in hereditary hemorrhagic telangiectasia. J Med Genet 2006;43:371-377. [PubMed: 16155196]

351. Blewitt RW, Brown CM, Wyatt JI. The pathology of acute hepatic disintegration in hereditary haemorrhagic telangiectasia. Histopathology 2003;42:265-269. [PubMed: 12605646]

352. Caselitz M, Bahr MJ, Bleck JS, Chavan A, Manns MP, Wagner S, et al. Sonographic criteria for the diagnosis of hepatic involvement in hereditary hemorrhagic telangiectasia (HHT). HePATOLOGY 2003;37:1139-1146. [PubMed: 12717395]

353. Wu JS, Saluja S, Garcia-Tsao G, Chong A, Henderson KJ, White RI. Liver involvement in hereditary hemorrhagic telangiectasia: CT and clinical findings do not correlate in symptomatic patients. AJR Am J Roentgenol 2006;187:W399-W405. [PubMed: 16985112]

354. Khalid SK, Garcia-Tsao G. Hepaticvascular malformations in hereditary hemorrhagic telangiectasia. Semin Liver Dis 2008;28:247-258. [PubMed: 18814078]

355. Runyon BA. Management of adult patients with ascites due to cirrhosis. HePATOLOGY 2004;39:841-856. [PubMed: 14999706]

356. Lerut J, Orlando G,Adam R, Sabba C, Pfitzmann R, Klempnauer J, et al. Liver transplantation for hereditary hemorrhagic telangiectasia: report of the European Liver Transplant Registry. Ann Surg 2006;244:854-864. [PubMed: 17122610]

357. Garcia-Tsao G, Gish RG, Punch J. MELD exception for her editaryhem-orrhagic telangiectasia. Liver Transpl 2006;12(Suppl 3):S108-S109. [PubMed: 17123286]

358. Boillot O, Bianco F, Viale JP, Mion F, Mechet I, Gille D, et al. Liver transplantation resolves the hyperdynamic circulation in hereditary hemorrhagic telangiectasia with hepatic involvement. Gastroenterology 1999; 116:187-192. [PubMed: 9869617]

359. Dominguez IB, Annet L, Waignein F, Sempoux C, Geubel A. Extensive ischemic liver necrosis complicating hereditary hemorrhagic telangiectasia: arare indication for liver transplantation. Liver Int 2005;25:677-679. [PubMed: 15910505]

360. Hillert C, Broering DC, Gundlach M, Knoefel WT, Izbicki JR, Rogiers X. Hepatic involvement in hereditary hemorrhagic telangiectasia: an unusual indication for liver transplantation. Liver Transpl 2001;7:266-268. [PubMed: 11244170] 
361. Flieger D, Hainke S, Fischbach W. Dramatic improvement in hereditary hemorrhagic telangiectasia after treatment with the vascular endothelial growth factor (VEGF) antagonist bevacizumab. Ann Hematol 2006;85: 631-632. [PubMed: 16807748]

362. Mitchell A, Adams LA, MacQuillan G, Tibballs J, vanden Driesen R, Delriviere L. Bevacizumab reverses need for liver transplantation in hereditary hemorrhagic telangiectasia. Liver Transpl 2008;14:210-213. [PubMed: 18236396]

363. Gallego C, Miralles M, Marin C, Muyor P, Gonzalez G, Garcia-Hidalgo E. Congenital hepatic shunts. Radiographics 2004;24:755-772. [PubMed: 15143226]

364. Morgan G, Superina R. Congenital absence of the portal vein: two cases and a proposed classification system for portasystemic vascular anomalies. J Pediatr Surg 1994;29:1239-1241. [PubMed: 7807356]

365. Murray CP, Yoo SJ, Babyn PS. Congenital extrahepatic portosystemic shunts. Pediatr Radiol 2003;33:614-620. [PubMed: 12879313]

366. Yoshimoto Y, Shimizu R, Saeki T, Harada T, Sugio Y, Nomura S, et al. Patent ductus venosus in children: a case report and review of the literature. J Pediatr Surg 2004;39:E1-E5.

367. Ortiz M, Cordoba J, Alonso J, Rovira A, Quiroga S,Jacas C, et al. Oral glutamine challenge and magnetic resonance spectroscopy in three patients with congenital portosystemic shunts. $\mathrm{J}$ Hepatol 2004;40: 552-557. [PubMed: 15123374]

368. Wojcicki M, Haagsma EB, Gouw AS, Slooff MJ, Porte RJ. Orthotopic liver transplantation for portosystemic encephalopathy in an adult with congenital absence of the portal vein. Liver Transpl 2004;10:1203-1207. [PubMed: 15350015] 
Table 1.

Grading System for Recommendations

\begin{tabular}{ll}
\hline Classification & \multicolumn{1}{c}{ Description } \\
\hline Class I & $\begin{array}{l}\text { Conditions for which there is evidence and/or general agreement that a given diagnostic evaluation, procedure or } \\
\text { treatment is beneficial, useful, and effective. } \\
\text { Conditions for which there is conflicting evidence and/or a divergence of opinion about the usefulness/efficacy of a } \\
\text { diagnostic evaluation, procedure or treatment. }\end{array}$ \\
Class II & $\begin{array}{l}\text { Weight of evidence/opinion is in favor of usefulness/efficacy. } \\
\text { Usefulness/efficacy is less well established by evidence/opinion. }\end{array}$ \\
Class IIb & $\begin{array}{l}\text { Conditions for which there is evidence and/or general agreement that a diagnostic evaluation/procedure/treatment is not } \\
\text { useful/effective and in some cases may be harmful. }\end{array}$ \\
Level of Evidence & \\
\hline Level A & Data derived from multiple randomized clinical trials or meta-analyses. \\
Level B & $\begin{array}{l}\text { Data derived from a single randomized trial, or nonrandomized studies. } \\
\text { Only consensus opinion of experts, case studies, or standard-of-care. }\end{array}$
\end{tabular}

Hepatology. Author manuscript; available in PMC 2019 August 16. 
Table 2.

Vascular Diseases of the Liver

Portal vein thrombosis

Hepatic artery diseases (aneurysm, thrombosis) ${ }^{*}$

Sinusoidal obstruction syndrome

Radiation-induced liver disease *

Peliosis hepatis and sinusoidal dilatation *

Budd-Chiari syndrome

Congenital vascular malformations

Not covered in this practice guideline 
Table 3.

\section{Local Risk Factors for Portal Vein Thrombosis}

\begin{tabular}{l}
\hline Local Risk Factors \\
\hline Cancer \\
Any abdominal organ \\
Focal inflammatory lesions \\
Neonatal omphalitis, ombilical vein catheterization \\
Diverticulitis, Appendicitis \\
Pancreatitis \\
Duodenal ulcer \\
Cholecystitis \\
Tuberculous lymphadenitis \\
Crohn's disease, Ulcerative colitis \\
Cytomegalovirus hepatitis \\
Injury to the portal venous system \\
Splenectomy \\
Colectomy, Gastrectomy \\
Cholecystectomy \\
Liver transplantation \\
Abdominal trauma \\
Surgical portosystemic shunting, TIPS, Liver transplantation \\
Cirrhosis \\
Preserved liver function with precipitating factors (splenectomy, surgical portosystemic shunting, TIPS dysfunction, thrombophilia) \\
Advanced disease in the absence of obvious precipitating factors \\
\hline
\end{tabular}


Table 4.

Prevalence of Thrombotic Risk Factors in Series of Routinely Investigated, Consecutive Adult Patients with Nontumorous and Noncirrhotic, Acute and/or Chronic PVT ${ }^{8-11,14,15,17-19,27}$ and in Consecutive Patients with Primary Budd-Chiari Syndrome (BCS) $9,11,14-16,27,207-210$

\begin{tabular}{lll}
\hline \multicolumn{1}{c}{ Risk Factors } & PVT Patients & BCS Patients \\
\hline Myeloproliferative disorders & $30 \%-40 \%$ & $40 \%-50 \%$ \\
$\quad$ Atypical & $14 \%$ & $25 \%-35 \%$ \\
$\quad$ Classical & $17 \%$ & $10 \%-25 \%$ \\
Antiphospholipid syndrome & $6 \%-19 \%$ & $4 \%-25 \%$ \\
Paroxysmal nocturnal hemoglobinuria & $0 \%-2 \%$ & $0 \%-4 \%$ \\
Behçet's disease & $0 \%-31 \%$ & $0 \%-33 \%$ \\
Factor V Leiden mutation & $6 \%-32 \%$ & $6 \%-32 \%$ \\
Factor II mutation & $14 \%-40 \%$ & $5 \%-7 \%$ \\
Protein C deficiency ${ }^{*}$ & $0 \%-26 \%$ & $10 \%-30 \%$ \\
Protein S deficiency ${ }^{*}$ & $2 \%-30 \%$ & $7 \%-20 \%$ \\
Antithrombin deficiency ${ }^{*}$ & $0 \%-26 \%$ & $0 \%-23 \%$ \\
Plasminogen deficiency ${ }^{*}$ & $0 \%-6 \%$ & $0 \%-4 \%$ \\
Recent pregnancy & $6 \%-40 \%$ & $6 \%-12 \%$ \\
Recent oral contraceptive use & $12 \%$ & $6 \%-60 \%$ \\
Hyperhomocysteinemia & $12 \%-22 \%$ & $37 \%$ \\
TT677 MTHFR genotype & $11 \%-50 \%$ & $12 \%-22 \%$ \\
\hline
\end{tabular}

Regarded as preceding the development of PVT or BCS 
Table 5.

\section{Tests for Prothrombotic Conditions in Patients with PVT or BCS}

\begin{tabular}{|c|c|}
\hline Prothrombotic Condition & Diagnostic Features \\
\hline Myeloproliferative disease & $\begin{array}{l}\text { - V617F JAK } 2 \text { mutation in granulocytes is } 100 \% \text { specific. Where it is undetectable or where the technique is } \\
\text { unavailable: } \\
\text { - Several clusters of dystrophic megakaryocytes at bone marrow biopsy; or endogenous erythroid colonies in } \\
\text { cultures of bone marrow or peripheral blood erythroid progenitors on erythropoietin-poor media } \\
\text { (Note: In many affected patients, blood cell counts are normal or decreased. The combination of an enlarged } \\
\text { spleen with platelet counts }>200,000 / \mathrm{mm}^{3} \text { highly suggests that a myeloproliferative disease is present.) }\end{array}$ \\
\hline $\begin{array}{l}\text { Paroxysmal nocturnal } \\
\text { hemoglobinuria }\end{array}$ & $\begin{array}{l}\text { - CD55 and CD59 deficient clone at flow-cytometry of peripheral blood cells } \\
\text { - Ham-Dacie and sucrose tests where flow-cytometry is unavailable }\end{array}$ \\
\hline Behçet's disease & - Set of conventional criteria (including IVC thrombosis) \\
\hline Antiphospholipid syndrome & $\begin{array}{l}\text { - Idiopathic venous or arterial thrombosis, or repeated miscarriage } \\
\text { - Plus, repeatedly detectable: } \\
\text { - high serum levels of anticardiolipin antibodies } \\
\text { or lupus anticoagulant } \\
\text { - or antibeta } 2 \text { glycoprotein } 1 \text { antibodies } \\
\text { (Note: In many patients low, fluctuating levels of anticardiolipin antibodies are present. Their diagnostic } \\
\text { value is uncertain.) }\end{array}$ \\
\hline Factor V Leiden & $\begin{array}{l}\text { - Increased protein } \mathrm{C} \text { resistance; } \\
\text { - When present, molecular biology for R605Q factor V mutation }\end{array}$ \\
\hline Factor II gene mutation & - Molecular biology for G20210A mutation \\
\hline $\begin{array}{l}\text { Inherited antithrombin } \\
\text { deficiency }\end{array}$ & $\begin{array}{l}\text { - Decreased antithrombin level and } \\
\text { - Normal prothrombin levels or family history thereof } \\
\text { (Note: In many patients, a definite diagnosis for underlying antithrombin deficiency will not be possible.) }\end{array}$ \\
\hline Inherited protein $\mathrm{C}$ deficiency & $\begin{array}{l}\text { - Decreased Protein C level and } \\
\text { - Normal prothrombin levels or family history thereof } \\
\text { (Note: In many patients, a definite diagnosis for underlying Protein C deficiency will not be possible.) }\end{array}$ \\
\hline Inherited protein $S$ deficiency & $\begin{array}{l}\text { - Decreased Protein } S \text { level and } \\
\text { - Normal prothrombin levels or family history } \\
\text { (Note: In many patients, a definite diagnosis for underlying protein } S \text { deficiency will not be possible.) }\end{array}$ \\
\hline Hyperhomocysteinemia & $\begin{array}{l}\text { - Increased serum homocysteine level prior to disease } \\
\text { - Uncertain value of C677T homozygous polymorphism } \\
\text { (Note: In many patients, a definite diagnosis for underlying hyperhomocysteinemia will not be possible. } \\
\text { Blood folate and serum vitamin B12 levels may be useful.) }\end{array}$ \\
\hline Oral contraceptives & - Ongoing oral contraceptive use at apparent onset \\
\hline Pregnancy & - Ongoing pregnancy at apparent onset \\
\hline
\end{tabular}


Table 6.

Indications for Permanent Anticoagulation Therapy for Noncirrhotic Portal Vein Thrombosis and for Primary Budd-Chiari Syndrome

\begin{tabular}{ll}
\hline Primary Budd-Chiari syndrome & All patients Recommendation Class I - Level C \\
Portal vein thrombosis acute or chronic, no cirrhosis & Permanent, non correctable prothrombotic disorder \\
& or \\
& Superior mesenteric vein currently or previously involved \\
when & Primary or secondary prophylaxis for gastrointestinal bleeding has been instituted \\
& Recommendations Class IIa - Level C \\
\hline
\end{tabular}


Table 7.

Drugs Implicated in Sinusoidal Obstruction Syndrome

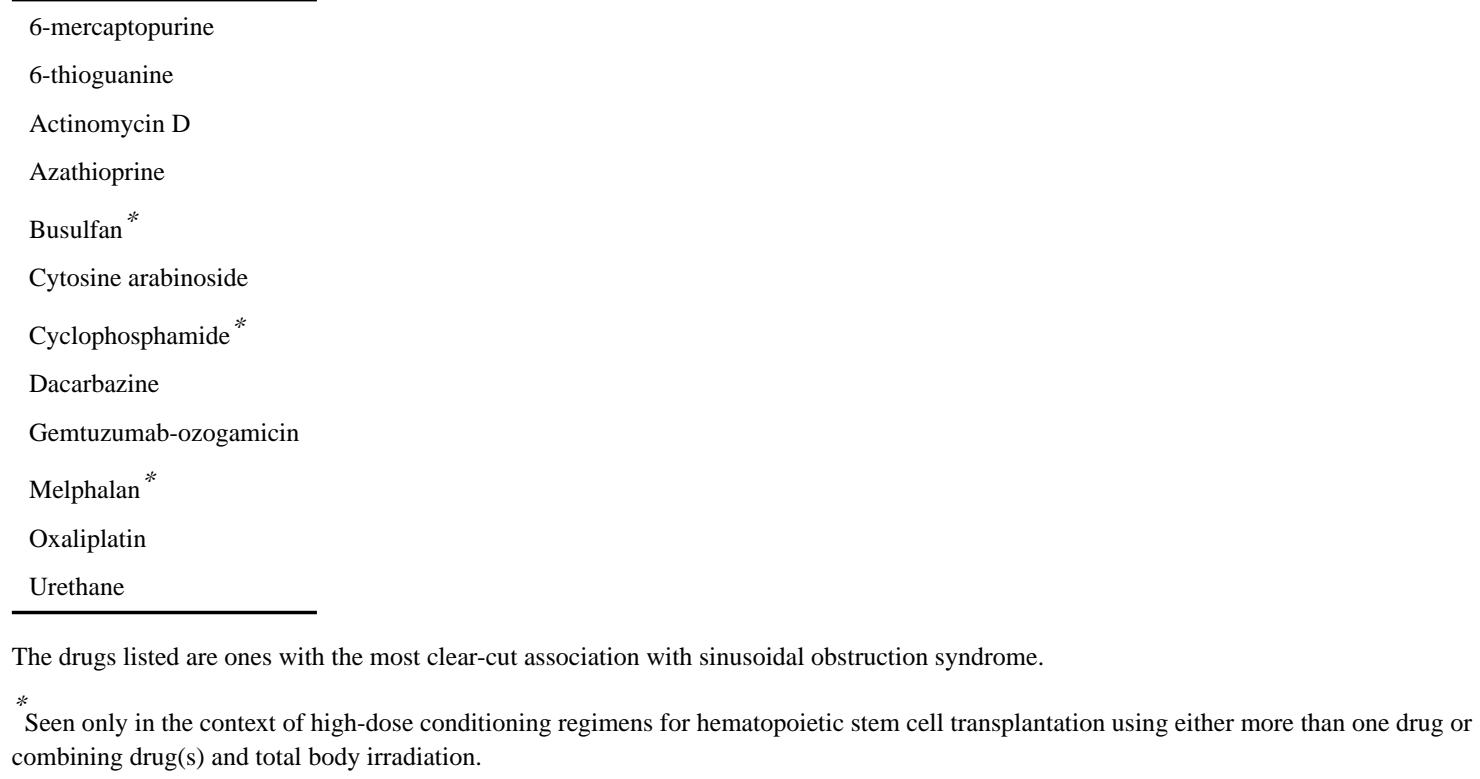

The drugs listed are ones with the most clear-cut association with sinusoidal obstruction syndrome.

Seen only in the context of high-dose conditioning regimens for hematopoietic stem cell transplantation using either more than one drug or combining drug(s) and total body irradiation. 

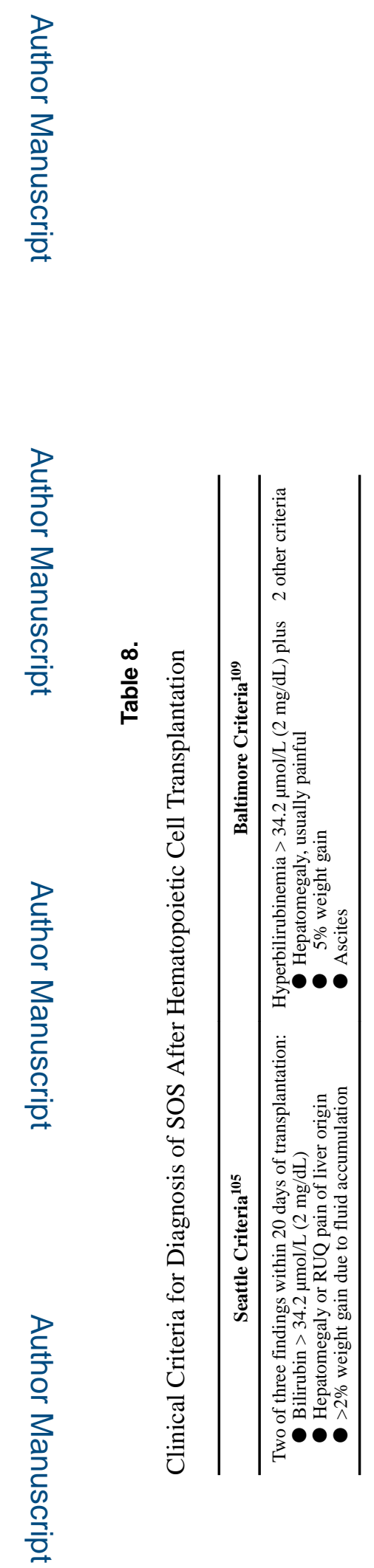

Hepatology. Author manuscript; available in PMC 2019 August 16. 